AUTARQUIA ASSOCIADA À UNIVERSIDADE DE SÃO PAULO

\title{
APLICAÇÃO DE MACRÓFITAS COMO BIOSSORVENTES NO TRATAMENTO DE REJEITOS RADIOATIVOS LÍQUIDOS
}

LUDMILA CABREIRA VIEIRA

Dissertação apresentada como parte dos requisitos para obtenção do Grau de Mestre em Ciências na Área de Tecnologia Nuclear - Aplicações

Orientador:

Prof. Dr. Julio Takehiro Marumo 
INSTITUTO DE PESQUISAS ENERGÉTICAS E NUCLEARES

Autarquia associada à Universidade de São Paulo

APLICAÇÃO DE MACRÓFITAS COMO BIOSSORVENTES NO TRATAMENTO DE REJEITOS RADIOATIVOS LÍQUIDOS

LUDMILA CABREIRA VIEIRA

Dissertação apresentada como parte dos requisitos para obtenção do Grau de Mestre em Ciências na Área de Tecnologia Nuclear - Aplicações

Orientador:

Prof. Dr. Julio Takehiro Marumo 


\section{A minha amada família.}




\section{AGRADECIMENTOS}

Agradeço a Deus pelas oportunidades que me foram dadas e as tantas que ainda virão.

Aos meus pais Cesar e Elizabeth, obrigada pela dedicação e carinho que sempre tiveram comigo. A minha irmã Maysa, pelo incentivo na busca dos meus sonhos.

Ao meu marido Ricardo, companheiro e amigo, pelo amor e apoio.

Ao Dr. Júlio Takehiro Marumo, pela excelente orientação, pelo apoio e incentivo, que só me fizeram crescer pessoal e profissionalmente.

Ao Dr. Rafael Vicente de Pádua Ferreira, pela amizade, paciência e valiosas sugestões.

Ao Dr. Edson Antônio da Silva, da UNIOESTE - Universidade Estadual do Oeste do Paraná pelo fornecimento das macrófitas utilizadas nesse trabalho.

Ao Rafael Canevesi, da UNIOESTE - Universidade Estadual do Oeste do Paraná pelo apoio na elaboração e análise das isotermas de adsorção.

Aos laboratórios e centros de pesquisas (CCN- IPEN, CCTM-IPEN, IQ/USP).

Aos amigos e colegas da Gerência de Rejeitos Radioativos, pelo auxílio, apoio e incentivo.

A Comissão Nacional de Energia Nuclear por tornar possível a realização deste trabalho por meio da concessão de bolsa de estudo. 
"Se não puder voar, corra Se não puder correr, ande Se não puder andar, rasteje mas continue em frente de qualquer jeito!" (Martin Lutherking)

"Tudo parece impossivel até que seja feito" (Nelson Mandela) 


\title{
APLICAÇÃO DE MACRÓFITAS COMO BIOSSORVENTES NO TRATAMENTO DE REJEITOS RADIOATIVOS LÍQUIDOS
}

\author{
Ludmila Cabreira Vieira
}

\begin{abstract}
RESUMO
O rejeito radioativo como qualquer outro tipo de resíduo, precisa receber tratamento adequado. É necessário considerar suas características físicoquímicas e radiológicas para a escolha da ação apropriada para o tratamento e a deposição final do rejeito. Muitas técnicas de tratamento utilizadas hoje são economicamente dispendiosas, inviabilizando muitas vezes o seu uso e impulsionando o estudo de outras técnicas de tratamento. Uma dessas técnicas é a biossorção, que demonstra alto potencial quando aplicada a rejeitos radioativos. Essa técnica utiliza materiais de origem biológica para a remoção de metais. Dos potenciais biossorventes encontrados, as macrófitas aquáticas apresentam-se vantajosas e possibilitam a remoção do urânio presente no rejeito radioativo líquido a baixo custo. O objetivo deste estudo foi avaliar a capacidade de biossorção das macrófitas aquáticas Pistia stratiotes, Limnobium laevigatum, Lemna sp e Azolla $s p$ no tratamento dos rejeitos radioativos líquidos. Este trabalho foi dividido em duas etapas, uma de caracterização e preparação e outra de ensaios de biossorção, realizados com soluções de urânio e com rejeito real. As biomassas foram testadas na sua forma bruta e os ensaios de biossorção foram realizados em frascos de polipropileno contendo $10 \mathrm{~mL}$ de solução de urânio ou $10 \mathrm{~mL}$ de rejeito radioativo e $0,20 \mathrm{~g}$ de biomassa. $\mathrm{O}$ comportamento das biomassas foi avaliado por meio da cinética de sorção e modelos de isotermas. As maiores capacidades de sorção foram observadas com as macrófitas Lemna sp com 162,1 mg/g e para a Azolla sp com $161,8 \mathrm{mg} / \mathrm{g}$. Os tempos de equilíbrio obtidos foram de 1 hora para a Lemna sp, e de 30 minutos para a Azolla sp. Com o rejeito real, a macrófita Azolla sp apresentou uma capacidade de sorção de 2,6 $\mathrm{mg} / \mathrm{g}$. Estes resultados sugerem que a Azolla sp possui maior capacidade de biossorção, sendo a mais indicada para estudos mais detalhados de tratamento de rejeitos radioativos líquidos.
\end{abstract}




\title{
APPLICATION OF MACROPHYTES AS BIOSORBENTS FOR RADIOACTIVE LIQUID WASTE TREATMENT
}

\author{
Ludmila Cabreira Vieira
}

\begin{abstract}
Radioactive waste as any other type of waste should be treated and disposed adequately. It is necessary to consider its physical, chemical and radiological characteristics for choosing the appropriate action for the treatment and final disposal. Many treatment techniques currently used are economically costly, often invalidating its use and favoring the study of other treatment techniques. One of these techniques is biosorption, which demonstrates high potential when applied to radioactive waste. This technology uses materials of biological origin for removing metals. Among potencial biosorbents found, macrophytes acquatics are useful because they may remove uranium present in the liquid radioactive waste at low cost. This study aims to evaluate the biosorption capacity of macrophyte acquatics Pistia stratiotes, Limnobium laevigatum, Lemna sp and Azolla sp in the treatment of liquid radioactive waste. This study was divided into two stages, the first one is characterization and preparation of biosorption and the other is tests, carried out with uranium solutions and real samples. The biomass was tested in its raw form and biosorption assays were performed in polypropylene vials containing $10 \mathrm{ml}$ of solution of uranium or $10 \mathrm{ml}$ of radioactive waste and $0.20 \mathrm{~g}$ of biomass. The behavior of biomass was evaluated by sorption kinetics and isotherm models. The highest sorption capacities found was $162.1 \mathrm{mg} / \mathrm{g}$ for the macrophyte Lemna $s p$ and $161.8 \mathrm{mg} / \mathrm{g}$ for the Azolla sp. The equilibrium times obtained were 1 hour for Lemna sp, and 30 minutes for Azolla sp. With the real waste, the macrophyte Azolla $s p$ presented a sorption capacity of $2.6 \mathrm{mg} / \mathrm{g}$. These results suggest that Azolla $s p$ has a larger capacity of biosorption, therefore it is more suitable for more detailed studies of treatment of liquid radioactive waste.
\end{abstract}




\section{SUMÁRIO}

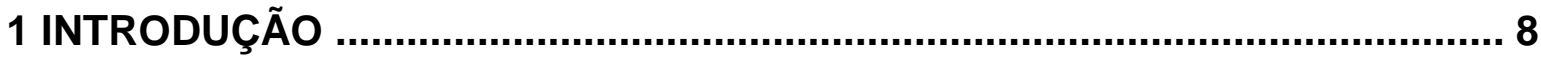

2 OBJETIVOS ................................................................................ 10

2.1 Objetivos específicos....................................................................... 10

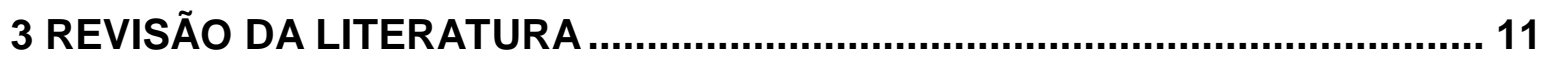

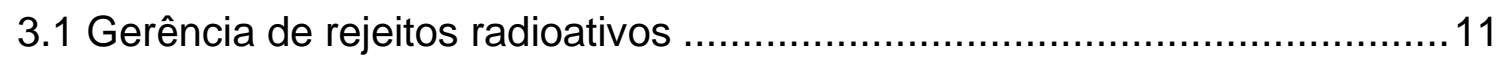

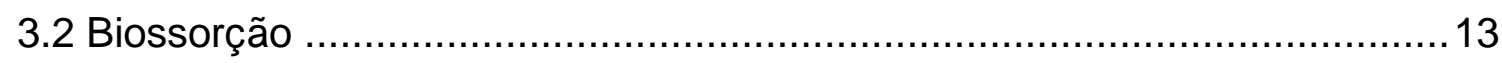

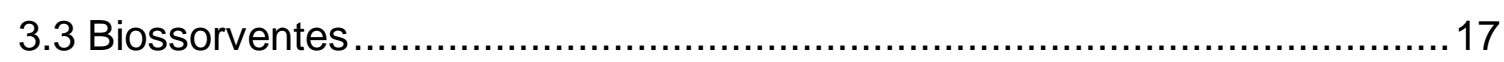

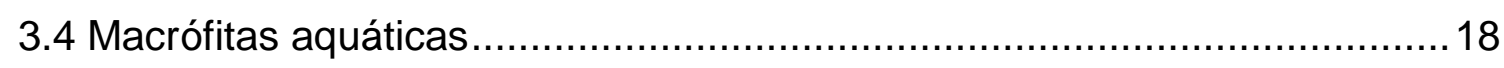

3.5 Remoção de metais tóxicos utilizando macrófitas aquáticas ......................20

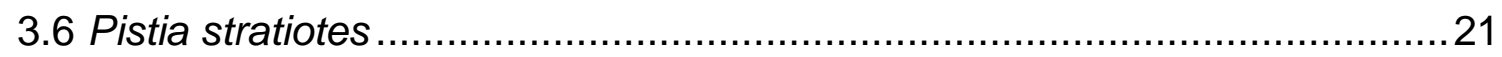

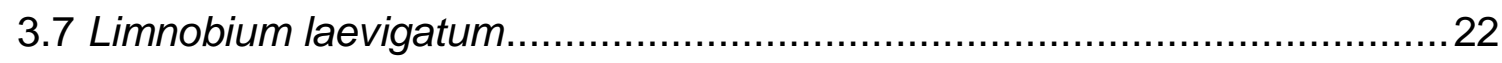

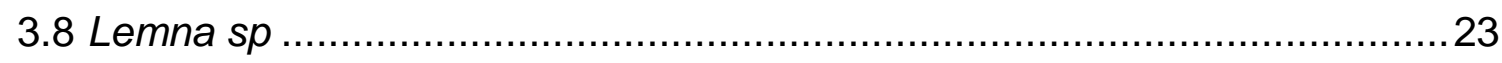

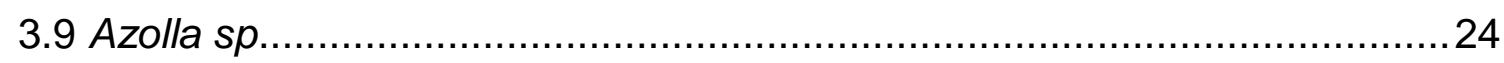

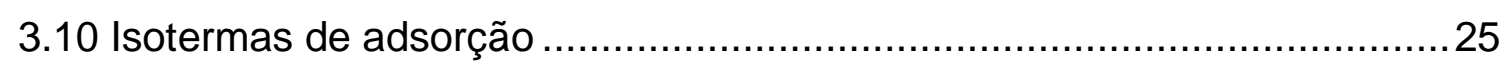

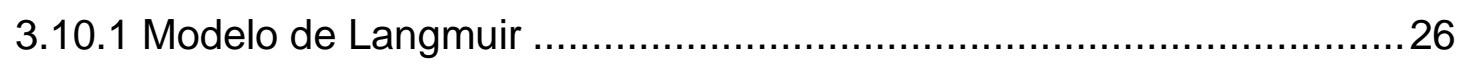

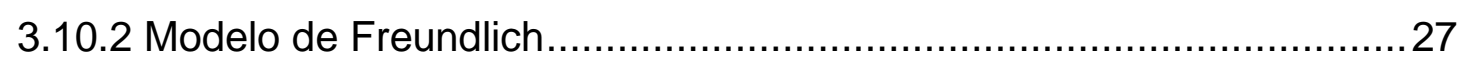

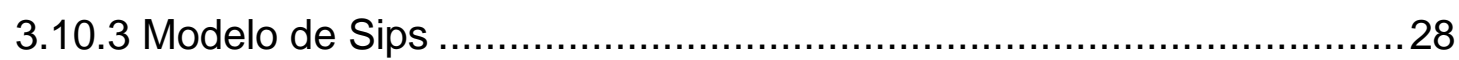

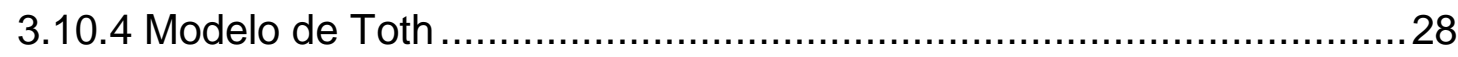

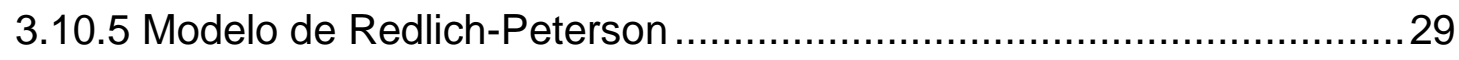

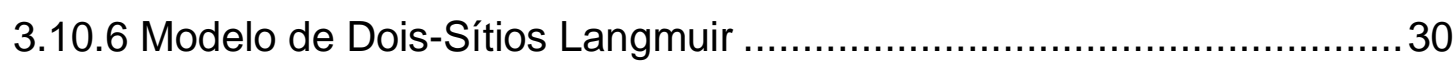

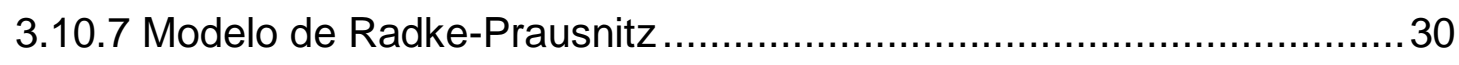

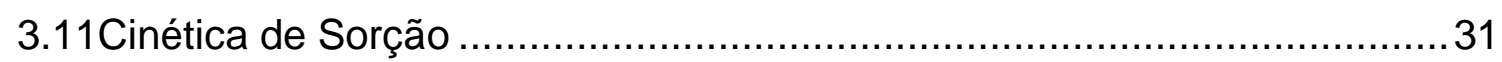

3.11.1 Modelo de Pseudo-Primeira Ordem ................................................ 32

3.11.2 Modelo de Pseudo-Segunda Ordem ……….................................. 32

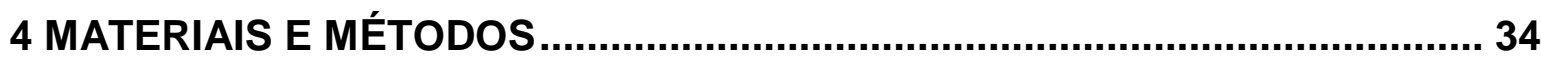

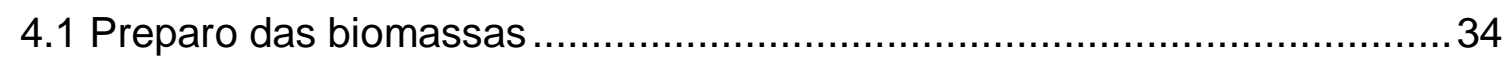

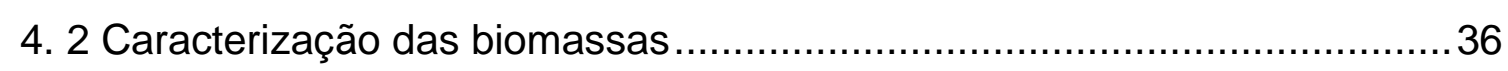

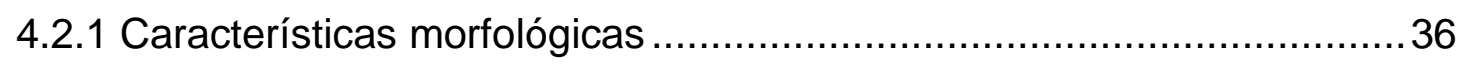

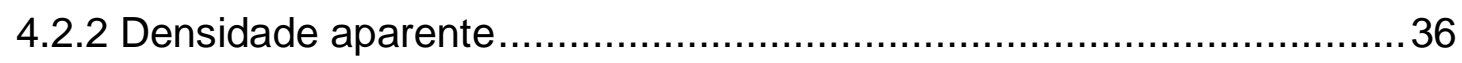

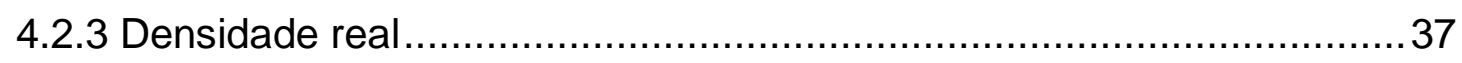

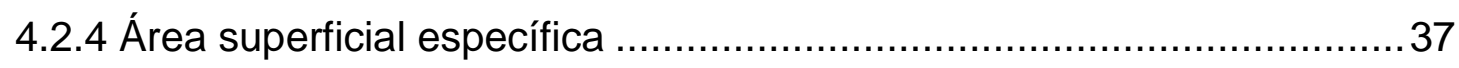


4.2.5 Análise dos grupos funcionais por infravermelho (IV) ......................37

4.3 Ensaios de biossorção ........................................................ 38

4.3.1 Determinação da concentração do urânio por ICP-OES .................... 40

4.3.2 Capacidade de biossorção do radionuclídeo..................................4 41

4.4 Estimativa dos parâmetros ...................................................... 42

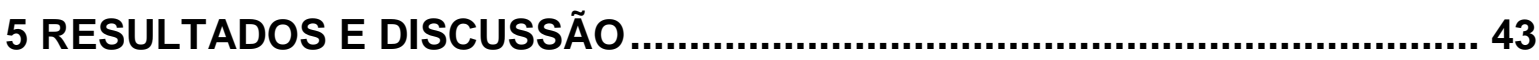

5.1 Caracterização das biomassas .......................................................... 43

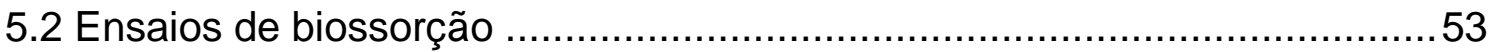

5.2.1 Tempo de equilíbrio ......................................................... 53

5.2 .2 Capacidade de biossorção .................................................. 54

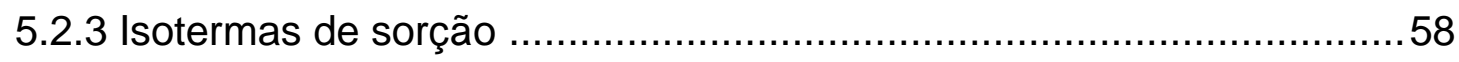

5.2 .4 Cinética de biossorção ...................................................... 68

6. CONCLUSÕES...................................................................................... 73

SUGESTÕES PARA TRABALHOS FUTUROS ........................................... 74

REFERÊNCIAS BIBLIOGRÁFICAS ........................................................... 75 


\section{LISTA DE FIGURAS}

FIGURA 1 - Etapas do gerenciamento de rejeitos .......................................... 12

FIGURA 2 - Diagrama de um processo de biossorção......................................... 17

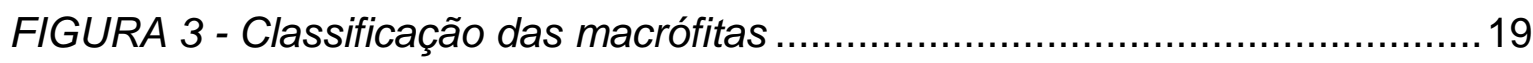

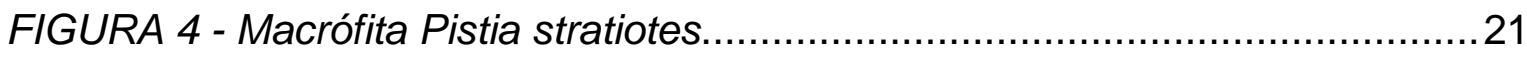

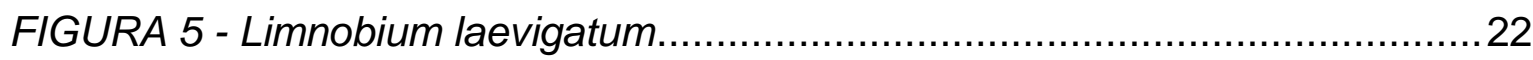

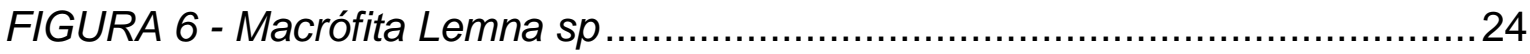

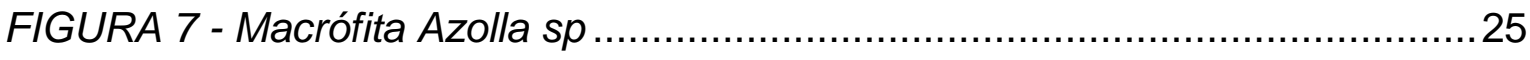

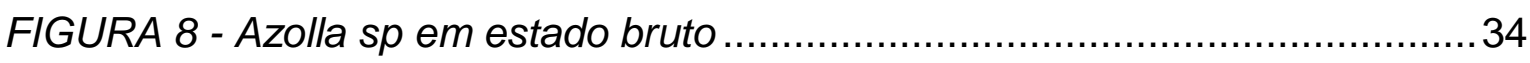

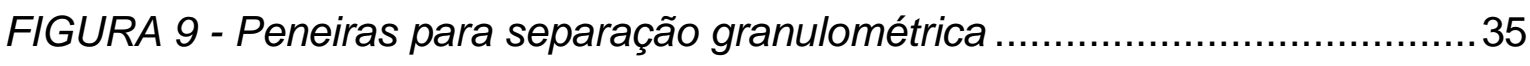

FIGURA 10 - Incubadora Orbital Shaker...................................................... 40

FIGURA 11 - ICP-OES Perkin Elmer ..................................................... 41

FIGURA 12 - Eletromicrografia da biomassa Pistia stratiotes bruta ..................... 43

FIGURA 13 - Eletromicrografia da biomassa Limnobium laevigatum bruta ........... 44

FIGURA 14 - Eletromicrografia da biomassa Lemna sp. bruta..............................44

FIGURA 15 - Eletromicrografia da biomassa Azolla sp. bruta .............................. 45

FIGURA 16 - Espectros de FTIR da biomassa Pistia stratiotes.............................48

FIGURA 17 - Espectros de FTIR da biomassa Limnobium laevigatum ................. 49

FIGURA 18 - Espectros de FTIR da biomassa Lemna sp. ................................50

FIGURA 19 - Espectros de FTIR da biomassa Azolla sp. .................................. 51

FIGURA 20 - Biossorção do urânio pelas macrófita Pistia stratiotes, Limnobium laevigatum, Lemna sp e Azolla sp em função do tempo

FIGURA 21 - Representação gráfica do ajuste dos modelos de isotermas aos dados experimentais para Pistia stratiotes

FIGURA 22 - Representação gráfica do ajuste dos modelos de isotermas aos

dados experimentais para Limnobium laevigatum

FIGURA 23 - Representação gráfica do ajuste dos modelos de isotermas aos dados experimentais para Lemna $s p$.

FIGURA 24 Representação gráfica do ajuste dos modelos de isotermas aos dados experimentais para Azolla sp.

FIGURA 25 Representação gráfica dos ajustes dos modelos de cinética aos dados experimentais para a Pistia stratiotes. 
FIGURA 26 - Representação gráfica dos ajustes dos modelos de cinética aos dados experimentais para a Limnobium laevigatum

FIGURA 27 - Representação gráfica dos ajustes dos modelos de cinética aos dados experimentais para a lemna $s p$

FIGURA 28 - Representação gráfica dos ajustes dos modelos de cinética aos dados experimentais para a Azolla $s p$ 


\section{LISTA DE TABELAS}

TABELA 1 - Comparação entre biossorção e biocumulação ..................................14

TABELA 2 - Resultado em porcentagem da análise das macrófitas por EDS .......46

TABELA 3 - Valores de densidade aparente, densidade real e área específica para as biomassas Pistia stratiotes, Limnobium laevigatum, Lemna sp. e Azolla sp

TABELA 4 - Identificação dos grupos funcionais presentes na Pistia stratiotes, Limnobium laevigatum, Lemna sp e Azolla sp.

TABELA 5- Valores da capacidade de biossorção no equilíbrio experimental solução de urânio 55

TABELA 6- Valores da capacidade de biossorção com o rejeito radioativo .56

TABELA 7 - Parâmetros das isotermas calculados para a Pistia stratiotes. .58

TABELA 8 - Parâmetros das isotermas calculados para a Limnobium laevigatum .59

TABELA 9 - Parâmetros das isotermas calculados para a Lemna sp 60

TABELA 10 - Parâmetros das isotermas calculados para a Azolla $s p$ 61

TABELA 11 - Parâmetros das cinéticas calculados para as biomassas utilizadas69 


\section{INTRODUÇÃO}

O uso da tecnologia nuclear no controle dos processos industriais, na irradiação de alimentos, na medicina, na produção dos radioisótopos e nos centros de pesquisa, gera rejeitos radioativos e, com isso, há a necessidade de se prover o tratamento adequado para assim garantir a segurança do homem e do meio ambiente.

O rejeito radioativo como qualquer outro tipo de resíduo, precisa receber tratamento e destinação adequados e a escolha da ação apropriada depende das suas características físicas, químicas e radiológicas. A etapa de tratamento pode envolver um número grande de ações, que visem principalmente a minimização do volume. No caso dos rejeitos radioativos líquidos, podem ainda haver a necessidade de uma etapa de imobilização em um produto monolítico, usualmente o cimento.

Buscar novas alternativas de tratamento desses rejeitos que aliem baixo custo e eficiência é uma tarefa importante e difícil, já que, nesse caso, cuidados adicionais devem ser considerados por se tratar de rejeitos radioativos, que estão em estado físico de fácil dispersão. Diversos métodos descritos na literatura para tratamento dos rejeitos líquidos como filtração, precipitação, adsorção, troca iônica e separação por membranas, não podem ser sempre empregadas quando as concentrações dos radionuclídeos presentes são pequenas. Há ainda a incineração e evaporação, que são muito eficientes, porém de custo elevado e inviáveis para instalações onde o volume de rejeito gerado é pequeno.

A biossorção pode ser uma alternativa na remoção de metais, pois apresenta a vantagem econômica de utilizar materiais de baixo custo e que não necessitam de alta tecnologia para sua produção ou aquisição (VOLESKY, 2003).

Como biossorventes, destacam-se os materiais vindos do beneficiamento das indústrias alimentícias, cascas de banana (BONIOLO, 2008), 
fibra de coco, palha de arroz (FERREIRA, 2014), e também as algas marinhas (YANG \& VOLESKY, 1999; KHANI et al 2011).

Um material biossorvente que vem demonstrando possuir alta capacidade na remoção de metais pesados de efluentes são as macrófitas aquáticas, sobre as quais esse trabalho se desenvolve (MARTIN, 2008; SANTANA, 2012; UMALI, 2006; KHOSRAVI, 2005).

As macrófitas aquáticas são vegetais que durante seu processo evolutivo migraram do ambiente terrestre para o aquático. Por possuírem várias características de vegetais terrestres, como a presença de cutícula e de estômatos na maioria das espécies não funcionais, apresentam grande capacidade de adaptação e grande amplitude ecológica (ESTEVES, 1998).

As macrófitas aquáticas habitam diversos ambientes que vão desde lagos, cachoeiras, brejos, represas, bacias e até ambientes salgados como recifes de corais, tornando possível encontrar uma mesma espécie de macrófita habitando vários ambientes, sua versatilidade é tamanha que suporta até longos períodos de estiagem (ESTEVES, 1988).

Por sua versatilidade e adaptação aos mais diversos climas e condições, por ser facilmente encontrada e extraída da natureza, podendo ainda ser cultivada de forma ostensiva e com baixo custo; somada a sua alta capacidade na retenção de íons de metais pesados, as macrófitas podem se tornar um eficiente e atrativo meio de tratamento dos rejeitos radioativos. 


\section{OBJETIVOS}

O objetivo deste trabalho foi avaliar a capacidade de biossorção das macrófitas aquáticas das espécies Pistia stratiotes, Limnobium laevigatum, Lemna $s p$, e Azolla sp, quando expostas a diferentes concentrações de urânio em solução.

\subsection{Objetivos específicos}

$\checkmark$ Caracterizar as macrófitas quanto às propriedades estruturais e de superfície;

$\checkmark$ Determinar a capacidade de biossorção de urânio de diferentes espécies de macrófitas, por meio de ensaios de biossorção em laboratório e avaliar os resultados por meio de isotermas e cinética de biossorção;

$\checkmark$ Determinar a capacidade de biossorção em rejeito radioativo das macrófitas que apresentarem o melhor desempenho. 


\section{REVISÃO DA LITERATURA}

A biossorção é o foco principal desse trabalho. Dentro do gerenciamento dos rejeitos radioativos, a biossorção faz parte da etapa de tratamento, pois ela resultaria na redução de volume e na mudança do estado físico do rejeito radioativo.

\subsection{Gerência de rejeitos radioativos}

Rejeito radioativo (ou simplesmente rejeito) - é definido pela Comissão Nacional de Energia Nuclear na Norma CNEN NN 6.09: "Critérios de Aceitação para Deposição de Rejeitos Radioativos de Baixo e Médio Nível de Radiação" como "qualquer material resultante de atividades humanas, que contenha radionuclídeos em quantidades superiores aos limites de isenção, limites esses que estão especificados na Norma CNEN-NN-8.01: "Gerência de Rejeitos Radioativos de Baixo e Médio Níveis de Radiação" e para o qual a reutilização é imprópria ou não prevista" (CNEN 2002; CNEN, 2014).

A gestão segura do rejeito radioativo envolve uma série de atividades tanto administrativas como operacionais, desde a geração até a sua disposição final (HIROMOTO, 1999). Esse conjunto de atividades, definido como gerência de rejeitos, é responsável por implementar medidas eficazes de segurança enquanto o rejeito possa ser considerado perigoso, pois um mal gerenciamento pode acarretar danos ao homem e ao meio ambiente. Na FIG 1 é apresentado um fluxograma genérico das etapas da gerência de rejeitos 


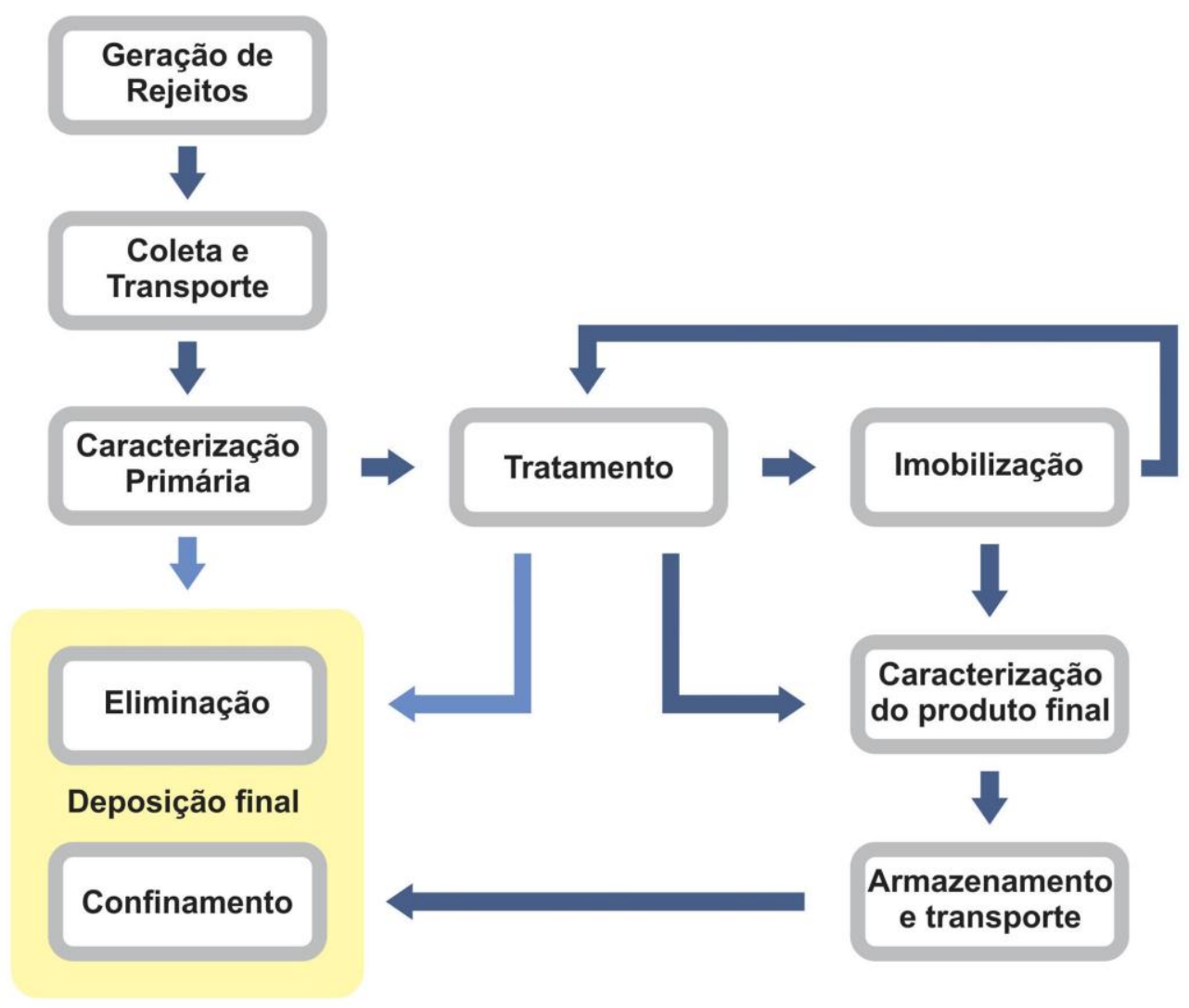

FIGURA 1 - Etapas do gerenciamento de rejeitos

Este trabalho está relacionado com a etapa de tratamento, no qual são realizados diversos processos como acondicionamento, redução do volume e, no caso em que o rejeito não pode ser colocado diretamente na embalagem de condicionamento, compatibilização do rejeito com a matriz de imobilização.

Para o tratamento dos rejeitos radioativos, deve-se levar em consideração o conteúdo radioisotópico, o tipo e o nível de radiação emitida, a meia vida dos radionuclídeos, o estado físico do rejeito (sólido, líquido ou gasoso) e a presença de outros compostos no rejeito - CNEN NN 8.01 "Gerência de Rejeitos Radioativos". (CNEN, 2014).

No tratamento dos rejeitos radioativos líquidos, as técnicas comumente empregadas são a evaporação, troca iônica, precipitação química, adsorção, filtração, evaporação e separação por membranas. 
De acordo com VOLESKY (2001), a troca iônica, a adsorção e a separação por membranas, são processos caros quando usados para tratar grandes quantidades de efluentes contendo baixas concentrações de metais pesados.

A inviabilidade dos métodos tradicionais devido ao alto custo, muitas vezes devido ao emprego da alta tecnologia e limitações quanto à concentração dos resíduos e rejeitos, possibilitou diversas pesquisas por métodos alternativos.

A biossorção destaca-se frente aos processos convencionais de remoção de metais por ser um processo relativamente rápido que alia baixo custo, alta eficiência, empregando materiais que não precisam de alta tecnologia para sua produção ou obtenção (VOLESKY, 2003).

\subsection{Biossorção}

A biossorção se refere a um tipo específico de sorção baseada na remoção de metais ou radionuclídeos por um material de origem biológica sem atividade metabólica celular (VOLESKY, 2003), por meio de processos físicos químicos entre os íons e os grupos funcionais presentes na superfície do material biológico (KUYUCAK \& VOLESKY, 1988; GADD, 2009). A biossorção é um processo passivo que independe da energia da biomassa e é diferente da biocumulação, que ocorre quando há a captação de um íon ou espécie metálica por meio de material biológico com atividade metabólica, ou seja, material biológico vivo (VOLESKY, 2003).

Segundo VOLESKY (2001), a disseminação do uso da biossorção dos metais ocorreu após o entendimento de que a remoção de determinado metal pelo material biossorvente deve-se mais às propriedades químicas desse material que sua atividade biológica.

Os primeiros estudos envolvendo a biossorção na remoção de metais pesados tiveram inicio na década de 1980, quando uma grande variedade de materiais biológicos foi utilizada, baseados na capacidade de captação, na remoção dos metais a baixas concentrações e a baixo custo (VIEIRA \& VOLESKY, 2000). 
A aplicação da biossorção na remoção de ${ }^{239} \mathrm{Pu}$, em água por lodo ativado foi aplicada por Rutherford em 1949, mas somente em 1986 a biossorção foi reconhecida como tecnologia emergente pela Solvent Engineering Extration and ín Exchange Group of the Society of Chemical Industry no Reino Unido (VOLESKY, 1990).

A maior parte dos estudos sobre biossorção estão relacionados aos metais, no entanto a biossorção vem sendo aplicada na remoção de corantes, produtos farmacêuticos, esteroides (VOLESKY, 2007; HONORATO, 2015).

Tanto a biossorção quanto a biocumulação demonstram capacidade remoção dos íons e metais pesados, porém a biossorção apresenta vantagens quando comparada a biocumulação, conforme apresentada na TAB 1.

TABELA 1 - Comparação entre biossorção e biocumulação

\begin{tabular}{|c|c|c|}
\hline Fatores & Biossorção & Biocumulação \\
\hline Custo & $\begin{array}{l}\text { Geralmente baixo. Os biossorventes } \\
\text { usados são na maioria das vezes } \\
\text { biomassas vindos de processos } \\
\text { industriais ou da agricultura. O custo } \\
\text { envolve o transporte ou alterações } \\
\text { de processos }\end{array}$ & $\begin{array}{l}\text { Normalmente altos, pois o } \\
\text { processo envolve células } \\
\text { vivas e o custo da } \\
\text { manutenção das células vivas }\end{array}$ \\
\hline $\mathrm{pH}$ & $\begin{array}{l}\text { O pH influencia fortemente na } \\
\text { capacidade de adsorção da } \\
\text { biomassa, porém o processo pode } \\
\text { ser realizado num amplo alcance de } \\
\text { pH }\end{array}$ & $\begin{array}{l}\text { As células vivas são } \\
\text { fortemente afetadas em } \\
\text { condições extremas de pH }\end{array}$ \\
\hline Temperatura & $\begin{array}{l}\text { É possível uma } \\
\text { processo com o } \\
\text { temperatura. }\end{array}$ & $\begin{array}{l}\text { A temperatura afeta } \\
\text { severamente o processo. }\end{array}$ \\
\hline $\begin{array}{l}\text { Manutenção e } \\
\text { armazenamento }\end{array}$ & De fácil uso e armazenamento & $\begin{array}{l}\text { A energia metabólica externa } \\
\text { é necessária para a } \\
\text { manutenção da cultura }\end{array}$ \\
\hline Seletividade & $\begin{array}{l}\text { Pobre, porém a mesma pode ser } \\
\text { melhorada pela modificação, } \\
\text { ativação da biomassa. }\end{array}$ & Melhor que a biossorção \\
\hline
\end{tabular}




\begin{tabular}{|c|c|c|}
\hline Fatores & Biossorção & Biocumulação \\
\hline Versatilidade & $\begin{array}{l}\text { Razoavelmente boa. Os sítios de } \\
\text { ligação podem acomodar uma } \\
\text { variedade de íons. }\end{array}$ & $\begin{array}{l}\text { Não muito flexível. Propenso a } \\
\text { ser afetado pelas altas } \\
\text { concentrações de metais/sais. }\end{array}$ \\
\hline $\begin{array}{l}\text { Grau de } \\
\text { Absorção }\end{array}$ & $\begin{array}{l}\text { Muito alto. Algumas biomassas } \\
\text { absorvem uma quantidade de } \\
\text { substância tóxica quase tão elevada } \\
\text { quanto o seu peso seco. }\end{array}$ & $\begin{array}{l}\text { Sensíveis a altas } \\
\text { concentrações de substâncias } \\
\text { tóxicas e a remoção é } \\
\text { geralmente baixa. }\end{array}$ \\
\hline $\begin{array}{l}\text { Taxa de } \\
\text { absorção }\end{array}$ & Geralmente rápida & $\begin{array}{l}\text { Mais lentas que a biossorção } \\
\text { pois a acumulação intracelular } \\
\text { é consumidora de tempo }\end{array}$ \\
\hline $\begin{array}{l}\text { Regeneração e } \\
\text { reutilização }\end{array}$ & $\begin{array}{l}\text { Alta possibilidade de regeneração } \\
\text { do biossorvente com possível uso } \\
\text { em altos números de ciclos }\end{array}$ & $\begin{array}{l}\text { Como a maioria dos tóxicos } \\
\text { são acumuladores } \\
\text { intracelulares, as chances são } \\
\text { bem limitadas. }\end{array}$ \\
\hline $\begin{array}{l}\text { Recuperação da } \\
\text { substância tóxica }\end{array}$ & $\begin{array}{l}\text { As soluções ácidas e alcalinas em } \\
\text { muitos casos tornam se meios } \\
\text { eficientes para a recuperação de } \\
\text { tóxicos }\end{array}$ & $\begin{array}{l}\text { A biomassa não poderá ser } \\
\text { utilizada no próximo ciclo. }\end{array}$ \\
\hline Imobilização & $\begin{array}{l}\text { É possível utilizar a biomassa em } \\
\text { estruturas sólidas. }\end{array}$ & $\begin{array}{l}\text { Não é possível imobilizar a } \\
\text { biomassa viva. }\end{array}$ \\
\hline Reversibilidade & Possível & Parcialmente reversível \\
\hline Velocidade & Rápida & Lenta \\
\hline $\begin{array}{l}\text { Número de } \\
\text { estágios }\end{array}$ & Estágio único (somente biossorção). & $\begin{array}{l}\text { Estágio duplo (biossorção e } \\
\text { biocumulação) }\end{array}$ \\
\hline Ligação do metal & $\begin{array}{l}\text { Os metais se ligam na superfície } \\
\text { celular }\end{array}$ & $\begin{array}{l}\text { Os metais se ligam na } \\
\text { superfície celular e em seu } \\
\text { interior. }\end{array}$ \\
\hline
\end{tabular}

Adaptação de (SOOD et al 2011)

A biossorção pode ser definida geralmente como o sequestro dos íons metálicos por uma biomassa metabolicamente inativa. Essa captação dos íons metálicos ocorre nos sítios ativos das biomassas as quais possuem diferentes grupos funcionais que são responsáveis pela junção dos íons na partícula do biossorvente, como por exemplo, as carboxilas, hidroxilas, aminas, sulfetos e 
fosfatos, ocorrendo de forma isolada ou pela combinação de vários mecanismos citados abaixo (VOLESKY, 2003).

- Adsorção é o processo em que as moléculas ou íons se aderem na superfície de um sólido. A atração dos íons muitas vezes está baseada nas cargas eletrostáticas. A adsorção negativa é adsorção de espécies positivas em sitos de adsorção negativos e vice versa para a adsorção positiva. Se a adsorção ocorre, implica que os sítios ativos estão livres para aceitar os íons metálicos.

- Quelação é baseado na formação de um agente quelante, a partir da ligação ente um ligante e um íon metálico contendo no mínimo dois grupos funcionais doadores de elétrons, formando um anel heterocíclico que sequestra o íon de interesse.

- Complexação ocorre a formação de espécies pela associação de duas ou mais espécies Quando uma das espécies é um íon metálico ocorre a formação de um complexo metálico.

- Troca iônica é um processo onde ocorre a troca de íons entre moléculas ou espécies atômicas. Este processo não necessita que os sítios ativos para a biossorção estejam livres, pois é baseado na troca de íons com diferentes afinidades pelo material adsorvente, podendo o íon de maior afinidade trocar de posição com o íon do sítio ativo.

- Coordenação quando um átomo central de um complexo está ligado a outros átomos por ligações covalentes formadas como resultado da aceitação de um par de elétrons de um átomo não metálico.

- Precipitação ocorre quando a solubilidade do metal no interior ou exterior do biossorvente chega ao seu limite, formando assim precipitados insolúveis.

A aplicação da biossorção para a remoção de íons metálicos pode envolver várias etapas, conforme apresentado na FIG. 2. 


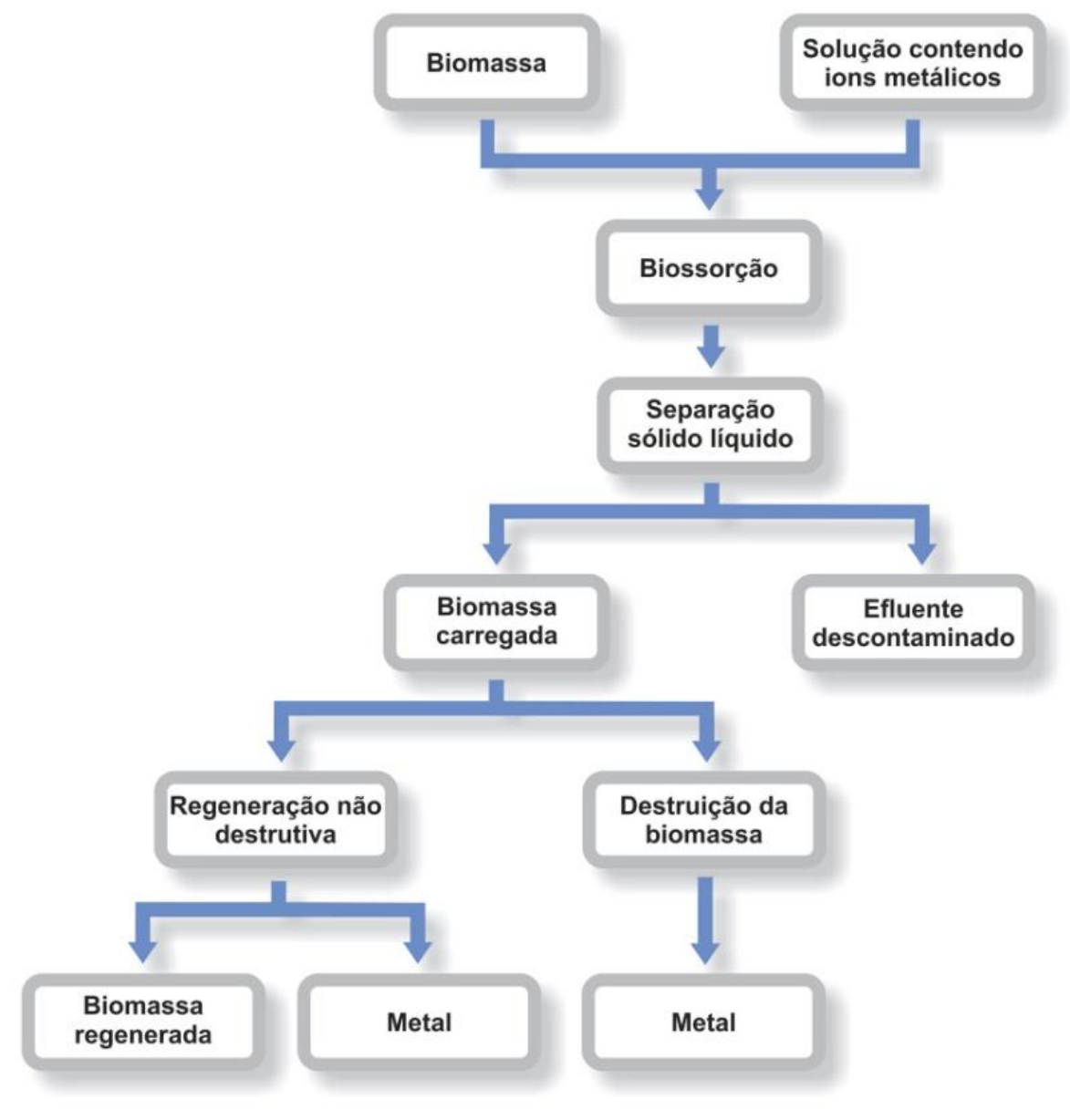

FIGURA 2 - Diagrama de um processo de biossorção (BENVINDO DA LUZ, 2002)

\subsection{Biossorventes}

$\mathrm{Na}$ literatura pode-se encontrar uma grande variedade de biossorventes como as algas, microrganismos, fungos, materiais vindos da indústria alimentícia, do beneficiamento de grãos (DAVIS et al, 2003; BONIOLO, 2008; VIJAYARAGHAVAN \& YUN, 2008; FERREIRA, 2014).

De acordo com VOLESKY (1987) para que o material biossorvente seja considerado um bom biossorvedor é necessário que ele possua algumas características. 
- Ser rápido e eficiente na captação do metal

- Ter baixo custo e ser reutilizável

- Ser passível de remoção da solução de forma rápida, eficiente e barata.

- Ter elevada seletividade de adsorção e dessorção do metal.

Um biossorvente que vem demonstrando possuir alta capacidade na remoção de metais pesados, de efluentes industriais e na remoção de urânio em soluções aquosas são as macrófitas aquáticas.

\subsection{Macrófitas aquáticas}

As macrófitas aquáticas são vegetais que devido ao seu processo evolutivo possuem capacidade de adaptação tanto em ambientes terrestres como aquáticos estando presentes desde lagos e represas a ambientes salobros $\mathrm{e}$ salgados. As características de vegetais terrestres que ainda permanecem nas macrófitas são cutículas e estômatos.

Segundo ESTEVES (1998) as macrófitas aquáticas podem ser classificadas de quanto ao seu biótipo que são denominados grupos ecológicos.

a) Macrófitas aquáticas emersas: plantas enraizadas apresentando folhas fora da água. Ex: Typha, Pontederia, Echínodorus, Eleocharis,

b) Macrófitas aquáticas com folhas flutuantes: plantas enraizadas no sedimento e com folhas flutuando livremente no espelho d água. Ex: Nymphaea Vitoria e Nymphoides.

c) Macrófitas aquáticas submersas enraizadas: Plantas enraizadas no sedimento que crescem totalmente submersas na água, podendo cresceram em até 11 metros de profundidade aproximadamente, dependendo da disponibilidade da luz, apresentando na maioria, seus órgão reprodutivos flutuando na superfície ou aéreos. Ex: Myriophyllum, Elodea, Egeria, Hydrilla, Vallisneria, Mayaca e a maioria das espécies do gênero Potamogeton.

d) Macrófitas aquáticas submersas livres: plantas com raízes pouco desenvolvidas que flutuam submersas em locais de pouca turbulência, águas tranquilas, ficando presas aos caules das macrófitas emersas e aos 
talos das macrofitas aquáticas de folhas flutuantes, emitindo flores emersas no seu período reprodutivo. Ex: Utricularia e Ceratophyllum

e) Macrófitas aquáticas flutuantes: plantas que flutuam na superfície d'água com seu desenvolvimento máximo ocorrendo e locais protegidos pelo vento: Pistia stratiotes, Lemna sp, Azolla sp, Salvinia auriculata.

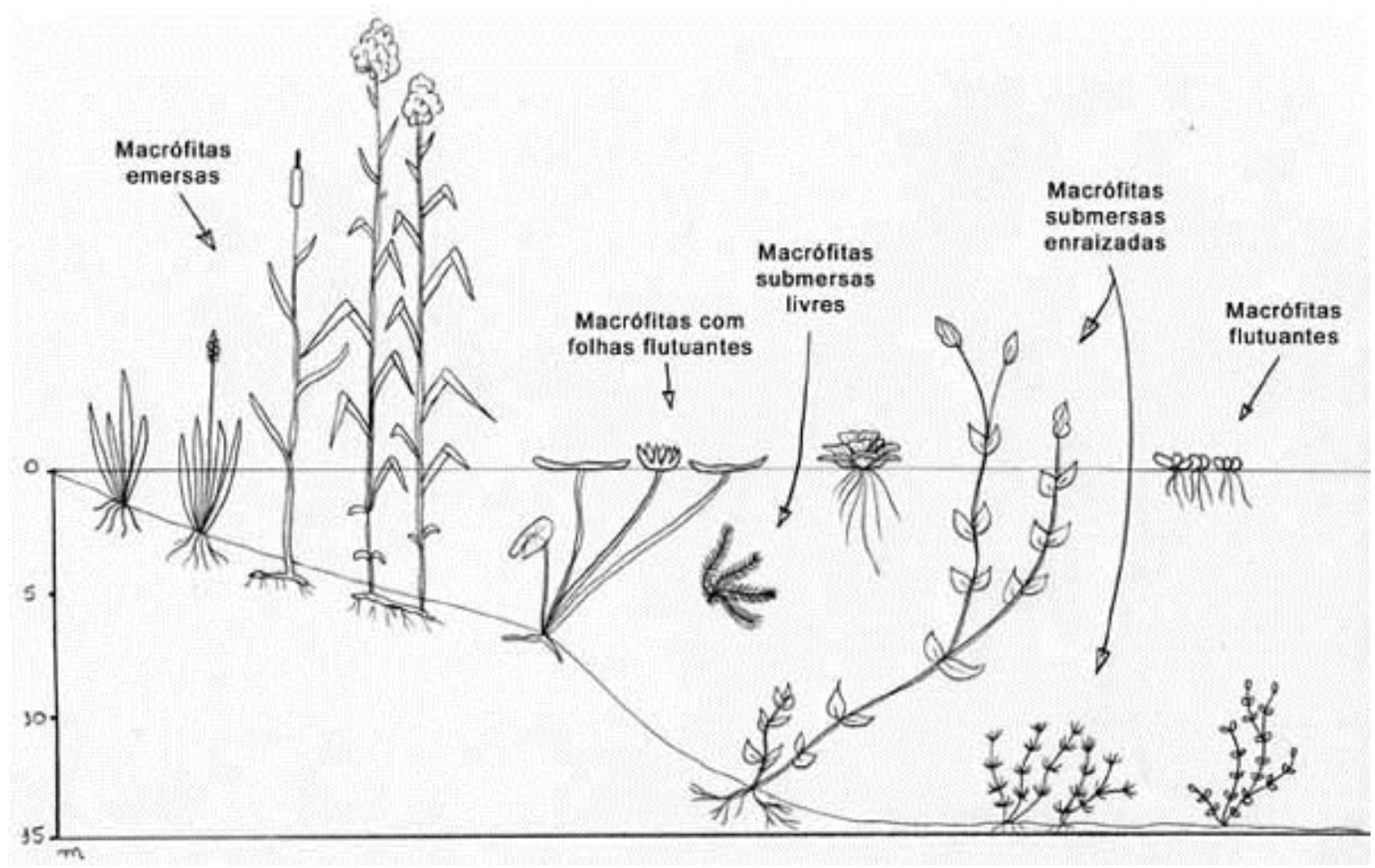

FIGURA 3 - Classificação das macrófitas

Fonte: PROBIO, 2016

As macrófitas aquáticas atuam como bioindicadores e como grandes produtoras de matéria orgânica controlando a dinâmica de nutrientes no ecossistema.

Com relação à distribuição geográfica das macrófitas, apresentam uma distribuição cosmopolita e estão presentes em praticamente todos os Estados do país, na Bacia hidrográfica do Rio das Contas, estado da Bahia sendo identificadas (SANTOS et al, 2009), no estado de São Paulo, nas Bacias do Rio 
Tietê, Rio Paranapanema, Paraíba, Grande etc. (MARTINS et al, 2012; VALITUTTO, 2004).

\subsection{Remoção de metais tóxicos utilizando macrófitas aquáticas}

Há diversos estudos sobre a utilização de macrófitas aquáticas na remoção de metais pesados que demonstram alta eficiência na remoção de íons metálicos, alguns dos quais citados abaixo.

O desempenho da Azolla filiculoides na recuperação dos resíduos de ouro provenientes das indústrias de douração de metais foi verificado por (UMALI et al, 2005).

A capacidade de remoção de Cd por macrófitas flutuantes foi avaliado MAINE et al, (2000) e a Pistia stratiotes apresentou remoção satisfatória na remoção de íons de cádmio.

O potencial de remoção de urânio e arsênio pela macrófita Lemna gibba nos rejeitos de antigas minas de urânio contaminadas com arsênio foi avaliado por MKANDAWIRE (2004) com remoção de 8,96 mg/ g de urânio e 10,21 $\mathrm{mg} / \mathrm{g}$ de arsênio, mostrando assim uma alta capacidade de remoção anual desses contaminantes.

A biossorção do $\mathrm{Cr}(\mathrm{III})$ e $\mathrm{Cr}(\mathrm{IV})$ por plantas aquáticas foi estudada por (ELANGOVAN et al 2008). Na remoção de Cr (VI), Rhizophora mangle obteve a máxima remoção de $8,87 \mathrm{mg} / \mathrm{g}$ seguida da macrófita Nymphaea sp com máxima remoção de $8,44 \mathrm{mg} / \mathrm{g}$. O biossorvente Cannomois virgata foi o que mostrou a maior capacidade na remoção do $\mathrm{Cr}$ (III) de 7,18mg/g. Esses biossorventes mostram se promissores na remoção de $\mathrm{Cr}$ (III) e $\mathrm{Cr}(\mathrm{IV})$ de ambientes aquáticos.

$\mathrm{Na}$ avaliação da capacidade de sorção dos íons de $\mathrm{Cr}$, Cd e $\mathrm{Ni}$ utilizando as macrófitas Eichhornia crassipes, Valisneria spiralis e Pistia stratiotes a macrófita Valisneria spiralis demonstrou uma maior capacidade de biossorção para os três íons quando comparadas as outras macrófitas em estudo segundo VERMA et al (2008). 


\subsection{Pistia stratiotes}

Conhecida como alface d'água, a Pistia stratiotes é uma macrófita aquática flutuante da família das Araceaes do gênero Spermatophyta. Essa espécie que muitas vezes é considerada como daninha por se proliferar com muita facilidade em diversos ecossistemas aquáticos.

A Pistia stratiotes possui folhas dispostas em rosetas, tendo o pecíolo maior e mais largo que as outras. São espatuladas, obtusas com sua face superior verde aveludada, pulverulentas, tendo 7 nervuras simples e longitudinais, coma face inferior de cor verde pálida esbranquiçada e cutalhinosa; as folhas radicais tem $9 \mathrm{~cm}$ de comprimento sobre $2 \mathrm{~cm}$ de cobertura na base e $6 \mathrm{~cm}$ no ápice. Suas outras folhas possuem tamanhos variáveis com $12 \mathrm{~cm}$ de comprimento sobre $9 \mathrm{~cm}$ no ápice (VALITUTTO, 2004).

O seu desenvolvimento acontece no indivíduo com a formação de um pequeno pecíolo que emite, em sua parte superior, uma ou mais folhas. Essas folhas se desenvolvem à medida que a planta cresce até atingir o seu tamanho natural, constituindo outros indivíduos em diversas direções ligados entre si e formando um verdadeiro banco de macrófitas (COSTA JUNIOR, 2007).

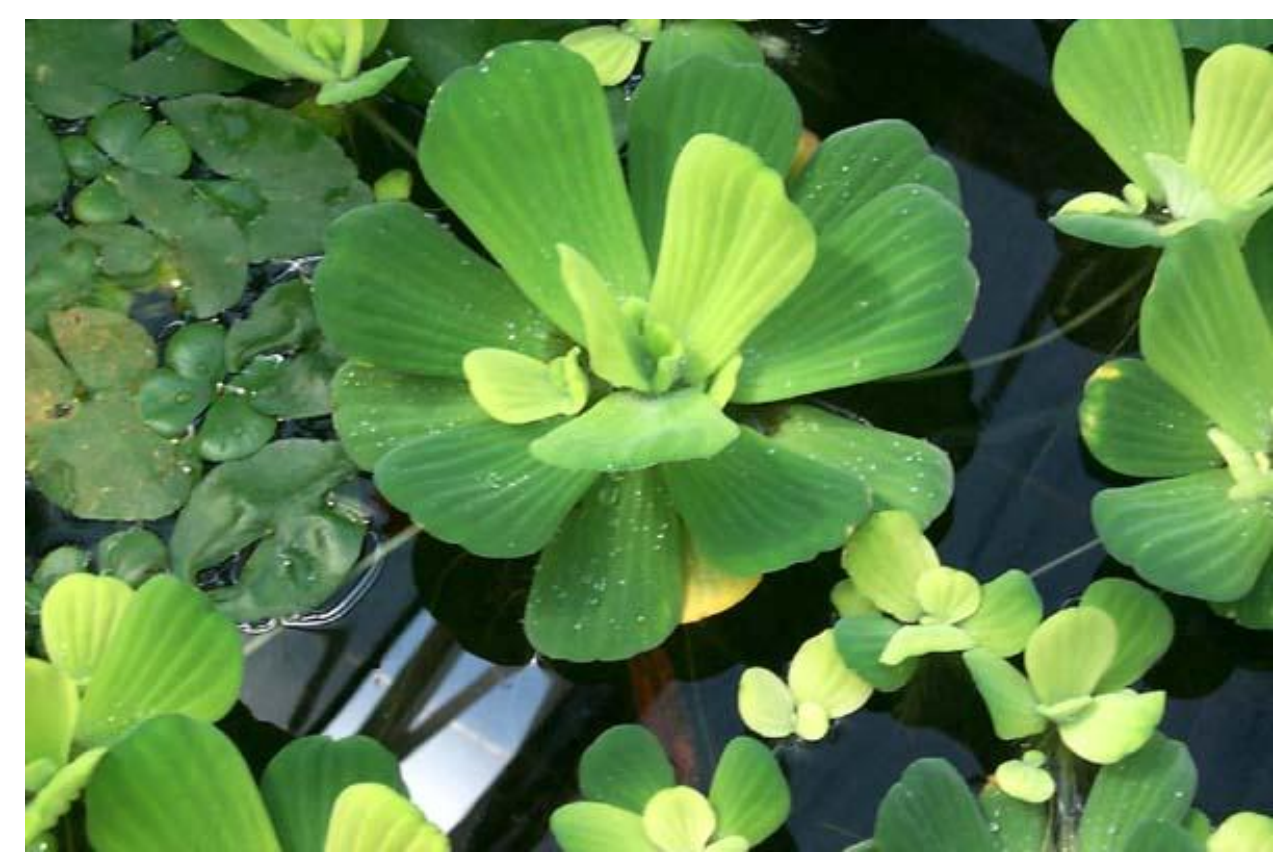

FIGURA 4 - Macrófita Pistia stratiotes

Fonte: Baker et al. 2012 


\subsection{Limnobium laevigatum}

O Limnobium laevigatum (Um. \& Bonpl. ex Wild) Heine, pertencente a família Hydrocharitaceae, é uma macrófita aquática flutuante livre, perene com pecíolos curtos, folhas circulares dispostas em rosetas com bordas livres brilhantes (VALDERRAMA, 1996). Apresentando laminas de 1-10 cm, face adaxial plana, e face abaxial convexa 2-3 x 2-3 cm, inflada com tecido aerênquimatoso, com flores unissexuadas contendo 3 sépalas e 3 pétalas na flor masculina, com ausência de pétalas na flor feminina com estiletes longos de cor creme. O fruto apresenta cápsula ovoide de aproximadamente $1 \mathrm{~cm}$ de comprimento. (RODRIGUES, 2011).

O Limnobium laevigatum vem sendo utilizado no tratamento das águas residuais da agroindústria (VALDERRAMA, 1996) melhorando as características microbiológicas dos efluentes com altas concentrações de material biológico.

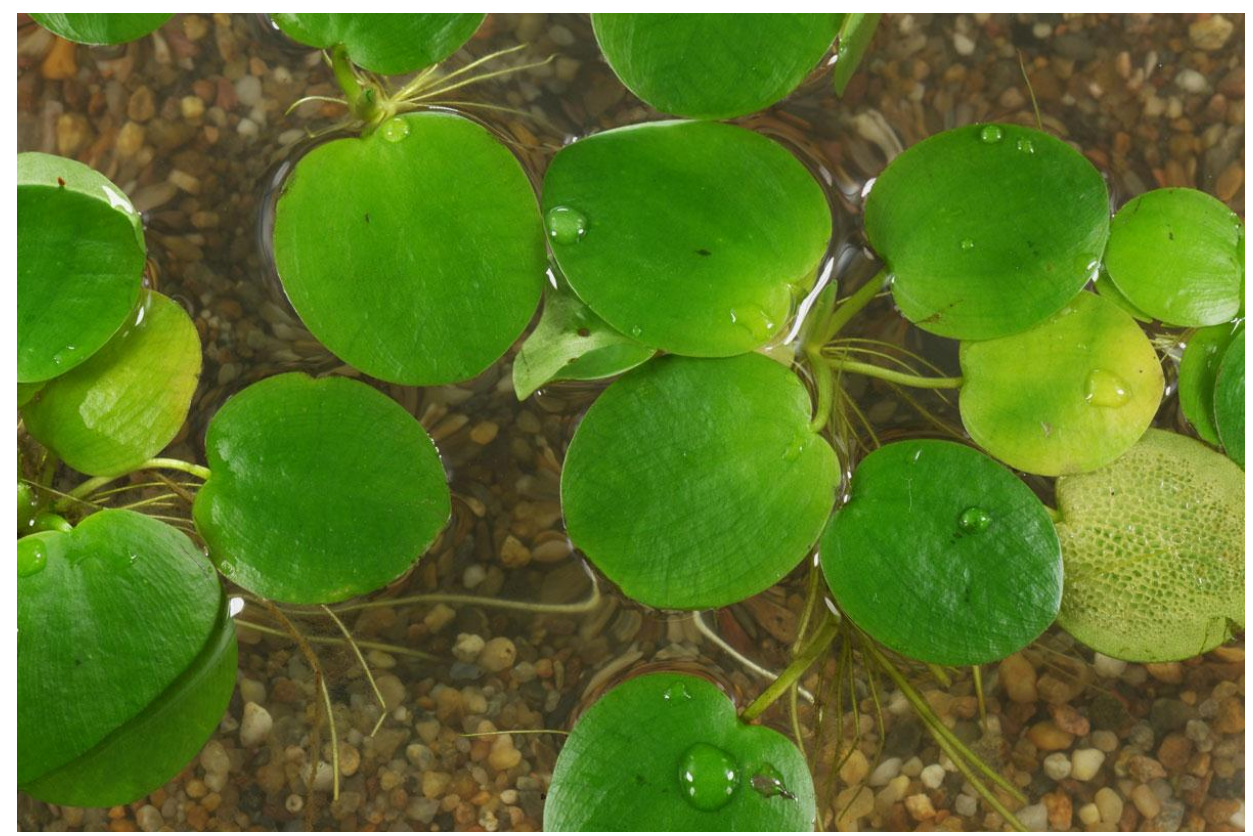

FIGURA 5 - Limnobium laevigatum

Fonte: Baker et al. 2012 


\subsection{Lemna sp}

A macrófita Lemna sp, comumente conhecida como lentilha d água ou duckweek pertence a família das Lemnáceas que são consideradas as menores plantas vasculares do mundo, com cerca de $2 \mathrm{~mm}$ de tamanho. Possuem laminas foliares com reduzida área e sistema radicular muito pouco desenvolvido (HENRY-SILVA e CAMARGO, 2006). Seu pequeno corpo tabloide vegetativo recebe o nome de fronte. São espécies andróginas, monoicas e anuais (SANTOS, 2008).

A Lemna sp é planta aquática flutuante que habita os mais diversos locais como rios, e lagos e inclusive nas cidades, com um desenvolvimento vegetativo onde uma planta dá origem a outra multiplicando-se facilmente podendo até dobrar de quantidade em até uma semana. A Lemna sp tem sido utilizada na alimentação de animais, como o gado, aves e suínos apresentando resultados favoráveis (JOURNEY et al., 1993). Segundo TAVARES (2004) a introdução da Lemna $s p$ na alimentação de tilápias mostraram resultados satisfatórios em relação ao ganho de peso das mesmas podendo ser utilizadas na sua alimentação. 


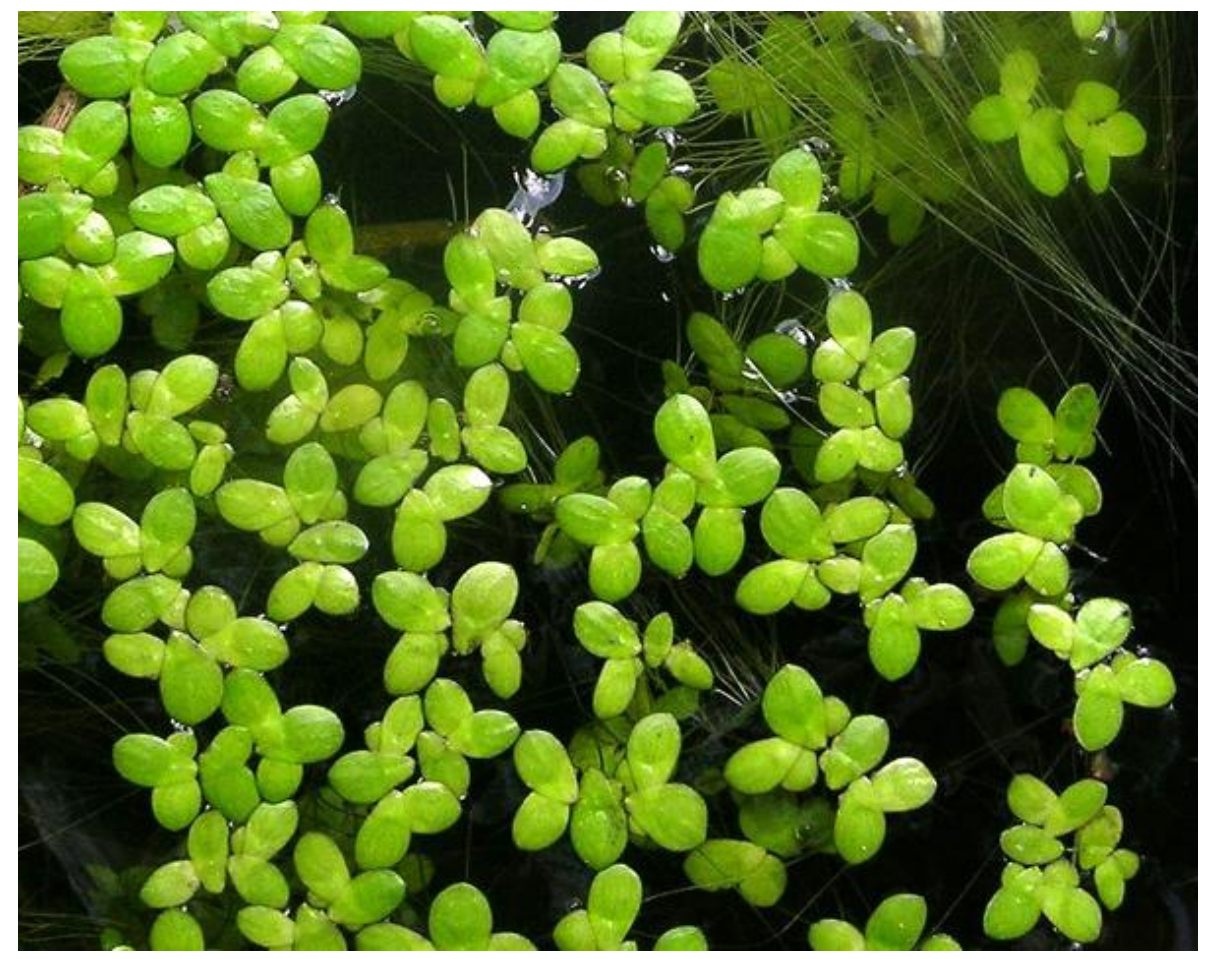

FIGURA 6 - Macrófita Lemna sp

Fonte: Baker et al. 2012

\subsection{Azolla sp}

A samambaia d água, nome popular da Azolla sp, é uma pequena macrófita aquática flutuante da família Azollaceae, pertencente a mesma classe das avencas e samambaias (Pteridófitos).

A Azolla sp possui forma arredondada com 1-2 cm de diâmetro, folhas alternadas com folíolos de 0,5 - 1 mm possuindo cavidades no lombo dorsal. Apresenta rizoma com raízes individuais ramificadas com $1-3 \mathrm{~cm}$ em determinados pontos (RUSCHEL, 1987; STAFFORD, 2003).

Por viver em simbiose com a Cianobacteria Anabaena Azollae que fixa o nitrogênio em altas taxas, a Azolla sp, é muito utilizada como fertilizante nitrogenado na produção de arroz irrigado (SCIVITTARO et al, 2008), e também por apresentar alto potencial na remoção de metais como césio e estrôncio (MASHKANI et al, 2009). 


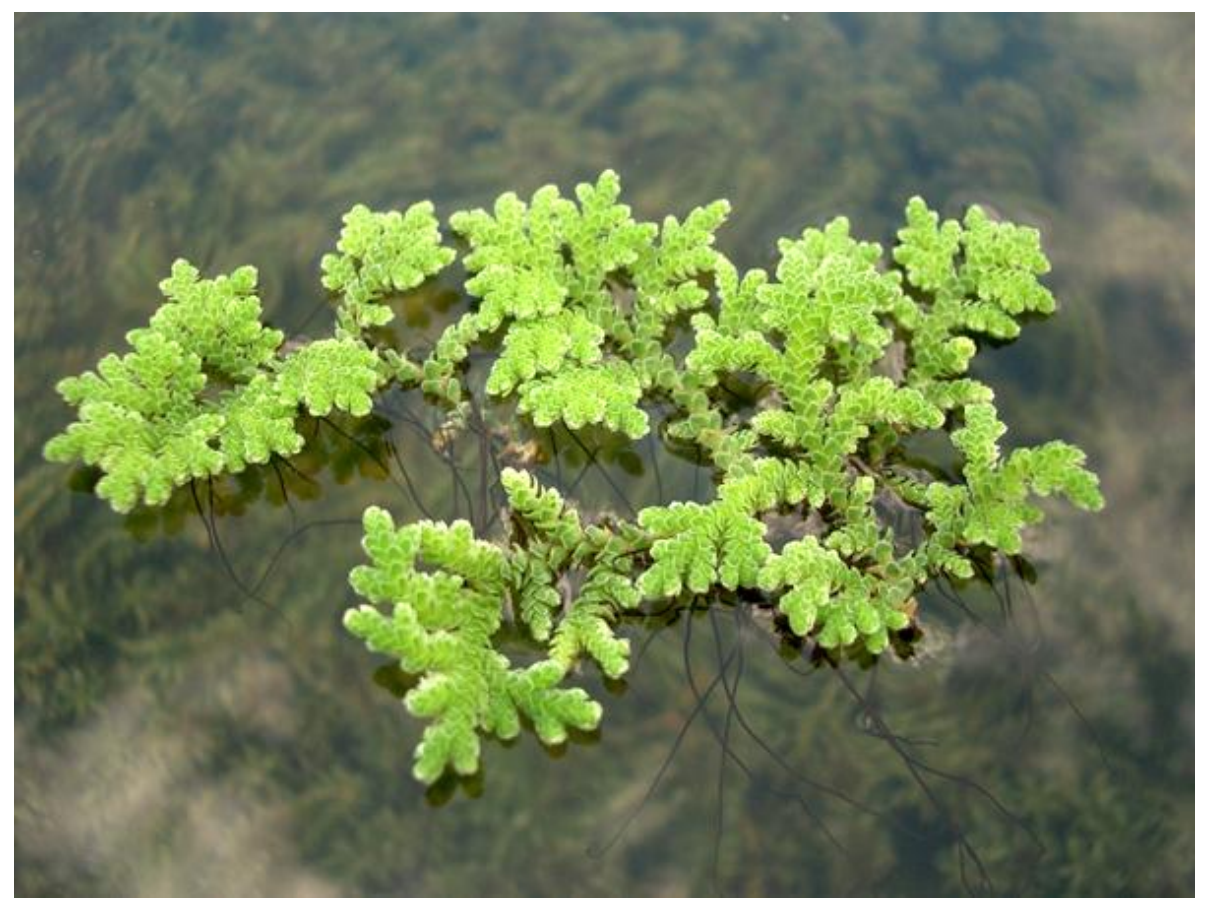

FIGURA 7 - Macrófita Azolla sp

Fonte: Baker, A.L. et al. 2012

\subsection{Isotermas de adsorção}

No processo de adsorção o estudo do equilíbrio fornece informações sobre a capacidade de adsorção ou afinidade de um material biossorvente pelo adsorvato.

O equilíbrio de adsorção ocorre quando quantidade de soluto adsorvida sobre o adsorvente é igual a quantidade dessorvida. Atingido o equilíbrio as concentrações do soluto na fase liquida e na fase sólida permanecem constantes (ALLEN et al, 2003).

O equilíbrio de adsorção é representado graficamente por meio de isotermas de adsorção que expressam a relação entre a concentração de íons retidos no material biossorvente e a quantidade remanescente em solução. As isotermas são baseadas em modelos matemáticos e os parâmetros dos modelos de isotermas de adsorção são obtidos a partir dos dados obtidos experimentalmente. 
Seus parâmetros físico-químicos, juntamente com os pressupostos dos modelos fornecem uma visão sobre o mecanismo de adsorção, bem como o grau de afinidade dos adsorventes. (FOO \&HAMED, 2009).

Para descrever adequadamente os dados de equilíbrio de adsorção, deve-se primeiramente escolher uma equação que descreva os dados obtidos com exatidão e em segundo lugar os métodos de regressão devem ser aplicados para encontrar os parâmetros ideais. (HINZ, 2001).

Ao longo dos anos, vários modelos foram formulados, sendo os mais usados os modelos de Langmuir e Freundlich, por serem de fácil aplicação e interpretação.

Os modelos de isotermas de adsorção utilizados neste trabalho foram os modelos de Langmuir, Freundlich, Sips, Toth, Redilch-Peterson, Dois-Sítios Langmuir e Radke-Prausnitz.

\subsubsection{Modelo de Langmuir}

O modelo de Langmuir (1918) conforme representado pela Eq 2 é um modelo simples e dos mais utilizados. Proposto inicialmente para o estudo da adsorção de um gás sobre a superfície de um sólido, foi estendido para incluir a adsorção em uma interface sólido-líquido.

Esse modelo sugere que a superfície do sólido é uniforme e a adsorção ocorre nos sítios ativos, havendo a formação de uma monocamada onde um sítio de adsorção adsorve uma única molécula de sorbato. Nesse caso, os sítios de adsorção são equivalentes e têm a mesma afinidade para o sorbato, não havendo interação entre os sítios vizinhos.

$$
\mathrm{q}_{\mathrm{eq}}=\frac{\mathrm{q}_{\max \mathrm{K}_{\mathrm{L}} \mathrm{C}_{\mathrm{e}}}}{1+\mathrm{K}_{\mathrm{L}} \mathrm{C}_{\mathrm{e}}}
$$

Onde:

$q_{\text {eq }}$ é a quantidade por unidade de massa da espécie (metal) adsorvido no equilíbrio ( $\mathrm{mmol} . \mathrm{g}^{-1}$ )

$\mathbf{q}_{\max }$ é a capacidade máxima de adsorção $\left(\mathrm{mmol} \mathrm{g}^{-1}\right)$ 


\begin{abstract}
$\mathbf{K}_{\mathrm{L}}$ é a constante de Langmuir relacionada a energia de adsorção (L.mmol ${ }^{-1}$ )
$\mathbf{C}_{\mathrm{e}}$ é a concentração do adsorvato não adsorvido quando o sistema está em equilíbrio (mmol. $\left.\mathrm{L}^{-1}\right)$
\end{abstract}

\title{
3.10.2 Modelo de Freundlich
}

A isoterma de Freundlich descreve a adsorção como não ideal e reversível, não restrita a formação de monocamada (FREUNDLICH, 1907) citada por (HUBBE et al, 2011). É um modelo empírico no qual a adsorção ocorre em múltiplas camadas, com uma distribuição não uniforme de calor de adsorção aplicada a sistemas heterogêneos. Assim, os sítios de ligação mais fortes são ocupados primeiro até que a energia de adsorção diminuía com a conclusão do processo de adsorção.

A equação empírica pode ser descrita por:

$$
\mathrm{q}_{\mathrm{eq}}=\mathrm{K}_{\mathrm{f}} \mathrm{C}_{\mathrm{e}}^{1 / \mathrm{n}}
$$

Onde:

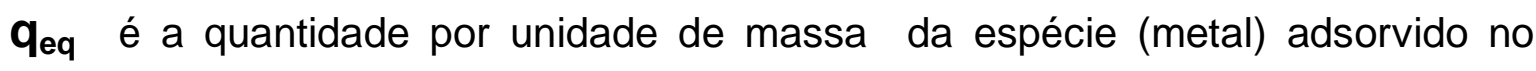
equilíbrio $\left(\mathrm{mmol} . \mathrm{g}^{-1}\right)$

$\mathbf{C}_{\mathrm{e}}$ é a concentração do adsorvato não adsorvido quando o sistema está em equilíbrio $\left(\mathrm{mmol}^{-1} \mathrm{~L}^{-1}\right)$

$\mathbf{K}_{\mathbf{f}}$ é uma constante relacionada com a capacidade de adsorção (L. $\mathrm{mmol}^{-1}$ )

n é uma constante e representa a intensidade da sorção e a distribuição dos sítios ativos.

$0<1 / \mathrm{n} \leq 1$, adsorção favorável das espécies químicas no adsorvente

$1 / n>1$ adsorção desfavorável das espécies químicas no adsorvente 


\subsubsection{Modelo de Sips}

A isoterma de Sips é uma forma combinada das expressões deduzidas dos modelos isotérmicos de Langmuir e Freundlich para antecipar sistemas heterogêneos de adsorção e contornar a limitação da concentração crescente associada ao modelo de Freundlich. (SIPS 1978).

Em baixas concentrações de adsorção, segue a isoterma de Freundlich, quando em altas concentrações há a formação de monocamada característica do modelo de Langmuir. Os parâmetros da equação são governados pelas condições de operação, como alteração de $\mathrm{pH}$, temperatura e concentração.

$$
\mathrm{q}_{\mathrm{eq}}=\frac{\mathrm{K}_{\mathrm{s}} \mathrm{C}_{\mathrm{e}}^{\beta_{\mathrm{s}}}}{1+\mathrm{a}_{\mathrm{s}} \mathrm{C}_{\mathrm{e}}^{\beta_{\mathrm{s}}}}
$$

Onde:

$\mathbf{q}_{\text {eq }}$ é a quantidade da espécie (metal) adsorvido no equilíbrio (mmol. $\mathrm{g}^{-1}$ )

$\mathbf{C}_{\mathrm{e}}$ é a concentração do adsorvato não adsorvido quando o sistema está em equilíbrio (mmol. $\left.\mathrm{L}^{-1}\right)$

$\mathbf{k}_{\mathbf{s}}$ constante relacionada a energia de adsorção (L.mmol ${ }^{-1}$ )

$\mathbf{a}_{\mathbf{s}}$ constante de Sips (L.mmol $\left.{ }^{-1}\right)$

$\boldsymbol{\beta}_{\mathrm{s}}$ indica a heterogeneidade do biossorvente, se $\beta_{\mathrm{s}}=10$ modelo se reduz a Langmuir

\subsubsection{Modelo de Toth}

O modelo de isoterma de Toth (TOTH 1971) é uma equação empírica desenvolvida para melhorar os dados experimentais da isoterma de Langmuir, descrevendo sistemas heterogêneos de adsorção. Este modelo apresenta uma distribuição de energia Gaussiana em que a maioria dos sítios de adsorção possui energia mais baixa que o pico ou a energia máxima de adsorção. (ALLEN et al, 2003; PADMESH e VIJAYARAGHAVAN, 2006). 


$$
\mathrm{q}_{\mathrm{eq}}=\frac{\mathrm{K}_{\mathrm{T}} \mathrm{C}_{\mathrm{e}}}{\left(\mathrm{a}_{\mathrm{T}}+\mathrm{C}_{\mathrm{e}}^{\mathrm{t}}\right)^{1 / \mathrm{t}}}
$$

$\mathbf{q}_{\mathrm{e}}$ é a quantidade da espécie (metal) adsorvido no equilíbrio ( $\mathrm{mmol} . \mathrm{g}^{-1}$ )

$\mathbf{C}_{\mathrm{e}}$ é a concentração do adsorvato não adsorvido quando o sistema está em equilíbrio (mmol. $\left.\mathrm{L}^{-1}\right)$

$\mathbf{K}_{\mathbf{T}}$ é a constante da isoterma de Toth (L.mmol $\left.{ }^{-1}\right)$

$\mathbf{a}_{\mathrm{T}}$ é a constante da isoterma de Toth $\left(\mathrm{L} \cdot \mathrm{mmol}^{-1}\right)$

t é o tempo

\subsubsection{Modelo de Redlich-Peterson}

O modelo de Redlich-Peterson (REDLICH \& PETERSON 1959) é uma isoterma híbrida com as isotermas de Langmuir e Freundlich, que incorporam três parâmetros numa equação empírica.

Esse modelo apresenta uma dependência linear da concentração em seu numerador e uma função exponencial no denominador representando o equilíbrio de adsorção numa vasta gama de concentração, podendo ser aplicado tanto em sistemas homogêneos como heterogêneos (FOO \& HAMED 2009). Pode ser utilizado para representar uma ampla faixa de concentração (ALLEN et al, 2003).

$$
\mathrm{q}_{\mathrm{eq}}=\frac{\mathrm{K}_{\mathrm{Rp}} \mathrm{C}_{\mathrm{e}}}{1+\mathrm{a}_{\mathrm{Rp}} \mathrm{C}_{\mathrm{e}}^{\beta}}
$$

$\mathbf{q}_{\text {eq }}$ é a quantidade da espécie (metal) adsorvido no equilíbrio (mmol. $\mathrm{g}^{-1}$ )

$\mathbf{C}_{\mathrm{e}}$ é a concentração do adsorvato não adsorvido quando o sistema está em equilíbrio (mmol. $\left.\mathrm{L}^{-1}\right)$

$K_{\mathbf{R p}}$ é a primeira constante da isoterma $R-P(1 / \mathrm{mol})$

$\mathbf{a}_{\mathrm{Rp}}$ é a segunda constante da isoterma $\mathrm{R}-\mathrm{P}(\mathrm{L} / \mathrm{mmol})$ 
$\boldsymbol{\beta}$ é um expoente cujo valor compreende entre 0 e 1

$\beta=1$ será uma isoterma de Langmuir

$\beta=0$ será uma isoterma de Freundlich

\subsubsection{Modelo de Dois-Sítios Langmuir}

O modelo de Dois-Sítios Langmuir assume que existem 2 tipos diferentes de sítios de ligação com diferentes energias de adsorção. (DEMIREL et al, 2007; ESCUDERO et al , 2009). A adsorção no segundo tipo de sítio não é independente estando associadas às moléculas que já foram adsorvidas no primeiro sitio de ligação sendo resultado de uma interação lateral (KORESH, 1982).

$$
q_{e q}=\frac{Q_{1} b_{1} C_{e}}{1+b_{1} C_{e}}+\frac{Q_{2} b_{2} C_{e}}{1+b_{2} C_{e}}
$$

$q_{\text {eq }}$ é a quantidade da espécie (metal) adsorvido no equilíbrio (mmol. $\mathrm{g}^{-1}$ )

$\mathbf{C}_{\mathbf{e}}$ é a concentração do adsorvato não adsorvido quando o sistema está em equilíbrio (mmol. $\mathrm{L}^{-1}$ )

$\mathbf{Q}_{1}$ e $\mathbf{Q}_{2}$ são as capacidades máximas de adsorção $\left(\mathrm{mmol} \cdot \mathrm{g}^{-1}\right.$ ) onde a capacidade máxima total é a somatória de $Q_{1}+Q_{2}$

b1 e b2 são os coeficientes de afinidade dos sítios 1 e 2 respectivamente $\left(\right.$ L. $\left.\mathrm{mmol}^{-1}\right)$

\subsubsection{Modelo de Radke-Prausnitz}

O modelo de Radke-Prausnitz é uma modificação do modelo de Langmuir para melhorar os dados experimentais a partir da adição de um novo parâmetro descrevendo a fase de equilíbrio sobre uma ampla faixa de concentração (PERUZZO 2003; PADMESH e VIJAYARAGHAVAN, 2006). Em altas concentrações a equação se reduz a Freundlich, a baixas concentrações se reduz a forma de Henry e quando nrp $=0$ a equação segue Langmuir. 


$$
\mathrm{q}_{\mathrm{eq}}=\frac{\mathrm{q}_{\mathrm{max}} \mathrm{K}_{\mathrm{RP}} \mathrm{C}_{\mathrm{e}}}{\left(1+\mathrm{K}_{\mathrm{RP}} \mathrm{C}_{\mathrm{e}}\right)^{1 / \mathrm{nRP}}}
$$

$q_{\text {eq }}$ é a quantidade da espécie (metal) adsorvido no equilíbrio (mmol. $\mathrm{g}^{-1}$ )

$\mathbf{q}_{\max }$ é a capacidade máxima de adsorção ( $\mathrm{mmol} . \mathrm{g}^{-1}$ )

$\mathbf{C}_{\mathrm{e}}$ é a concentração do adsorvato não adsorvido quando o sistema está em equilíbrio $\left(\mathrm{mmol} . \mathrm{L}^{-1}\right)$

$\mathbf{K}_{\mathbf{R P}}$ é a constante de Radke-Prausnitz relacionada a energia de adsorção (L.mmol ${ }^{-1}$ )

$\mathbf{n}_{\mathbf{R P}}$ é o expoente adimensional de Radke-Prausnitz

\subsection{Cinética de Sorção}

Determinar a cinética de biossorção é fundamental para avaliar a eficiência da remoção de metais pelas macrófitas. A cinética de sorção descreve a taxa de adsorção do soluto, determinando a velocidade e o tempo de equilíbrio em que ocorre a sorção (MARTINS, 2012).

A cinética de sorção pode ser controlada por diversos processos independentes.

$\checkmark$ Processo de transferência de massa externa que inclui a difusão em massa do absorbato em solução e filme de difusão através da fronteira em torno do biossorvente

$\checkmark$ Difusão intra partícula do adsorbato a partir da superfície interna

$\checkmark$ Quimissorção, envolvendo reações químicas entre os sítios ativos no biossorvente e adsorvato (AUTA \& HAMEED 2013).

Os modelos de Pseudo-Primeira Ordem (Lagergren) e PseudoSegunda Ordem foram utilizados neste trabalho para analisar a cinética de biossorção do urânio pelas macrófitas, Pistia stratiotes, Limnobium laevigatum, Lemna sp e Azola sp. 


\subsubsection{Modelo de Pseudo-Primeira Ordem}

O Modelo de Pseudo-Primeira Ordem Lagergren (1898) foi a primeira equação de taxa estabelecida para um sistema sólido/ líquido.

Muito utilizada sendo baseada na capacidade de adsorção de sólidos.

Neste modelo a taxa de variação da captação do soluto com o tempo é proporcional a diferença entre a quantidade adsorvida em equilíbrio e a adsorvida em qualquer parte do processo. O modelo de pseudo-primeira ordem é calculado de acordo com a equação 9.

$$
\mathrm{q}(\mathrm{t})=\mathrm{q}_{\mathrm{eq}}\left(1-\mathrm{e}^{\mathrm{k} 1 \mathrm{t}}\right)
$$

Eq. 8

Onde q é a quantidade de íons por unidade de massa de biossorvente no instante $\mathrm{t}(\mathrm{mmol} / \mathrm{g})$

$\mathbf{q}_{\text {eq }}$ é a quantidade de íons por unidade de massa de biossorvente no equilíbrio $(\mathrm{mmol} / \mathrm{g})$

$\mathrm{k}_{1}$ é a constante de biossorção de pseudo-primeira-ordem $\left(\mathrm{min}^{-1}\right)$

\subsubsection{Modelo de Pseudo-Segunda Ordem}

O Modelo de Pseudo-Segunda Ordem assume que a taxa de biossorção de uma espécie metálica varia proporcionalmente ao quadrado da concentração do íon no material adsorvente (FERREIRA, 2014).

$$
q(t)=q_{e q} \frac{q_{e q}{ }^{k 2 t}}{q_{e q}{ }^{k 2 t+1}}
$$


q é a quantidade de íons por unidade de massa de biossorvente no instante t $(\mathrm{mmol} / \mathrm{g})$

$\mathbf{q}_{\text {eq }}$ é a quantidade de íons por unidade de massa de biossorvente no equilíbrio $(\mathrm{mmol} / \mathrm{g})$

$\mathrm{k}_{2}$ é a constante de biossorção de pseudo-segunda-ordem (g.mmol $\left.{ }^{-1} \cdot \mathrm{min}^{-1}\right)$. 


\section{MATERIAIS E MÉTODOS}

A parte experimental deste trabalho foi dividida em duas etapas. I) Preparo e caracterização da biomassa, II) Realização dos ensaios de biossorção.

\subsection{Preparo das biomassas}

As biomassas secas utilizadas no desenvolvimento desse trabalho, as macrófitas aquáticas Limnobium laevigatum, Pistia stratiotes, Lemna sp. e Azolla $s p$. foram cultivadas, coletadas e fornecidas pela Universidade Estadual do Oeste Paraná(Unioeste).

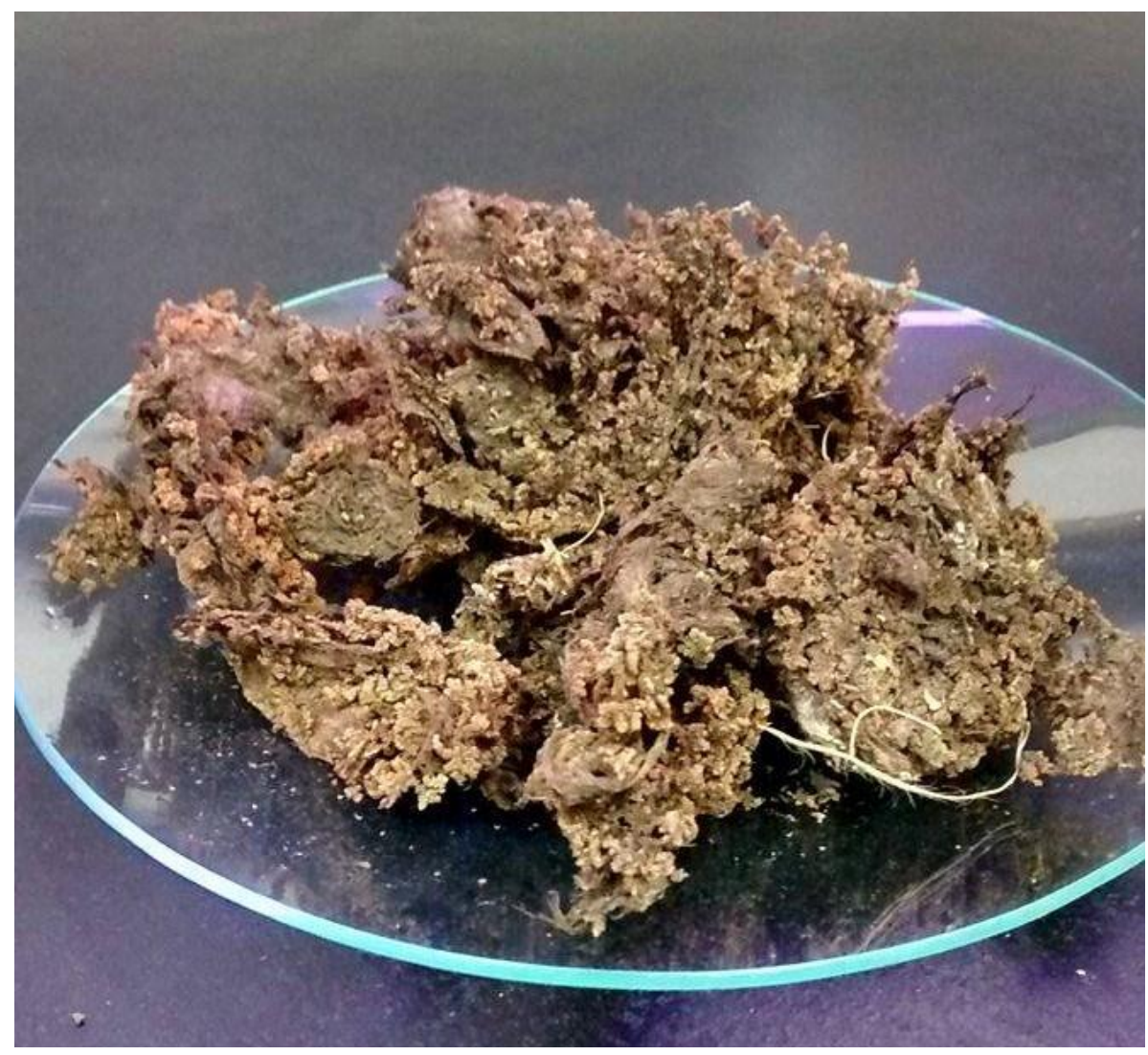

FIGURA 8 - Azolla sp em estado bruto

As biomassas foram lavadas com água corrente, água destilada e secas em estufa a $80^{\circ} \mathrm{C}$, durante 24 horas. Em seguida, todas as partes das 
biomassas foram trituradas, peneiradas e separadas em partículas com frações que variam entre com $0,125 \mathrm{~mm}$ e $0,297 \mathrm{~mm}$ de acordo com os bons resultados obtidos em trabalho prévio realizado por (FERREIRA 2014).

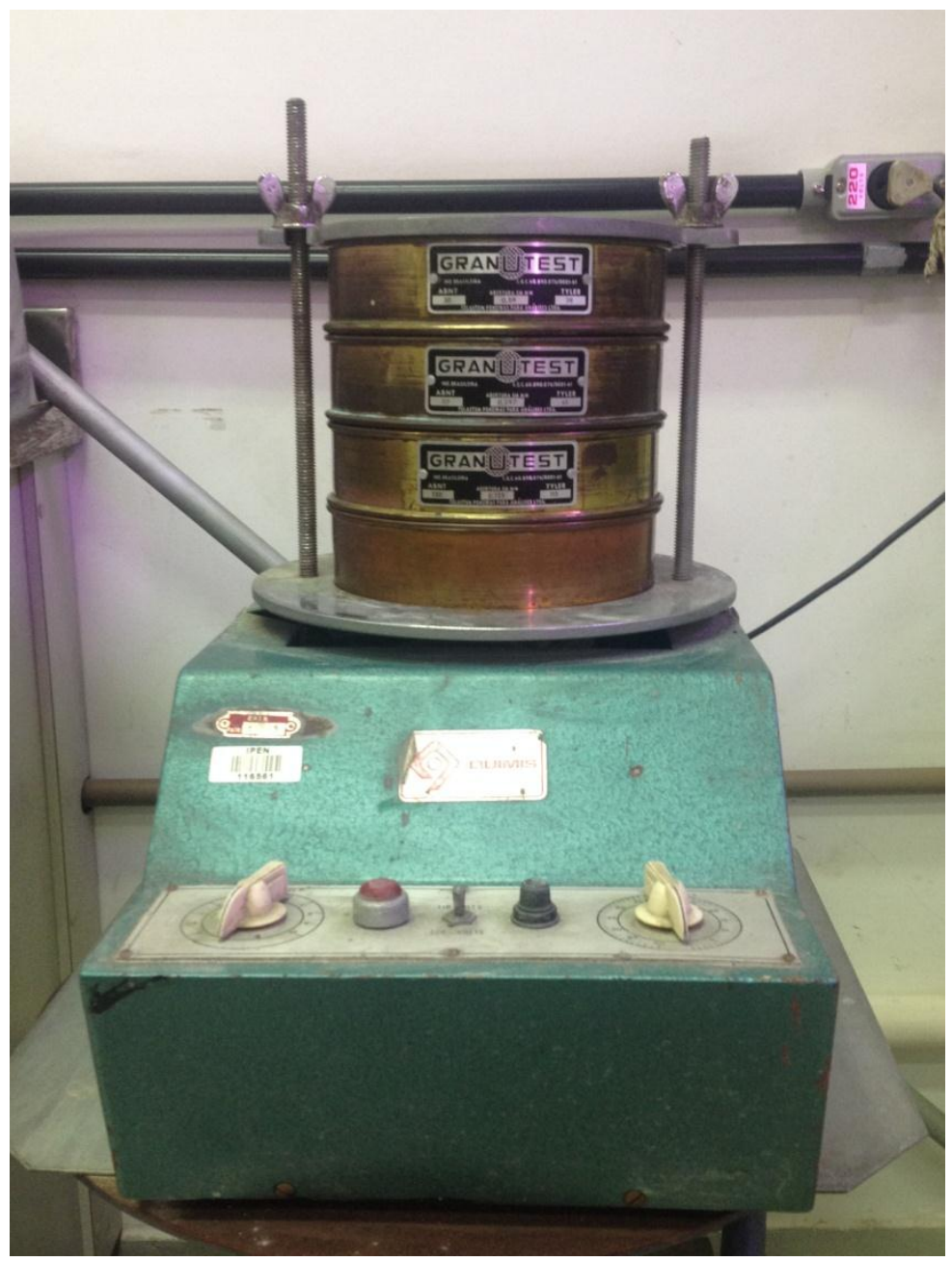

FIGURA 9 - Peneiras para separação granulométrica

Posteriormente, as biomassas foram esterilizadas por radiação ultravioleta (UV) durante 30 minutos para evitar a deterioração por proliferação de fungos ou bactérias. 


\section{2 Caracterização das biomassas}

A caracterização das biomassas foi realizada por meio da análise morfológica, das densidades real e aparente, área superficial específica e pela análise de espectroscopia de absorção atômica na região do infravermelho com transformada de Fourier.

\subsubsection{Características morfológicas}

As características morfológicas das biomassas brutas foram analisadas por meio de microscopia eletrônica de varredura (MEV) utilizando o microscópio Philips (modelo XL30). As macrófitas foram secas em estufa por $24 \mathrm{~h}$ a $80^{\circ} \mathrm{C}$, e, posteriormente uma pequena amostra foi depositada num suporte de cobre e sobre ela foi depositado um filme de ouro sobre ela num metalizador a vácuo.

\subsubsection{Densidade aparente}

A densidade aparente das macrófitas foi determinada de acordo com 0 método (LIMA E MARSHAL, 2005) por meio da relação entre a massa (g) e volume $\left(\mathrm{cm}^{3}\right)$.

Numa proveta graduada de $10 \mathrm{~mL}$, foi introduzido $1 \mathrm{~g}$ de amostra e a mesma foi nivelada levemente até apresentar aparência uniforme, sem alteração de volume. Os ensaios foram realizados em triplicata para cada uma das macrófitas e depois de medido o volume, as amostras foram pesadas e assim determinada a densidade aparente por meio da equação.

$$
\mathrm{d}=\frac{\mathrm{mc}}{\mathrm{Voc}}
$$

Onde:

$\mathrm{d}=$ densidade aparente $\left(\mathrm{g} / \mathrm{cm}^{3}\right)$

$\mathrm{mc}=$ massa do material biossorvente $(\mathrm{g})$

$\mathrm{V}_{\mathrm{oc}}=$ volume ocupado pelo biossorvente $\left(\mathrm{cm}^{3}\right)$ 


\subsubsection{Densidade real}

A densidade real das biomassas foi obtida por meio da técnica de picnometria de gás hélio. É determinado o volume da amostra pela medida da variação da pressão do gás hélio, que passa através das superfícies irregulares do solido qual é registrado no picnômetro. A partir do volume obtido $\left(\mathrm{cm}^{3}\right)$ e a massa(g) é possível calcular a densidade real $\left(\mathrm{g} . \mathrm{cm}^{-3}\right)$.

\subsection{4 Área superficial específica}

A área superficial específica foi determinada de acordo com o método Brunauer, Emmet e Teller (B.E.T), (REN et al, 2009), no qual as moléculas do gás nitrogênio $\left(\mathrm{N}_{2}\right)$ são adsorvidas e dessorvidas sobre uma superfície sólida. Os dados de adsorção do $\mathrm{N}_{2}$ foram obtidos em um analisador de área. A área superficial especifica por unidade de massa $\left(S_{m}\right)$ foi calculada pela seguinte equação.

$$
\mathrm{S}_{\mathrm{m}}=\frac{\mathrm{N}_{\mathrm{A}} \mathrm{V}_{\mathrm{m}} \mathrm{A}_{\mathrm{m}}}{\mathrm{V}_{\mathrm{mol}} \mathrm{M}_{\mathrm{s}}}
$$

Onde:

$\mathrm{N}_{\mathrm{A}}$ é a constante de Avogadro $\left(6,023 \times 10^{23}\right)$

$A_{M}$ é a área ocupada por uma molécula de gás adsorvido $\left(16,2 \times 10^{-20} \mathrm{~m}^{2}\right.$ para $\left.\mathrm{N}_{2}\right)$

$V_{M}$ é o volume da molécula de gás adsorvida (m3)

$V_{\mathrm{mol}}=$ volume de $1 \mathrm{~mol}$ de gás a temperatura ambiente

Ms é a massa da amostra $(\mathrm{g})$

\subsubsection{Análise dos grupos funcionais por infravermelho (IV)}

Os grupos funcionais presentes na estrutura das macrófitas foram identificados por meio da espectroscopia de infravermelho com transformada de Fourier (FTIR). As análises foram realizadas com um espectrômetro da marca 
Perkin Elmer, Modelo Frontier, e o acessório ATR de cristal de germânio. O espectro foi analisado na região de $600-4000 \mathrm{~cm}^{-1}$.

\subsection{Ensaios de biossorção}

Os ensaios de biossorção foram divididos em 3 subetapas :

As subetapas 1 e 2 foram realizadas com a solução de urânio preparada a partir da dissolução de nitrato de uranila $\left(\mathrm{UO}_{2}\left(\mathrm{NO}_{3}\right)_{2}\right)$ em água destilada, tendo seu $\mathrm{pH}$ ajustado ao valor $4,0 \mathrm{com} \mathrm{HNO}_{3}$. A solução teve seu $\mathrm{pH}$ ajustado a 4,0 pois a biossorção do urânio é favorecida em soluções ácidas devido a sua especiação. (YANG \& VOLESKY, 1999; VOLESKY 2003; KRESTOU, 2004).

Os ensaios da subetapa 3 foram realizados com o rejeito radioativo líquido armazenado na Gerência de Rejeitos Radioativos (GRR- IPEN), contendo $\mathrm{Am}, \mathrm{Cs}, \mathrm{U}$ e outros elementos, composto por água, acetato de etila e tributilfosfato com concentrações conhecidas (FERREIRA, 2014).

- Subetapa 1:

Nesta subetapa foram realizados experimentos de biossorção em bancada variando-se os tempos de contato da solução de urânio com o material biossorvente a fim de determinar o tempo de equilíbrio na cinética de sorção. Para os experimentos foram utilizados frascos de polietileno de $20 \mathrm{~mL}$ de capacidade, nos quais foram adicionadas $10 \mathrm{~mL}$ da solução com concentração de $150 \mathrm{mg} / \mathrm{L}$ e $0,20 \mathrm{~g}$ de biomassa.

Os experimentos foram realizados em temperatura de $21 \stackrel{\circ}{\circ} \mathrm{C}$ sob agitação constante em incubadora Orbital Shaker BT $400 \mathrm{com}$ velocidade de 130rpm. Os tempos de contato foram de 5, 30, 60, 120 e 240 minutos e os experimentos foram realizados em triplicata para cada uma das macrófitas.

Em seguida, as biomassas foram separadas por meio de filtração com os filtros de papel (filtração lenta, para precipitados finos com teor de cinzas $0,00012 \mathrm{~g}$ ) e nova filtração com sistema a vácuo com filtro de polipropileno de 0,1 
$\mu \mathrm{m}$ para evitar a presença de qualquer resíduo de biomassa na solução remanescente que pudesse interferir nos resultados.

- Subetapa 2:

Após o estabelecimento do tempo de equilíbrio para cada uma das macrófitas, foram realizados novos experimentos de biossorção variando as concentrações de solução urânio para a construção das isotermas de adsorção. Para os experimentos foram utilizados frascos de polietileno de $20 \mathrm{~mL}$ de capacidade, nos quais foram adicionadas $10 \mathrm{~mL}$ da solução e 0,20 $\mathrm{g}$ de biomassa. Em seguida, foram mantidos sob agitação constante, a $21^{\circ} \mathrm{C}$, em incubadora Orbital Shaker BT 400, com velocidade de 130 rpm. Os experimentos foram realizados em triplicata para cada uma das macrófitas estudadas. As concentrações das soluções de simulado de rejeito radioativo líquido variaram entre $75 \mathrm{mg} / \mathrm{L}$ a $20.000 \mathrm{mg} / \mathrm{L}$. Os tempos adotados nessa subetapa foram os tempos de equilíbrio obtidos para cada uma das macrófitas na subetapa 1 conforme as FIG. que variam de 20 a 23.

Em seguida, as biomassas foram separadas por meio de filtração com os filtros de papel (filtração lenta, para precipitados finos com teor de cinzas $0,00012 \mathrm{~g}$ ) e nova filtração com sistema a vácuo com filtro de polipropileno de 0,1 $\mu \mathrm{m}$ para evitar a presença de qualquer resíduo de biomassa na solução remanescente que pudesse interferir nos resultados.

- Subetapa 3:

Nessa subetapa foram realizados ensaios com o rejeito radioativo líquido utilizando as macrófitas que apresentaram a melhor capacidade de sorção avaliada nos resultados obtidos no ensaio anterior da subetapa 2.

As condições experimentais foram as mesmas da subetapa 2, sendo nesta substituída a solução de urânio $\left(\mathrm{UO}_{2}\left(\mathrm{NO}_{3}\right)_{2}\right)$ pelo rejeito radioativo com concentração de 60 ppm de urânio (concentração total 100\%). 


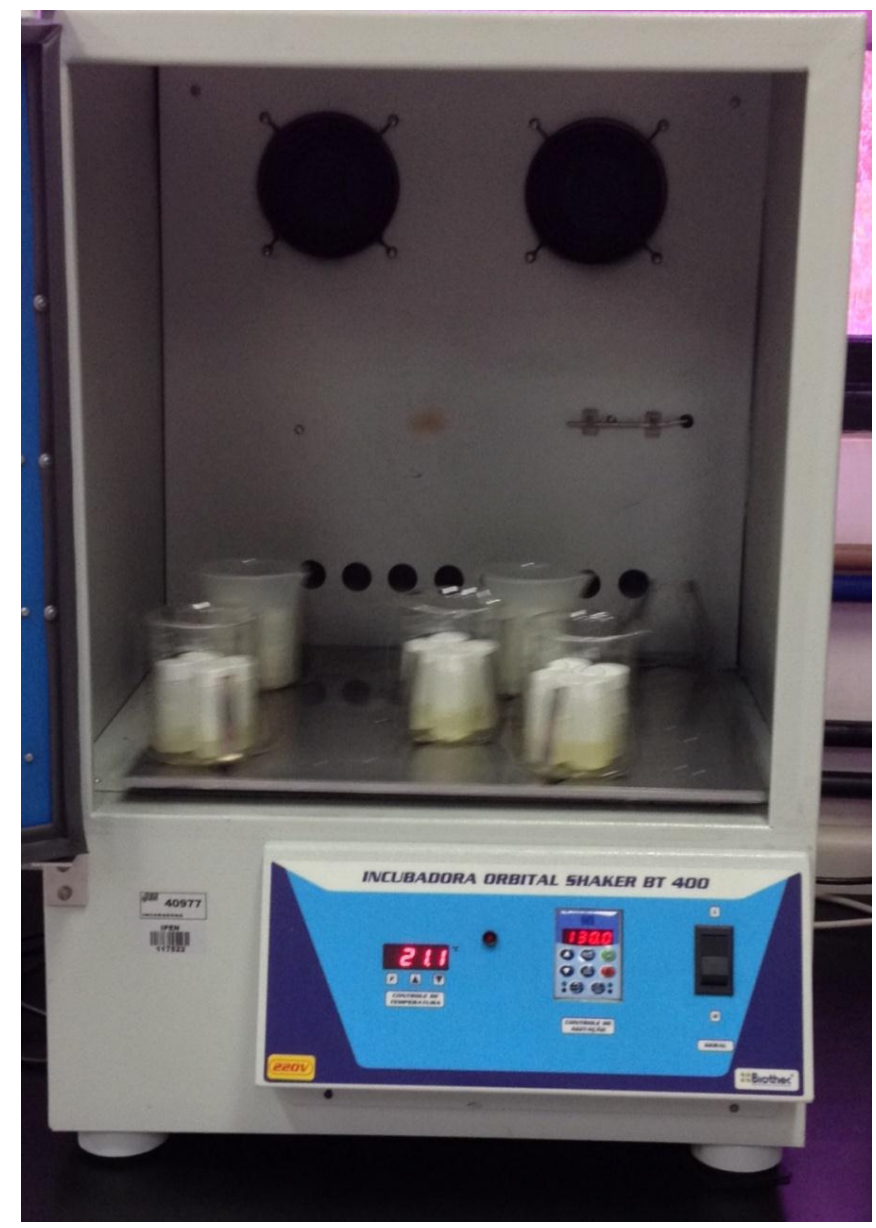

FIGURA 10 - Incubadora Orbital Shaker

\subsubsection{Determinação da concentração do urânio por ICP-OES}

As concentrações de urânio nas soluções remanescentes dos ensaios realizados nas subetapas 1, 2, e 3 foram determinadas por espectroscopia de emissão óptica com plasma acoplado indutivamente (ICP-OES) modelo Optima 7000 DV, da marca Perkin-Elmer conforme FIG 11, calibrado previamente com solução padrão de urânio (Johnson Matihey Company) com concentrações que variam de $\left(0,01\right.$ a $\left.10 \mathrm{mg} \cdot \mathrm{L}^{-1}\right)$.

O comprimento de onda $(\lambda)$ utilizado para a determinação de urânio foi de $424,167 \mathrm{~nm}$. 


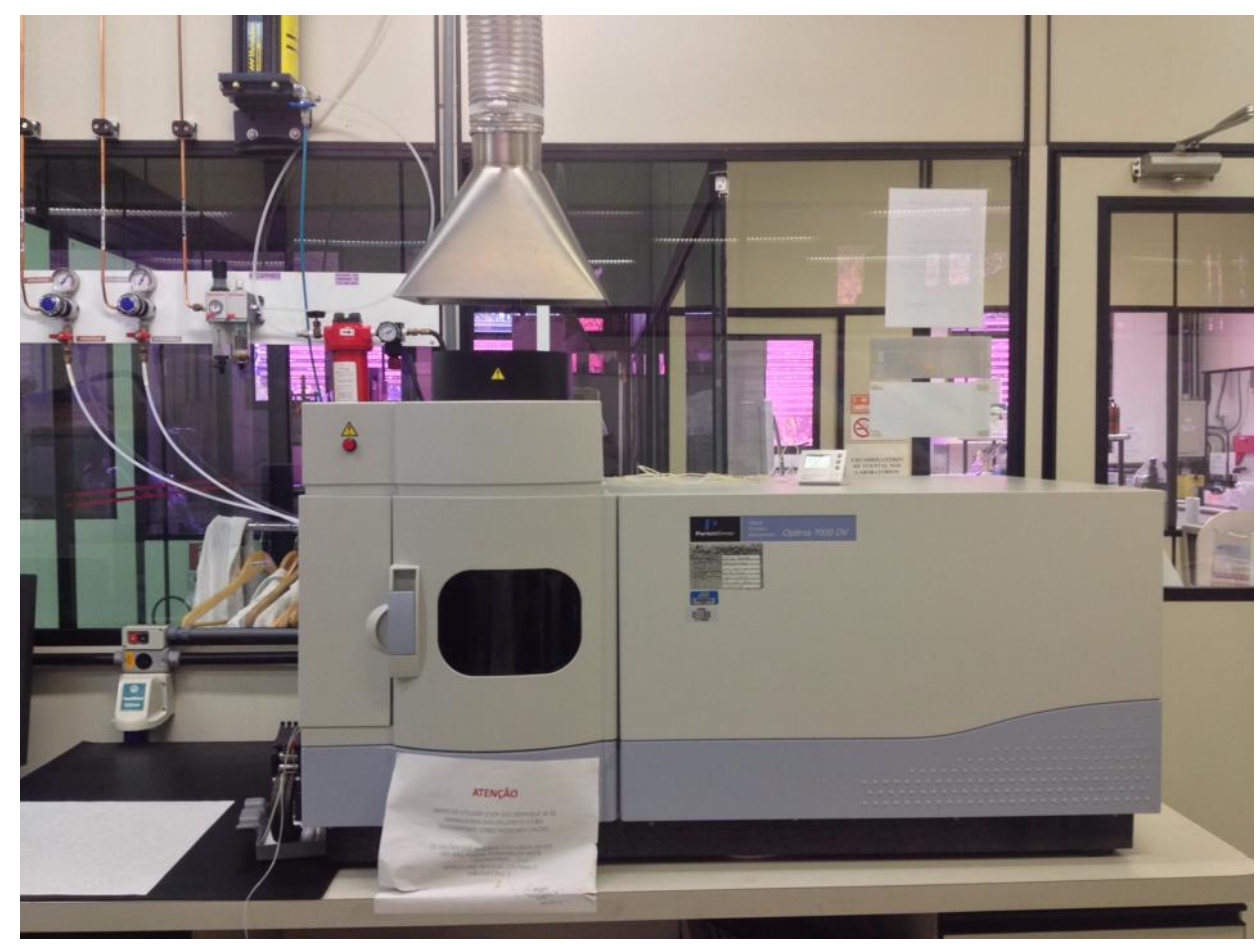

FIGURA 11 - ICP-OES Perkin Elmer

\subsubsection{Capacidade de biossorção do radionuclídeo}

A capacidade de biossorção do radionuclídeo foi determinada por meio da seguinte equação:

$$
q=\left(\frac{C_{i}-C_{f}}{m}\right) V
$$

Onde:

q é a capacidade de biossorção $\left(\mathrm{mg} \cdot \mathrm{g}^{-1}\right)$

$\mathbf{C}_{i}$ é a concentração inicial do íon metálico na solução $\left(\mathrm{mg} \cdot \mathrm{L}^{-1}\right)$

$\mathbf{C}_{\mathbf{f}}$ é a concentração do íon metálico na solução em equilíbrio (mg. $\mathrm{L}^{-1}$ )

V é o volume total da solução (L)

m é a massa do material biossorvente $(\mathrm{g})$ 


\subsection{Estimativa dos parâmetros}

Os parâmetros dos modelos das isotermas e cinética foram estimados por meio da minimização da função objetivo representada pela Eq. 13.

$$
F=\sum_{j=1}^{n}\left|\frac{q_{1_{j}}^{\text {EXP }}-q_{1_{j}}^{\text {MOD }}}{q_{1_{j}}^{E X P}}\right|
$$

Eq. 13

Onde:

$\mathrm{N}$ é o número de dados experimentais

$\mathrm{q}_{1}{ }^{\text {Exp }}$ representa as concentrações do íon no biossorvente da espécie 1, determinada experimentalmente.

$Q_{1}{ }^{M O D}$ concentração do íon no biossorvente da espécie 1 calculada pelo modelo

Para a minimização da função objetivo (Eq. 13) foi utilizado o método de otimização variável Simplex Downhill. 


\section{RESULTADOS E DISCUSSÃO}

\subsection{Caracterização das biomassas}

As análises morfológicas foram realizadas por meio de eletromicrografias apresentadas nas FIG. 12, 13, 14 e 15 obtidas para as biomassas Pistia stratiotes, Limnobium laevigatum, Lemna sp. e Azolla sp.

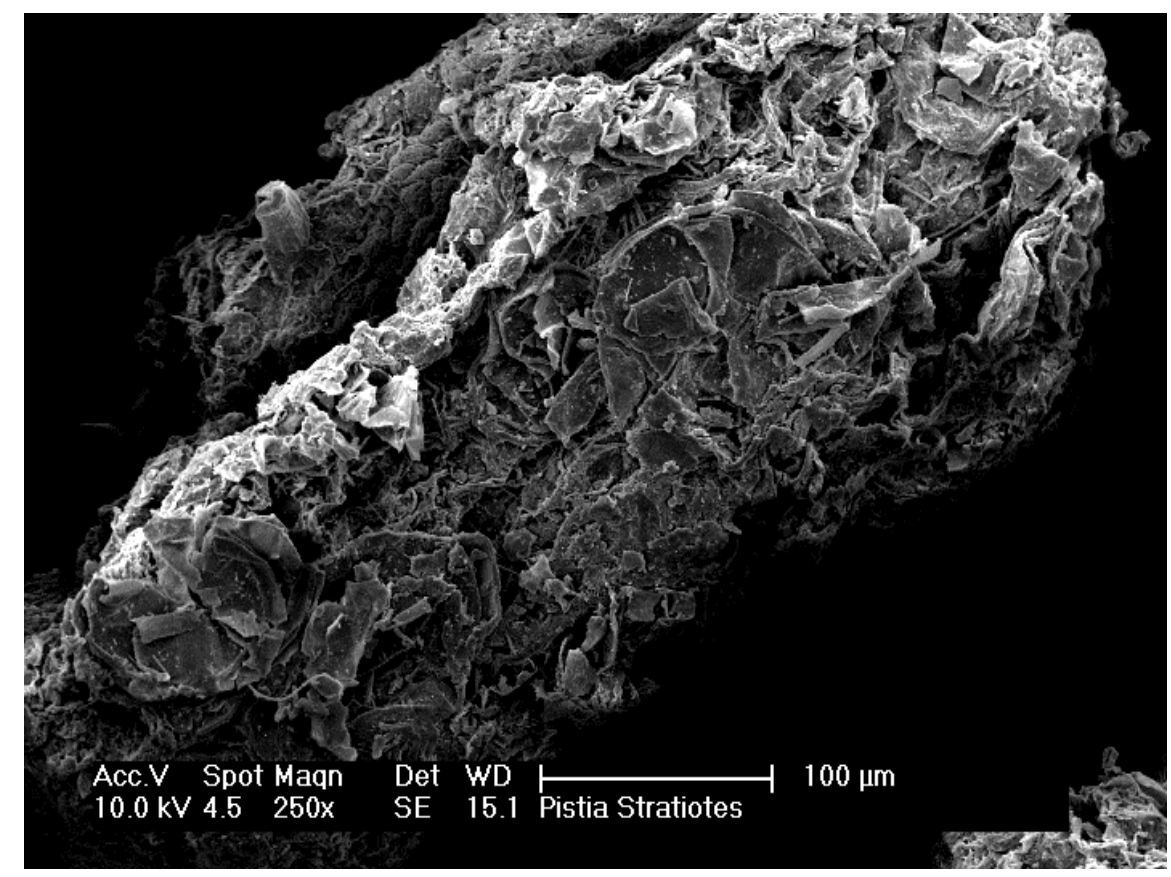

FIGURA 12 - Eletromicrografia da biomassa Pistia stratiotes bruta 


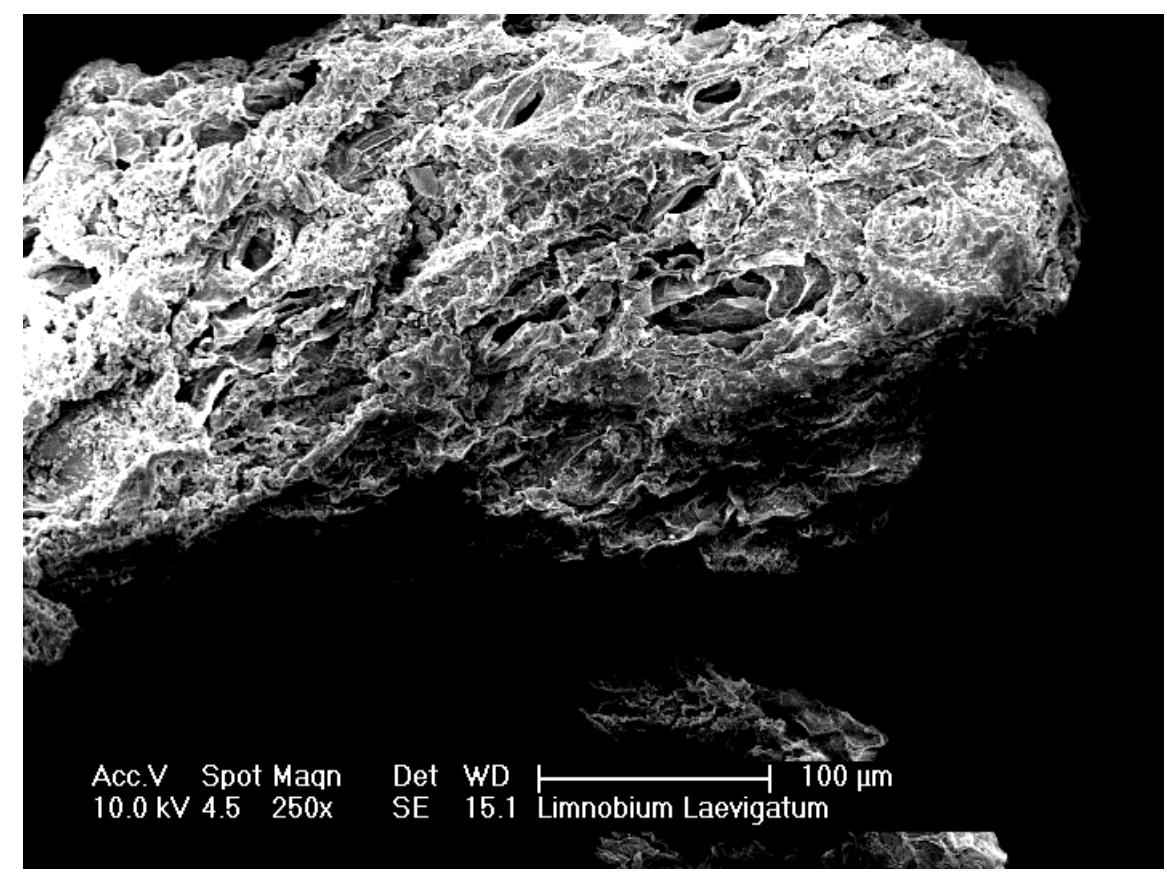

FIGURA 13 - Eletromicrografia da biomassa Limnobium laevigatum bruta

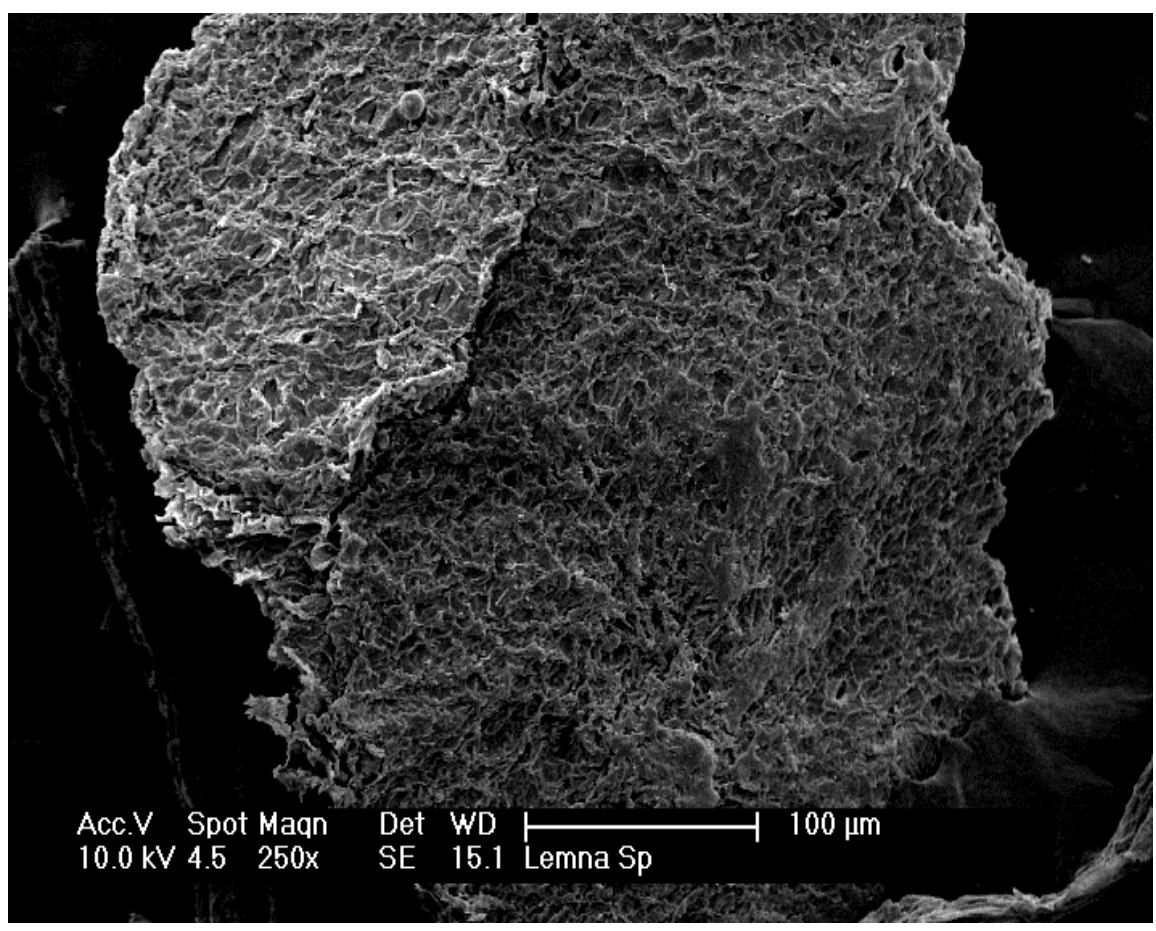

FIGURA 14 - Eletromicrografia da biomassa Lemna sp. bruta 


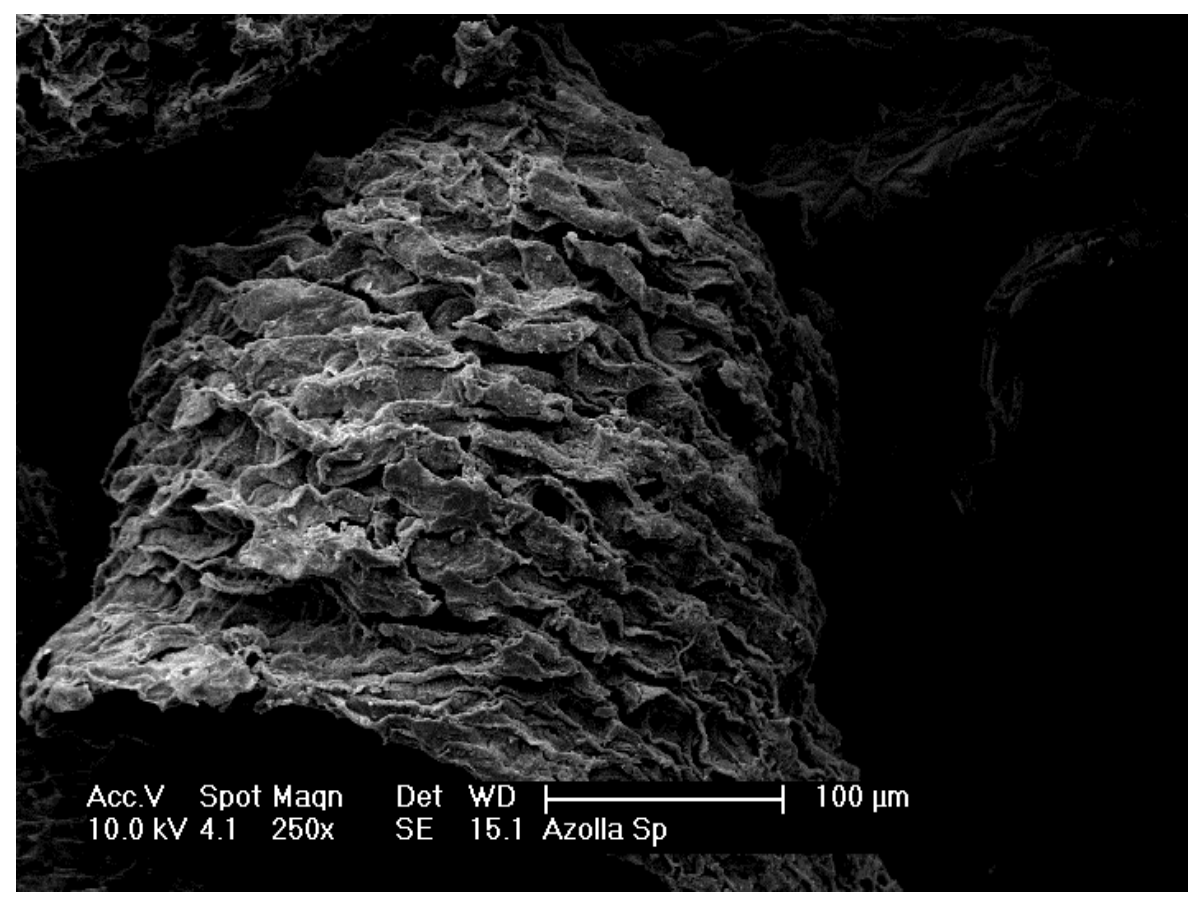

FIGURA 15 - Eletromicrografia da biomassa Azolla sp. bruta

Pode-se observar nas FIG. 12 a 15 que todas as macrófitas possuem estruturas irregulares. A biomassa Lemna sp é a que apresenta a superfície mais uniforme e compacta entre todas as outras. Não foi possível obter por meio da eletromicrografia, qualquer informação referente à porosidade das biomassas.

As análises de espectrometria de raios- $X$ por energia dispersiva (EDS) das macrófitas, cujos resultados estão apresentados na TAB. 2, revelaram uma composição química bem distinta entre elas. Por exemplo, a Azolla sp se destaca pelo percentual elevado de $\mathrm{Si}$, a Lemna $\mathrm{sp}$ pelo $\mathrm{K}$ e a Pistia stratiotes e Limnobium laevigatum pelo $\mathrm{Ca}$. 
TABELA 2 - Resultado em porcentagem da análise das macrófitas por EDS

\begin{tabular}{ccccc}
\hline Elemento & \multicolumn{5}{c}{ Biomassas } \\
\hline & $\begin{array}{l}\text { Pistia } \\
\text { stratiotes }\end{array}$ & $\begin{array}{l}\text { Limnobium } \\
\text { laevigatum }\end{array}$ & Lemna sp. & Azolla sp \\
& & & & \\
\hline $\mathrm{Na}$ & 1,40 & --- & 0,90 & --- \\
$\mathrm{Mg}$ & 3,70 & 3,30 & 1,60 & --- \\
$\mathrm{Al}$ & --- & 0,70 & --- & 2,40 \\
$\mathrm{Si}$ & --- & 0,70 & 2,00 & 45,50 \\
$\mathrm{P}$ & --- & 2,40 & 1,80 & 8,40 \\
$\mathrm{~S}$ & 0,40 & 2,50 & 2,00 & 4,50 \\
$\mathrm{Cl}$ & 4,30 & 2,20 & 10,80 & --- \\
$\mathrm{K}$ & 19,60 & 29,80 & 43,90 & 1,90 \\
$\mathrm{Ca}$ & 52,50 & 55,10 & 28,80 & 14,90 \\
$\mathrm{Fe}$ & 18,10 & 3,30 & 6,20 & 22,40 \\
$\mathrm{Mn}$ & --- & --- & 2,00 & --- \\
\hline
\end{tabular}

Os minerais encontrados em quantidades consideráveis são conhecidos como macronutrientes e os minerais encontrados em menores proporções são os micronutrientes. Esses minerais são essenciais ao crescimento e ciclo de vida dos vegetais (EPSTEIN, 1975; VALITTUTO, 2004).

As macrófitas Pistia stratiotes e Limnobium laevigatum apresentam um percentual elevado de Cálcio ( $\mathrm{Ca}$ ) que possui a função estabilizadora da parede celular no sistema de membrana das células e na lamela média fazendo ligação entre os radicais das pectinas (MARTIN 2008).

O Potássio (K) presente em maior percentual na macrófita Lemna sp., é um ativador enzimático na síntese de ATP de carboidratos, na respiração e síntese das proteínas. Vegetais com deficiência de potássio apresentam menor síntese de proteínas e acúmulo de compostos nitrogenados solúveis como aminoácidos, nitratos e amida. (EPSTEIN 1975). 
O Silício (Si), encontrado na macrófita Azolla sp em maior quantidade, encontra-se no retículo endoplasmático, paredes celulares e espaços intracelulares. O acúmulo de silício no tecido das plantas apresenta melhoria no crescimento das mesmas e pode também aliviar a toxicidade de metais pesados nas plantas (EPSTEIN 1975).

Quanto às densidades, apresentadas na Tabela 3, pode-se afirmar que os valores obtidos para todas as macrófitas são muito próximos, apesar das análises microscópicas mostrarem que possuem aparências distintas.

Por meio dos resultados das análises das áreas superficiais específicas, pôde-se verificar que entre as macrófitas estudadas, a macrófita Azolla $s p$ é a que apresenta a maior área superficial. A caracterização dos biossorventes pela análise da área superficial específica é um fator importante, pois a adsorção é um fenômeno de superfície cuja intensidade da adsorção é maior quanto maior for sua área específica, ou seja, quanto maior for a área disponível para adsorção. Em partículas maiores a resistência de difusão é maior e grande parte da superfície interna da partícula não é disponibilizada para a adsorção (SEKAR et al, 2004). O acesso para os sítios de adsorção é facilitado quando a partícula é menor acarretando níveis mais altos de adsorção (BHATNAGAR e JAIN, 2005).

TABELA 3 - Valores de densidade aparente, densidade real e área específica para as biomassas Pistia stratiotes, Limnobium laevigatum, Lemna sp. e Azolla sp

\begin{tabular}{lccr}
\hline Biomassa & $\begin{array}{c}\text { Densidade aparente } \\
\left(\mathbf{g} / \mathbf{c m}^{\mathbf{3}}\right)\end{array}$ & $\begin{array}{c}\text { Densidade real } \\
\left(\mathbf{g} / \mathbf{c m}^{\mathbf{3}}\right)\end{array}$ & $\begin{array}{c}\text { Área superficial } \\
\left(\mathbf{m}^{\mathbf{2}} \mathbf{g}\right)\end{array}$ \\
\hline Pistia stratiotes & $0,34 \pm 0,02$ & $1,600 \pm 0,001$ & $13,80 \pm 0,70$ \\
Limnobium laevigatum & $0,32 \pm 0,01$ & $1,550 \pm 0,001$ & $3,10 \pm 0,30$ \\
Lemna sp & $0,30 \pm 0,01$ & $1,690 \pm 0,001$ & $6,60 \pm 0,70$ \\
Azolla sp & $0,25 \pm 0,02$ & $1,500 \pm 0,003$ & $14,00 \pm 1,00$ \\
\hline
\end{tabular}

*x \pm s ( média \pm desvio padrão) 
$\mathrm{Na}$ TAB. 4 são apresentados os grupos funcionais das biomassas antes da biossorção identificados através da análise FTIR. Esses espectros podem ser observados nas FIG. 16, 17, 18 e 19.

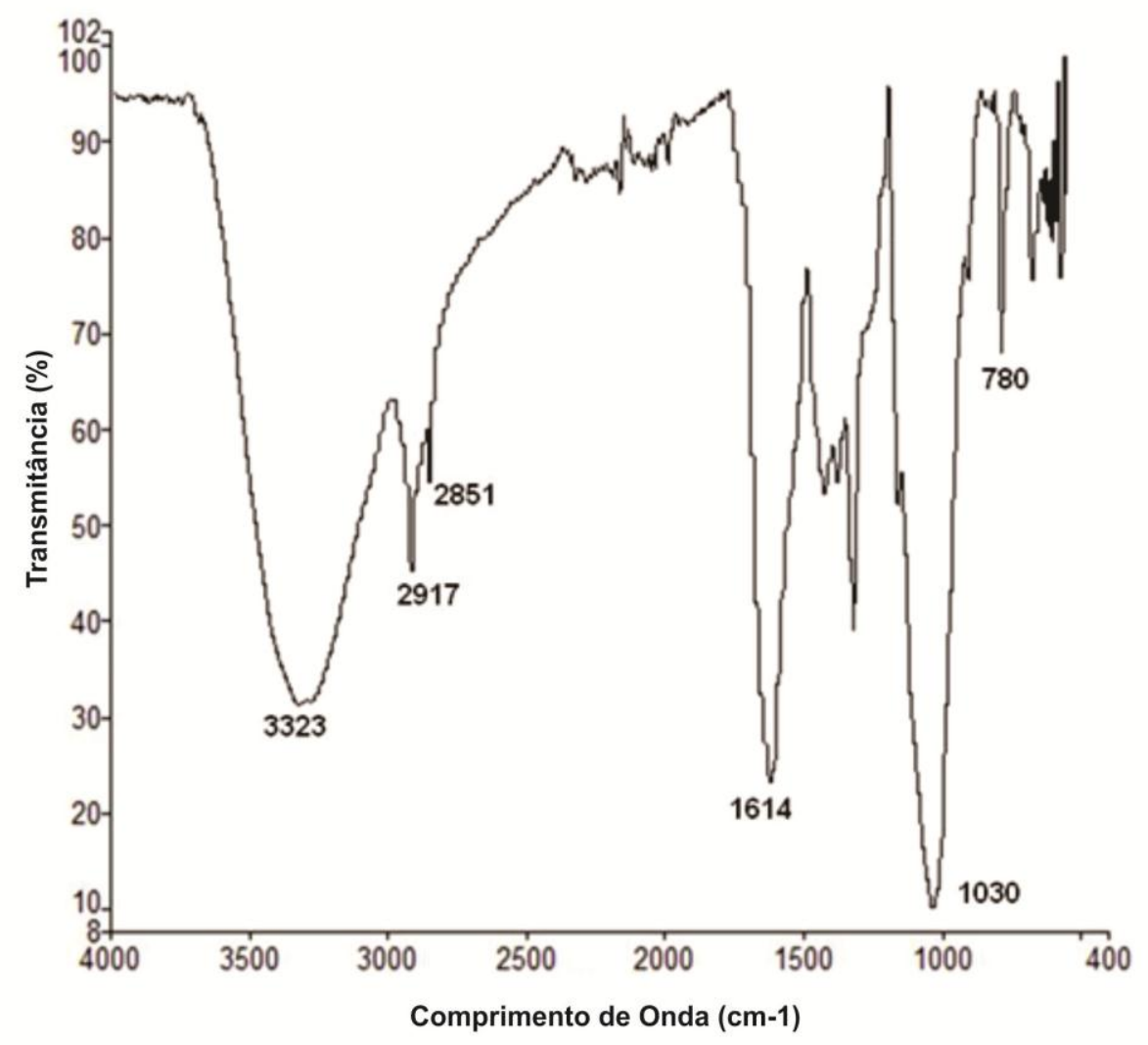

FIGURA 16 - Espectros de FTIR da biomassa Pistia stratiotes 


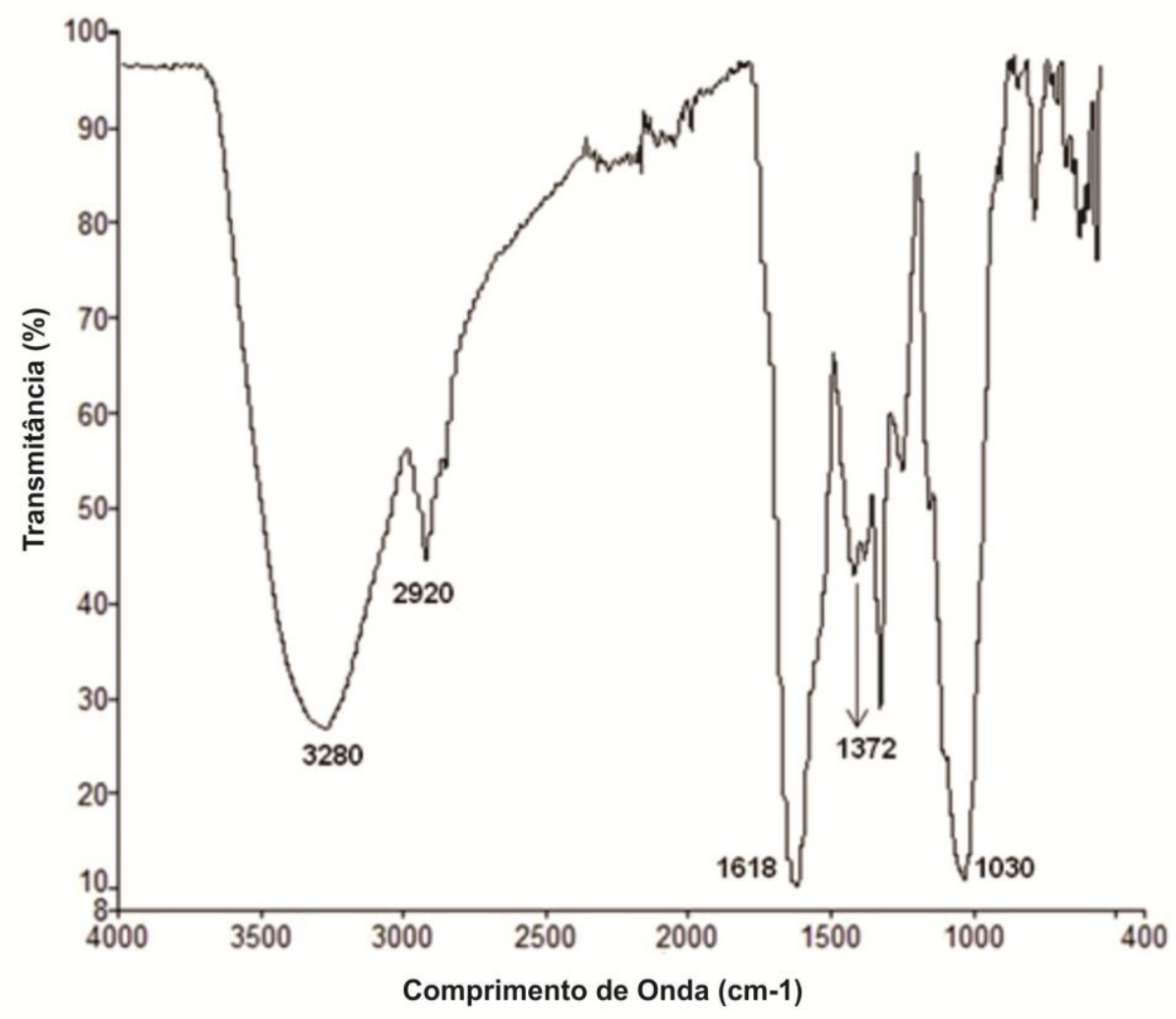

FIGURA 17 - Espectros de FTIR da biomassa Limnobium laevigatum 


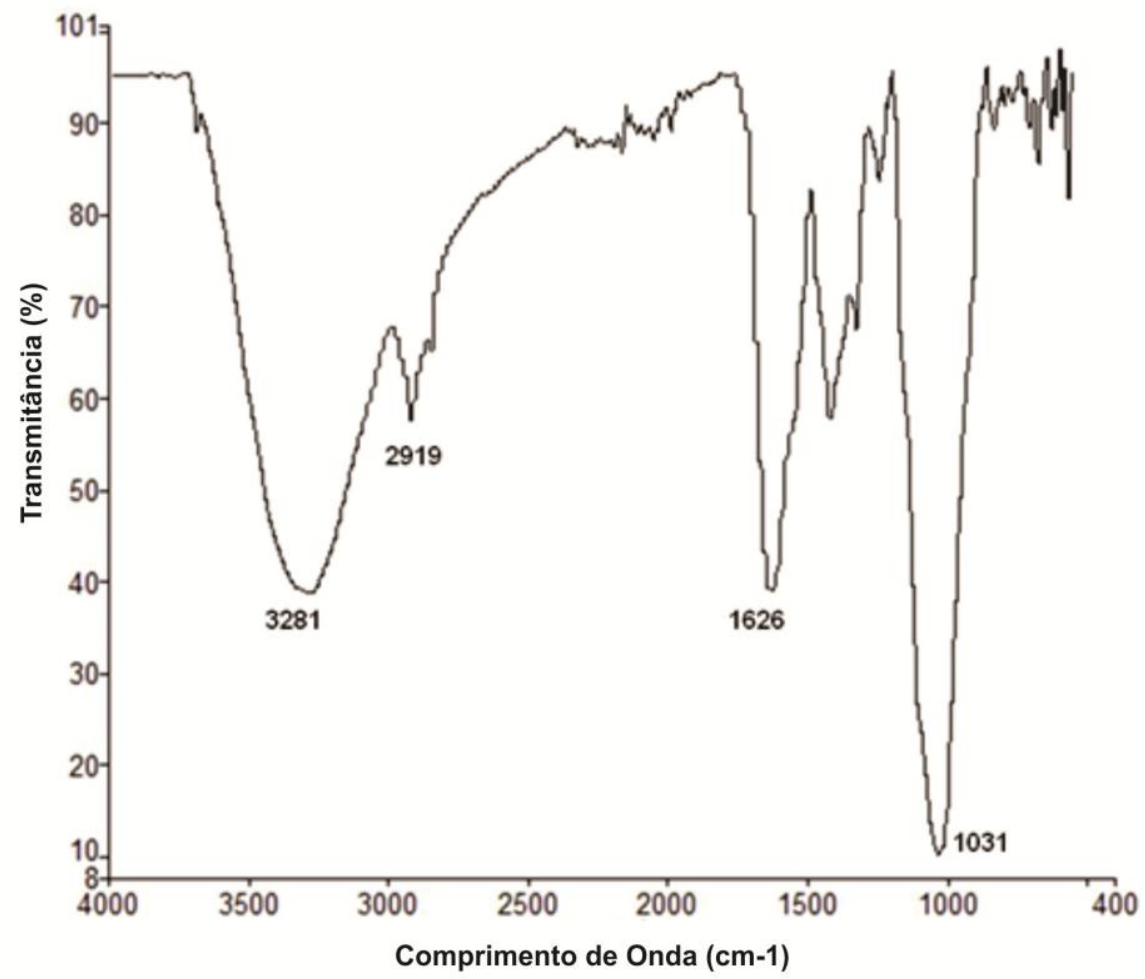

FIGURA 18 - Espectros de FTIR da biomassa Lemna sp. 


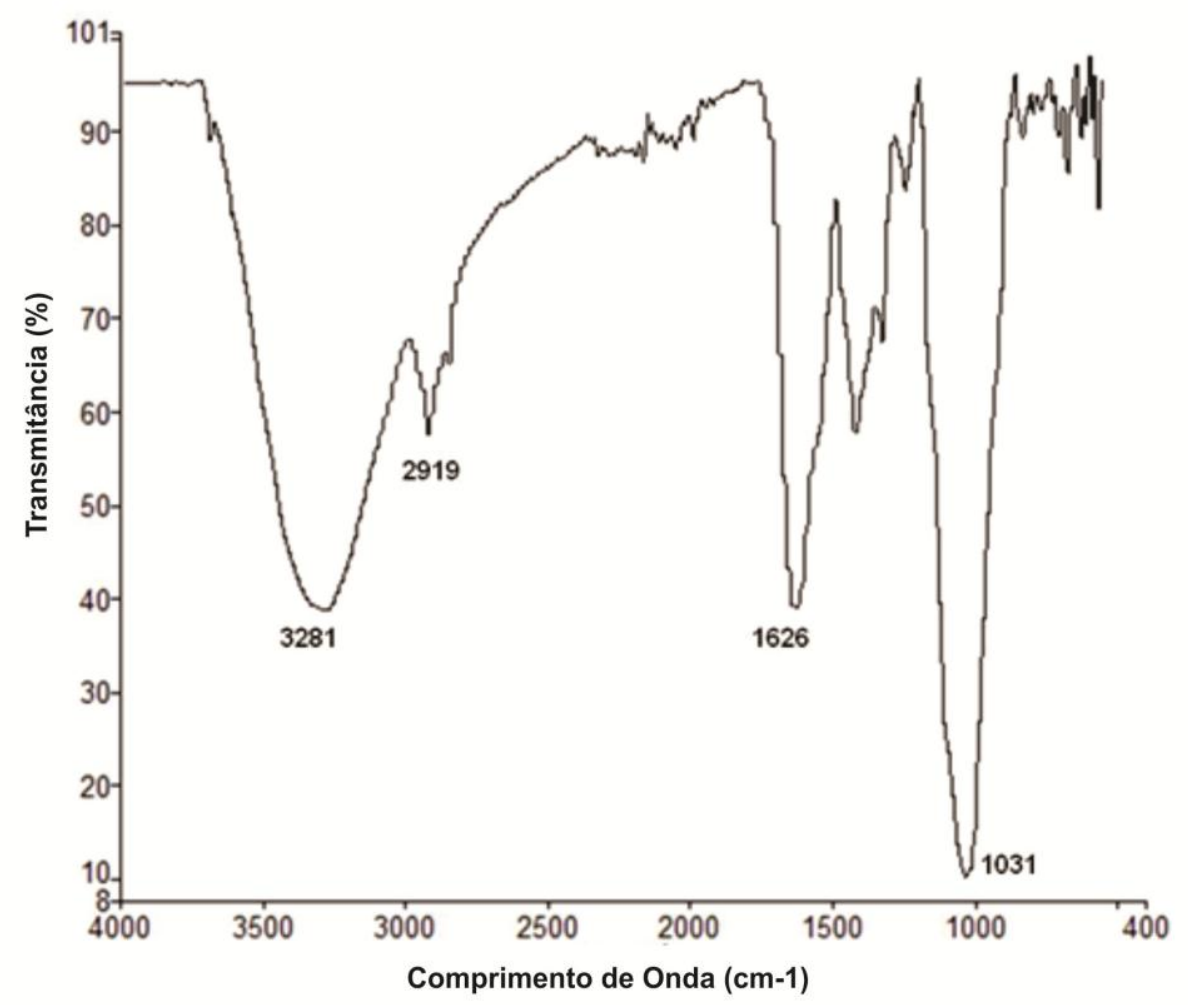

FIGURA 19 - Espectros de FTIR da biomassa Azolla sp.

TABELA 4 - Identificação dos grupos funcionais presentes na Pistia stratiotes, Limnobium laevigatum, Lemna sp e Azolla sp.

\begin{tabular}{lcc}
\hline Biomassa & Número de onda $\left(\mathbf{c m}^{-1}\right)$ & Grupo funcional \\
\hline & 3323 & $-\mathrm{O}-\mathrm{H},-\mathrm{N}-\mathrm{H}$ \\
Pistia stratiotes & 2917 & $-\mathrm{CH}$ \\
& 2851 & $-\mathrm{CH}$ \\
& 1614 & $-\mathrm{N}-\mathrm{H}$ \\
& 1030 & $-\mathrm{C}-\mathrm{O}$ \\
& 780 & $-\mathrm{C}-\mathrm{C}$ \\
\hline & 3280 & $-\mathrm{O}-\mathrm{H},-\mathrm{N}-\mathrm{H}$ \\
Limnobium laevigatum & 2920 & $-\mathrm{C}-\mathrm{H}$
\end{tabular}




\begin{tabular}{lcc} 
Biomassa & Número de onda $\left(\mathbf{c m}^{-1}\right)$ & Grupo funcional \\
\hline \multirow{2}{*}{ Limnobium laevigatum } & 1618 & $-\mathrm{N}-\mathrm{H}$ \\
& 1372 & $-\mathrm{CH} 3$ \\
& 1030 & $-\mathrm{C}-\mathrm{O}$ \\
\hline \multirow{3}{*}{ Lemna sp } & 3281 & $-\mathrm{O}-\mathrm{H},-\mathrm{N}-\mathrm{H}$ \\
& 2919 & $-\mathrm{C}-\mathrm{H}$ \\
& 1626 & $-\mathrm{N}-\mathrm{H}$ \\
& 1030 & $-\mathrm{C}-\mathrm{O}$ \\
Azolla sp & 3279 & $-\mathrm{O}-\mathrm{H},-\mathrm{N}-\mathrm{H}$ \\
& 2917 & $-\mathrm{C}-\mathrm{H}$ \\
& 2850 & $-\mathrm{C}-\mathrm{H}$ \\
& 1624 & $-\mathrm{N}-\mathrm{H}$ \\
& 1418 & $-\mathrm{C}-\mathrm{H}$ \\
& 1030 & $-\mathrm{C}-\mathrm{O}$ \\
& 719 & $-\mathrm{C}-\mathrm{H}$ \\
\hline
\end{tabular}

Para a análise das macrófitas, os espectros obtidos nas FIG 16 a 19 sugerem a presença dos grupos funcionais listados na Tabela 4.

A banda de absorção larga localizada em $3323 \mathrm{~cm}^{-1}$ na Pistia, 3280 $\mathrm{cm}^{-1}$ no Limnobium, $3281 \mathrm{~cm}^{-1}$ na Lemna e $3279 \mathrm{~cm}^{-1}$ na Azolla indicam que seja pela sobreposição de $(\mathrm{OH}$ e $\mathrm{NH})$, indicando a presença de dois grupos de hidroxilas livres na superfície e água (SALMAN et al, 2012).

As bandas $2919 \mathrm{~cm}^{-1}$ e $2850 \mathrm{~cm}^{-1}$ localizadas na Pistia, as bandas de $2919 \mathrm{~cm}^{-1} \mathrm{e} 2920 \mathrm{~cm}^{-1}$ no Limnobium e Lemna respectivamente e $2917 \mathrm{~cm}^{-1} \mathrm{e}$ $2850 \mathrm{~cm}^{-1}$ na Azolla correspondem ao estiramento de CH (PAVIA et al 2010).

As bandas presentes em $1614 \mathrm{~cm}^{-1}, 1618 \mathrm{~cm}^{-1}, 1626 \mathrm{~cm}^{-1} \mathrm{e} 1624 \mathrm{~cm}^{-1}$ são características da presença do dobramento do grupo amina $(\mathrm{NH})$ indicando também a presença de água (SALMAN et al, 2012).

O dobramento do grupo metila $(\mathrm{CH} 3)$ está localizado em $1372 \mathrm{~cm}^{-1}$ banda presente na macrófita Limnobium laevigatum (PAVIA et al 2010). 
Hidrocarbonetos simples (C-H) são encontrados nas bandas $1418 \mathrm{~cm}^{-1}$ e $720 \mathrm{~cm}^{-1}$ da Azolla sp.(SILVESTEIN \& WEBSTER, 2000).

As vibrações de estiramento do (CO) com ligações simples está se faz presente nas bandas de $1030 \mathrm{~cm}^{-1}$ nas quatro macrófitas estudadas.

Os espectros abaixo da região de $600 \mathrm{~cm}^{-1}$ foram considerados como ruídos, não sendo possível a identificação dos mesmos de acordo com a técnica utilizada.

Segundo FOUREST e VOLESKY (1996) os grupos funcionais responsáveis pela biossorção em macrófitas aquáticas são as aminas, carboxilas, carbonilas, hidroxilas, sulfonatos e tiol.

Os grupos amina, carboxila foram identificados como os responsáveis na biossorção de urânio por meio da macrófita Eichhornia crassipes (YI, 2016).

De acordo com os resultados das análises para a identificação dos grupos funcionais nas macrófitas estudadas, a hidroxila $(\mathrm{OH})$ identificada pode ser atribuída a presença de grupos álcoois e carboxílicos e o grupo amina (NH2) estão presente em todas as macrófitas, podendo assim participar diretamente do processo de biossorção.

\subsection{Ensaios de biossorção}

\subsubsection{Tempo de equilíbrio}

Os resultados da biossorção do urânio em função do tempo para as macrófitas Pistia stratiotes, Limnobium laevigatum, Lemna sp, Azolla sp., são apresentados nas FIG. 20. 


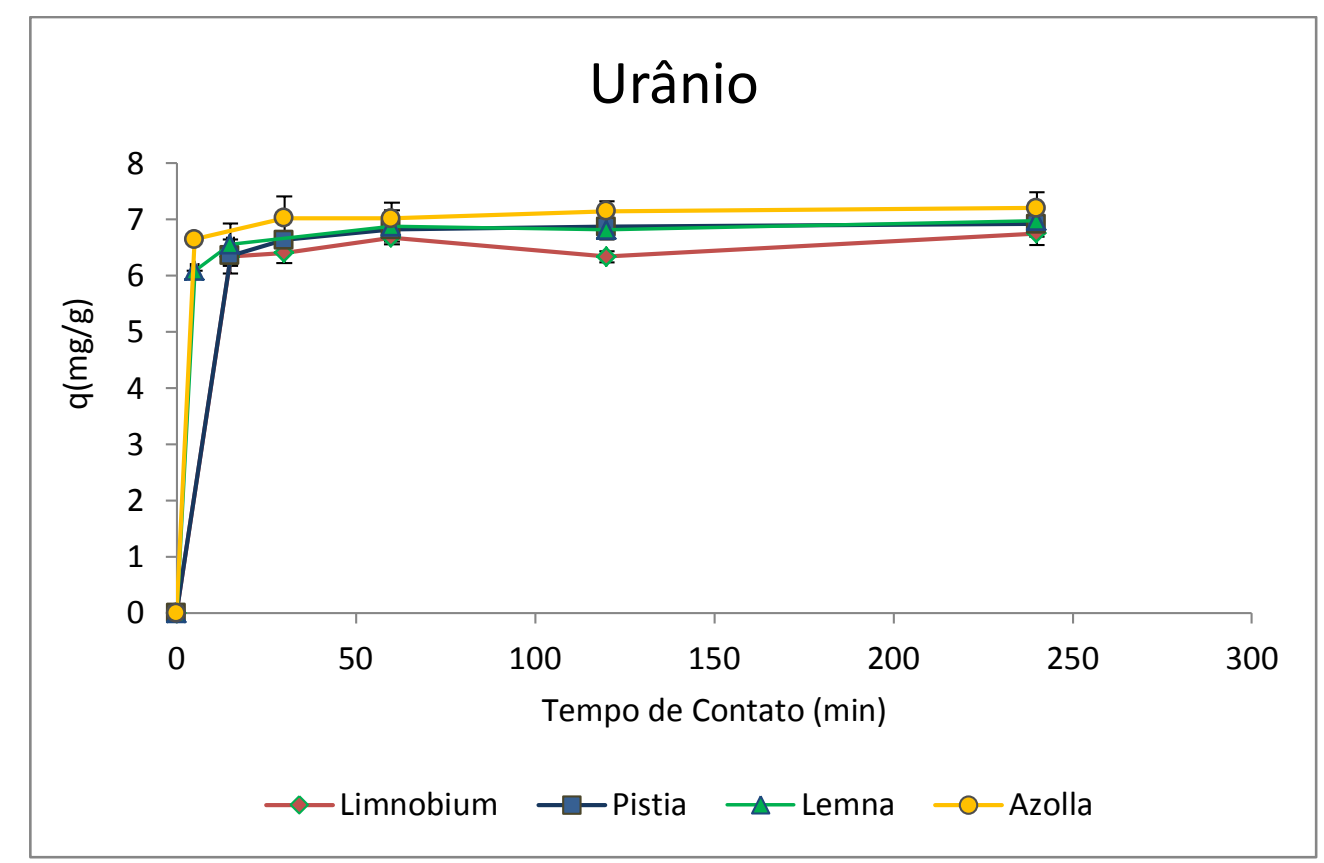

FIGURA 20 - Biossorção do urânio pelas macrófita Pistia stratiotes, Limnobium laevigatum, Lemna sp e Azolla sp em função do tempo

Os resultados dos experimentos de biossorção mostram que a concentração de urânio nas biomassas foi aumentando em função do tempo até o equilíbrio ser atingido. Comportamento esse esperado uma vez que o urânio se acumula nas biomassas nos sítios de adsorção até que ocorra o equilíbrio dinâmico, havendo a interação entre os íons onde a taxa de dessorção se aproxima da taxa de biossorção (FOO \& HAMED, 2009). O tempo de equilíbrio encontrado para as macrófitas Pistia stratiotes, Limnobium laevigatum e Lemna $s p$ foi de 60 minutos e para a macrófita Azolla sp de 30 minutos.

\subsubsection{Capacidade de biossorção}

Na TAB. 5 são apresentados os valores de capacidade de biossorção do urânio no equilíbrio observados em 60 minutos para Pistia stratiotes, Limnobium laevigatum e Lemna sp, e de 30 minutos para Azolla sp. 
TABELA 5- Valores da capacidade de biossorção no equilíbrio experimental solução de urânio

\begin{tabular}{lcc}
\hline Biomassa & Urânio & \\
\hline & $(\mathbf{m g} / \mathbf{g})^{\star}$ & $(\mathbf{m m o l} / \mathbf{g})^{\star}$ \\
Pistia stratiotes & $6,80 \pm 0,06$ & $(287 \pm 2,52) \times 10^{-7}$ \\
Limnobium laevigatum & $6,70 \pm 0,11$ & $(280 \pm 4,62) \times 10^{-7}$ \\
Lemna sp & $162,10 \pm 1,8$ & $(681 \pm 7,80) \times 10^{-6}$ \\
Azolla sp & $161,80 \pm 2,0$ & $(680 \pm 8,40) \times 10^{-6}$ \\
\hline & ${ }^{*} \times \pm$ s ( média \pm desvio padrão) &
\end{tabular}

A capacidade de sorção máxima não foi atingida nos experimentos com a Azolla sp e a Lemna sp, apesar de terem sido utilizadas soluções com concentrações elevadas, até $20.000 \mathrm{mg} / \mathrm{L}$. A capacidades de sorção aumentava à medida que a concentração também aumentava.

Os valores mais altos de capacidades de sorção foram observados com a Lemna sp $(162,1 \pm 1,8 \mathrm{mg} / \mathrm{g})$ e Azolla $s p$. $(161,8 \pm 2 \mathrm{mg} / \mathrm{g})$ para o simulado de rejeito.

Não foram encontrados na literatura trabalhos que pudessem ser utilizados para comparar diretamente os resultados obtidos. Há, no entanto, muitos trabalhos sobre bioacumulação e fitoremediação relacionados com outras macrófitas e metais, porém escassos para o urânio. Por exemplo, a macrófita Eichhornia crassipes foi estudada por YI et al (2016) para biossorção de urânio em soluções simuladas de rejeito. A capacidade de biossorção de urânio foi de $142,85 \mathrm{mg} / \mathrm{g}$, ligeiramente inferior aos resultados obtidos neste trabalho.

O comportamento da macrófita Lemna aequinoctialis foi estudado na presença de urânio e cobre, porém com finalidade distinta, para avaliar a toxicidade desses metais no crescimento da planta (CHARLES et al, 2006). O autor verificou que essa macrófita, por meio da biocumulação, retém esses metais influenciando negativamente no crescimento dela.

As macrófitas Callitriche stagnalis Scop, Potamogeton natans L. and Potamogeton pectinatus $L$. foram avaliadas por PRATAS et al (2014) para 
bioacumulação de urânio. A macrófita $P$ pectnatus a que apresentou a maior capacidade de sorção de urânio, $1,56 \mathrm{mg} / \mathrm{g}$, muito inferior aos obtidos neste trabalho.

Na TAB. 6, são apresentados os valores da capacidade de sorção no equilíbrio, obtidos nos ensaios com o rejeito radioativo.

TABELA 6- Valores da capacidade de biossorção com o rejeito radioativo

\begin{tabular}{lcc}
\hline \multirow{2}{*}{ Biomassa } & \multicolumn{2}{c}{ Rejeito Radioativo } \\
& $(\mathbf{m g} / \mathbf{g})^{*}$ & $(\mathbf{m m o l} / \mathbf{g})^{*}$ \\
\hline Lemna sp & $2,2 \pm 0,2$ & $(9,2 \pm 0,1) \times 10^{-6}$ \\
Azolla sp & $2,6 \pm 0,3$ & $(10,6 \pm 1,1) \times 10^{-6}$ \\
\hline & ${ }^{*} \mathrm{x} \pm \mathrm{s}$ ( média \pm desvio padrão)
\end{tabular}

Os valores de capacidade de sorção obtidos com as macrófitas Lemna sp $(2,2 \pm 0,2) \mathrm{mg} / \mathrm{g}$ e Azolla sp $(2,6 \pm 0,3) \mathrm{mg} / \mathrm{g}$ em contato com o rejeito radioativo foram ligeiramente superiores aos relatados por FERREIRA (2014). Nesse trabalho, as biomassas de casca de café bruta e fibra de coco bruta na biossorção de urânio em rejeito radioativo real apresentaram uma capacidade de sorção de $1,96 \pm 0,04 \mathrm{mg} / \mathrm{g}$ e $1,76 \pm 0,04 \mathrm{mg} / \mathrm{g}$.

Comparando-se os valores obtidos com a solução de urânio e o rejeito real, observam-se capacidades de sorção maiores na solução de urânio, que poderia ser explicada pelas próprias condições experimentais empregadas. Nesse caso, foram usadas soluções com apenas um elemento (urânio) e preparadas com pH favorável para a biossorção. O rejeito real, por sua vez, é constituído por uma solução com compostos orgânicos, multi-elementar (urânio, amerício e césio) e com $\mathrm{pH} 2,17$. Além do baixo $\mathrm{pH}$, diferente da faixa estipulada como $\mathrm{pH}$ ótimo na biossorção do urânio (KRESTOU, 2004; e MICHALAK, 2013), deve-se considerar também a competição dos elementos pelos sítios de adsorção presentes nas biomassas.

Dentre as biomassas estudadas, a Azolla sp foi a que apresentou a maior capacidade de remoção em um tempo menor, provavelmente em função da 
área específica parente maior, onde os sítios de adsorção estariam mais disponíveis. A capacidade máxima foi atingida em um tempo $50 \%$ inferior ao da Lemna sp, a biomassa que apresentou a segunda melhor capacidade.

Nas TAB. 7 a 10 são apresentados os parâmetros das isotermas obtidos para a macrófitas Pistia stratiotes, Limnobium laevigatum, Lemna sp e Azolla $S p$ e, as figuras 21 a 24 mostram as curvas relacionadas. 


\subsubsection{Isotermas de sorção}

TABELA 7 - Parâmetros das isotermas calculados para a Pistia stratiotes

\begin{tabular}{|c|c|c|c|c|c|c|}
\hline Biomassa & Modelos & & & Parâmetros & & \\
\hline \multirow{14}{*}{$\begin{array}{c}\text { Pistia } \\
\text { stratiotes }\end{array}$} & Langmuir & Q & $\mathrm{K}_{\mathrm{L}}$ & & & $\mathrm{R}^{2}$ \\
\hline & & 4,47E-05 & $1,75 \mathrm{E}+04$ & & & 0,91 \\
\hline & Freundlich & $\mathrm{K}$ & $1 / n$ & & & $\mathrm{R}^{2}$ \\
\hline & & $5,78 \mathrm{E}-03$ & $5,72 E-01$ & & & 0,93 \\
\hline & Sips & $\mathrm{K}_{\mathrm{S}}$ & $a_{s}$ & $\beta_{S}$ & & $\mathrm{R}^{2}$ \\
\hline & & 1,85E-02 & $6,24 \mathrm{E}-02$ & $4,11 \mathrm{E}-01$ & & 0,93 \\
\hline & Toth & $\mathrm{K}_{\mathrm{T}}$ & $\mathrm{a}_{\mathrm{T}}$ & $1 / \mathrm{t}$ & & $\mathrm{R}^{2}$ \\
\hline & & $5,42 \mathrm{E}-01$ & $1,00 \mathrm{E}+00$ & 9,59E-05 & & 0,88 \\
\hline & Redlich-Peterson & $\mathrm{K}_{\mathrm{RP}}$ & $a_{\mathrm{RP}}$ & $\beta$ & & $\mathrm{R}^{2}$ \\
\hline & & $3,63 E-01$ & $1,03 E+00$ & $1,00 \mathrm{E}+00$ & & 0,95 \\
\hline & Dois-sítios Langmuir & $\mathrm{Q}_{1}$ & $\mathrm{Q}_{2}$ & $b_{1}$ & $b_{2}$ & $\mathrm{R}^{2}$ \\
\hline & & $4,55 \mathrm{E}-19$ & 3,74E-05 & $1,74 \mathrm{E}+04$ & $2,56 \mathrm{E}+04$ & 0,89 \\
\hline & Radke-Prausnitz & $q_{\max }$ & $\mathrm{K}_{\mathrm{RP}}$ & $\mathrm{n}_{\mathrm{RP}}$ & & $\mathrm{R}^{2}$ \\
\hline & & $2,32 E+15$ & $2,52 E-03$ & $4,86 \mathrm{E}-01$ & & 0,93 \\
\hline
\end{tabular}


TABELA 8 - Parâmetros das isotermas calculados para a Limnobium laevigatum

\begin{tabular}{|c|c|c|c|c|c|c|}
\hline \multirow[t]{2}{*}{ Biomassa } & \multirow{2}{*}{$\begin{array}{l}\text { Modelos } \\
\text { Langmuir }\end{array}$} & \multicolumn{5}{|c|}{ Parâmetros } \\
\hline & & Q & $\mathrm{K}_{\mathrm{L}}$ & & & $\mathrm{R}^{2}$ \\
\hline & & 3,55E-05 & $2,68 \mathrm{E}+04$ & & & 0,98 \\
\hline & Freundlich & $\mathrm{K}$ & $1 / n$ & & & $\mathrm{R}^{2}$ \\
\hline & & $2,13 E-03$ & 4,76E-01 & & & 0,99 \\
\hline & Sips & $\mathrm{K}_{\mathrm{S}}$ & $a_{s}$ & $\beta_{S}$ & & $\mathrm{R}^{2}$ \\
\hline & & $3,40 \mathrm{E}-01$ & 2,28E-03 & $3,40 \mathrm{E}-01$ & & 0,99 \\
\hline \multirow{8}{*}{$\begin{array}{l}\text { Limnobium } \\
\text { laevigatum }\end{array}$} & Toth & $\mathrm{K}_{\mathrm{T}}$ & $\mathrm{a}_{\mathrm{T}}$ & $1 / \mathrm{t}$ & & $\mathrm{R}^{2}$ \\
\hline & & $6,34 \mathrm{E}-04$ & 1,63E-14 & $1,54 \mathrm{E}+00$ & & 0,99 \\
\hline & Redlich-Peterson & $\mathrm{K}_{\mathrm{RP}}$ & $\mathrm{a}_{\mathrm{RP}}$ & $\beta$ & & $\mathrm{R}^{2}$ \\
\hline & & 4,47E-03 & $4,34 \mathrm{E}+02$ & 4,64E-01 & & 0,99 \\
\hline & Dois-sítios Langmuir & $\mathrm{Q}_{1}$ & $\mathrm{Q}_{2}$ & $b_{1}$ & $b_{2}$ & $\mathrm{R}^{2}$ \\
\hline & & $3,45 \mathrm{E}+00$ & $1,60 \mathrm{E}-05$ & 2,81E-02 & $1,70 \mathrm{E}+05$ & 0,99 \\
\hline & Radke-Prausnitz & $q_{\max }$ & $\mathrm{K}_{\mathrm{RP}}$ & $\mathrm{n}_{\mathrm{RP}}$ & & $\mathrm{R}^{2}$ \\
\hline & & $6,12 \mathrm{E}-04$ & $1,65 \mathrm{E}+03$ & $1,19 \mathrm{E}+00$ & & 0,99 \\
\hline
\end{tabular}


TABELA 9 - Parâmetros das isotermas calculados para a Lemna sp

\begin{tabular}{|c|c|c|c|c|c|c|}
\hline \multirow[t]{2}{*}{ Biomassa } & \multirow{2}{*}{$\begin{array}{l}\text { Modelos } \\
\text { Langmuir }\end{array}$} & \multicolumn{5}{|c|}{ Parâmetros } \\
\hline & & Q & $\mathrm{K}_{\mathrm{L}}$ & & & $\mathrm{R}^{2}$ \\
\hline & & 7,37E-04 & $9,80 \mathrm{E}+02$ & & & 0,99 \\
\hline & Freundlich & $\mathrm{K}$ & $1 / n$ & & & $\mathrm{R}^{2}$ \\
\hline & & $2,184 \mathrm{E}-03$ & $3,008 \mathrm{E}-01$ & & & 0,96 \\
\hline & Sips & $\mathrm{K}_{\mathrm{S}}$ & $a_{s}$ & $\beta_{S}$ & & $\mathrm{R}^{2}$ \\
\hline \multirow[t]{9}{*}{ Lemna sp } & & 6,83E-04 & $5,27 \mathrm{E}+05$ & $1,92 \mathrm{E}+00$ & & 0,98 \\
\hline & Toth & $\mathrm{K}_{\mathrm{T}}$ & $a_{T}$ & $1 / \mathrm{t}$ & & $\mathrm{R}^{2}$ \\
\hline & & 3,42E-05 & 8,63E-01 & 1,73E-02 & & 0,97 \\
\hline & Redlich-Peterson & $\mathrm{K}_{\mathrm{RP}}$ & $a_{R P}$ & $\beta$ & & $\mathrm{R}^{2}$ \\
\hline & & $7,80 \mathrm{E}-04$ & $8,97 \mathrm{E}+02$ & $9,87 E-01$ & & 0,99 \\
\hline & Dois-sítios Langmuir & $\mathrm{Q}_{1}$ & $\mathrm{Q}_{2}$ & $b_{1}$ & $b_{2}$ & $\mathrm{R}^{2}$ \\
\hline & & $2,80 \mathrm{E}-04$ & 4,7E-04 & $3,27 \mathrm{E}+02$ & $1,57 \mathrm{E}+03$ & 0,99 \\
\hline & Radke-Prausnitz & $\mathbf{q}_{\max }$ & $\mathrm{K}_{\mathrm{RP}}$ & $\mathrm{n}_{\mathrm{RP}}$ & & $\mathrm{R}^{2}$ \\
\hline & & $8,45 E-04$ & $9,21 \mathrm{E}-01$ & $1,02 E+00$ & & 0,99 \\
\hline
\end{tabular}


TABELA 10 - Parâmetros das isotermas calculados para a Azolla sp

\begin{tabular}{|c|c|c|c|c|c|c|}
\hline \multirow[t]{2}{*}{ Biomassa } & \multirow{2}{*}{$\begin{array}{l}\text { Modelos } \\
\text { Langmuir }\end{array}$} & \multicolumn{5}{|c|}{ Parâmetros } \\
\hline & & Q & $\mathrm{K}_{\mathrm{L}}$ & & & $\mathrm{R}^{2}$ \\
\hline & & $5,04 \mathrm{E}-04$ & $2,54 \mathrm{E}+03$ & & & 0,96 \\
\hline & Freundlich & $\mathrm{K}$ & $1 / n$ & & & $\mathrm{R}^{2}$ \\
\hline & & 1,22E-03 & 2,58E-01 & & & 0,98 \\
\hline & Sips & $\mathrm{K}_{\mathrm{S}}$ & $a_{s}$ & $\beta_{S}$ & & $\mathrm{R}^{2}$ \\
\hline \multirow[t]{9}{*}{ Azolla sp } & & $3,34 \mathrm{E}-01$ & $1,40 E+00$ & 3,34E-01 & & 0,97 \\
\hline & Toth & $\mathrm{K}_{\mathrm{T}}$ & $a_{T}$ & $1 / \mathrm{t}$ & & $\mathrm{R}^{2}$ \\
\hline & & $2,20 \mathrm{E}+01$ & $1,36 \mathrm{E}+00$ & 4,53E-02 & & 0,94 \\
\hline & Redlich-Peterson & $\mathrm{K}_{\mathrm{RP}}$ & $a_{\mathrm{RP}}$ & $\beta$ & & $\mathrm{R}^{2}$ \\
\hline & & 1,01E-03 & $1,44 \mathrm{E}+03$ & $8,05 E-01$ & & 0,98 \\
\hline & Dois-sítios Langmuir & $\mathrm{Q}_{1}$ & $\mathrm{Q}_{2}$ & $b_{1}$ & $b_{2}$ & $\mathrm{R}^{2}$ \\
\hline & & 3,34E-02 & $3,20 \mathrm{E}-04$ & $1,53 \mathrm{E}-01$ & $5,34 \mathrm{E}+03$ & 0,98 \\
\hline & Radke-Prausnitz & $\mathbf{q}_{\max }$ & $\mathrm{K}_{\mathrm{RP}}$ & $\mathrm{n}_{\mathrm{RP}}$ & & $\mathrm{R}^{2}$ \\
\hline & & $3,82 \mathrm{E}+00$ & 1,22E-03 & $2,58 \mathrm{E}-01$ & & 0,98 \\
\hline
\end{tabular}




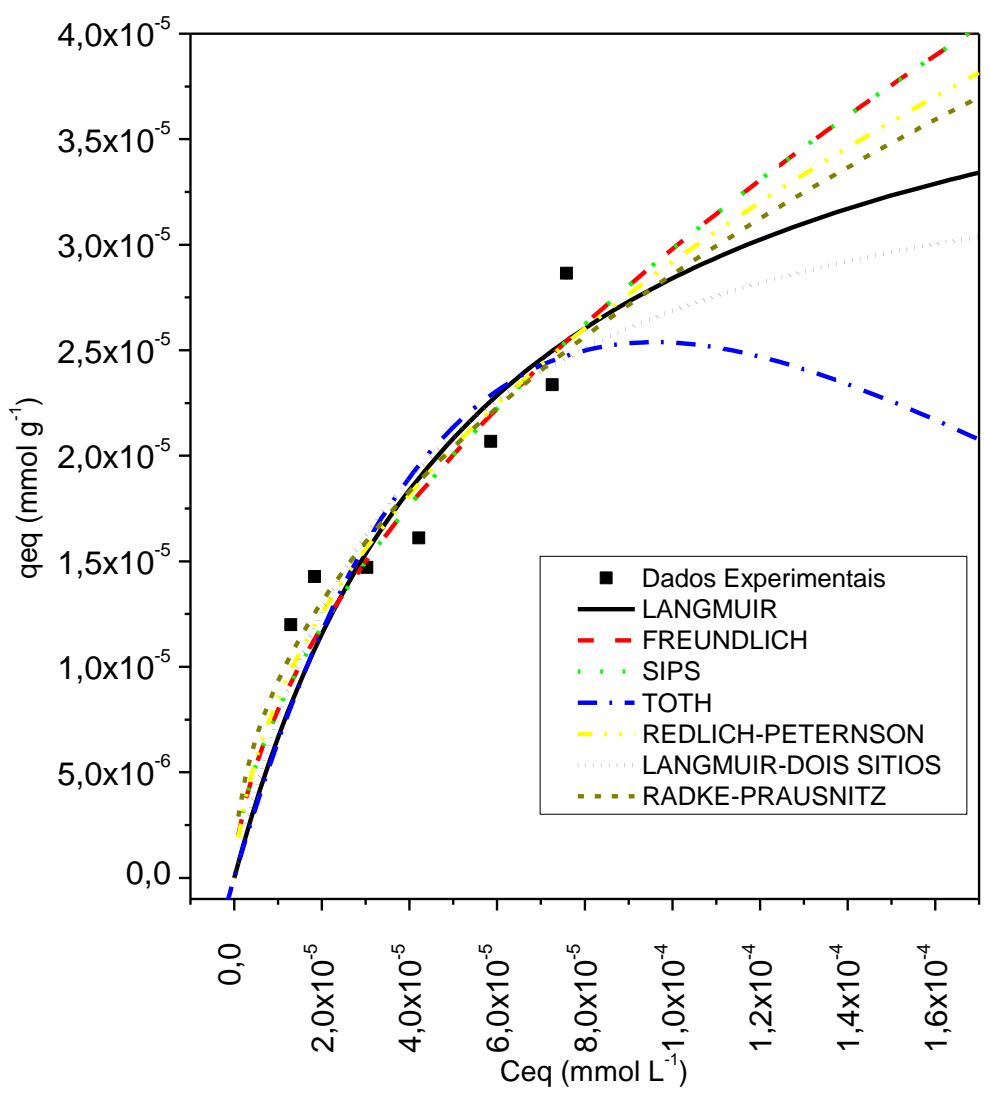

FIGURA 21 - Representação gráfica do ajuste dos modelos de isotermas aos dados experimentais para Pistia stratiotes 


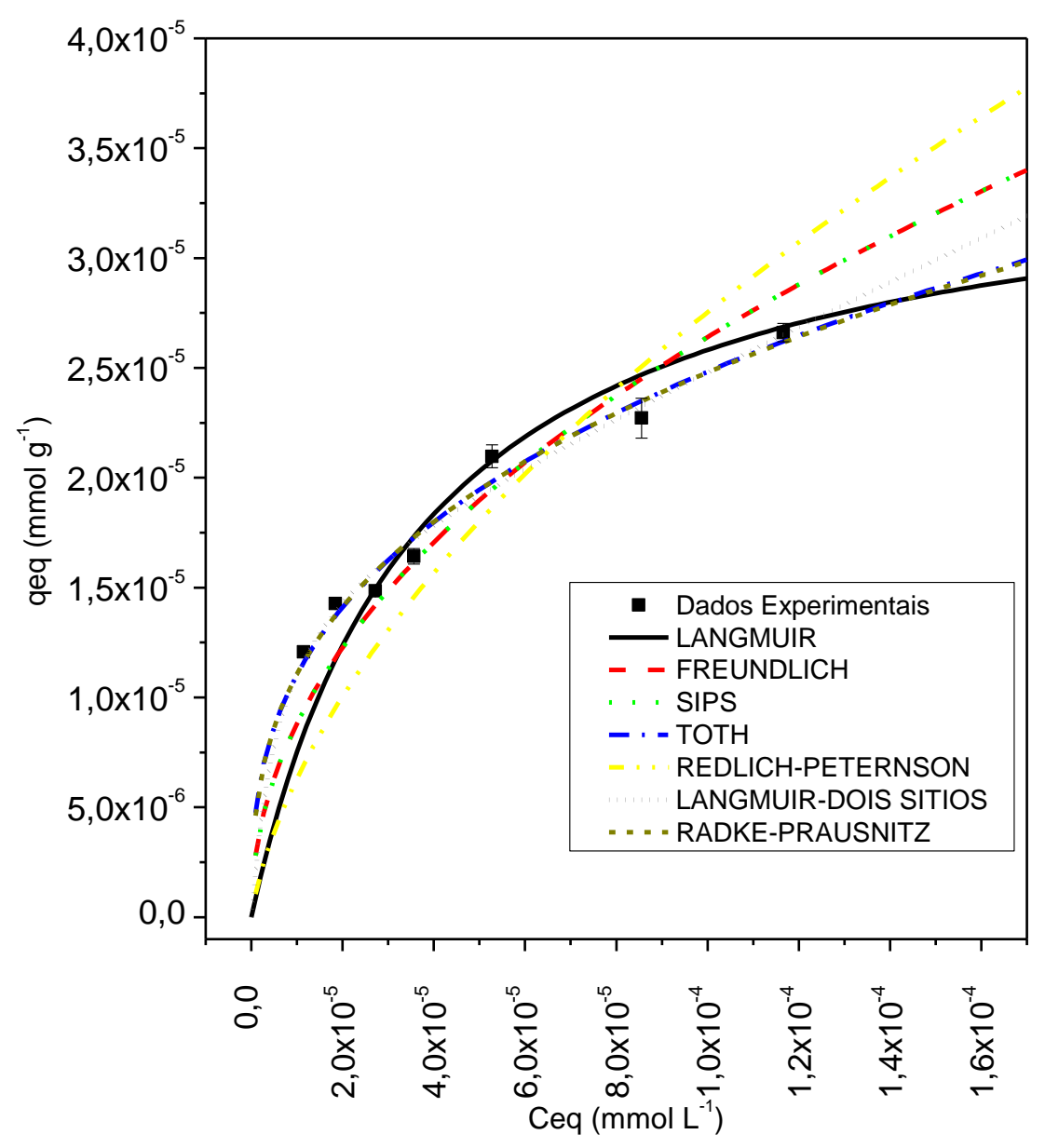

FIGURA 22 - Representação gráfica do ajuste dos modelos de isotermas aos dados experimentais para Limnobium laevigatum 


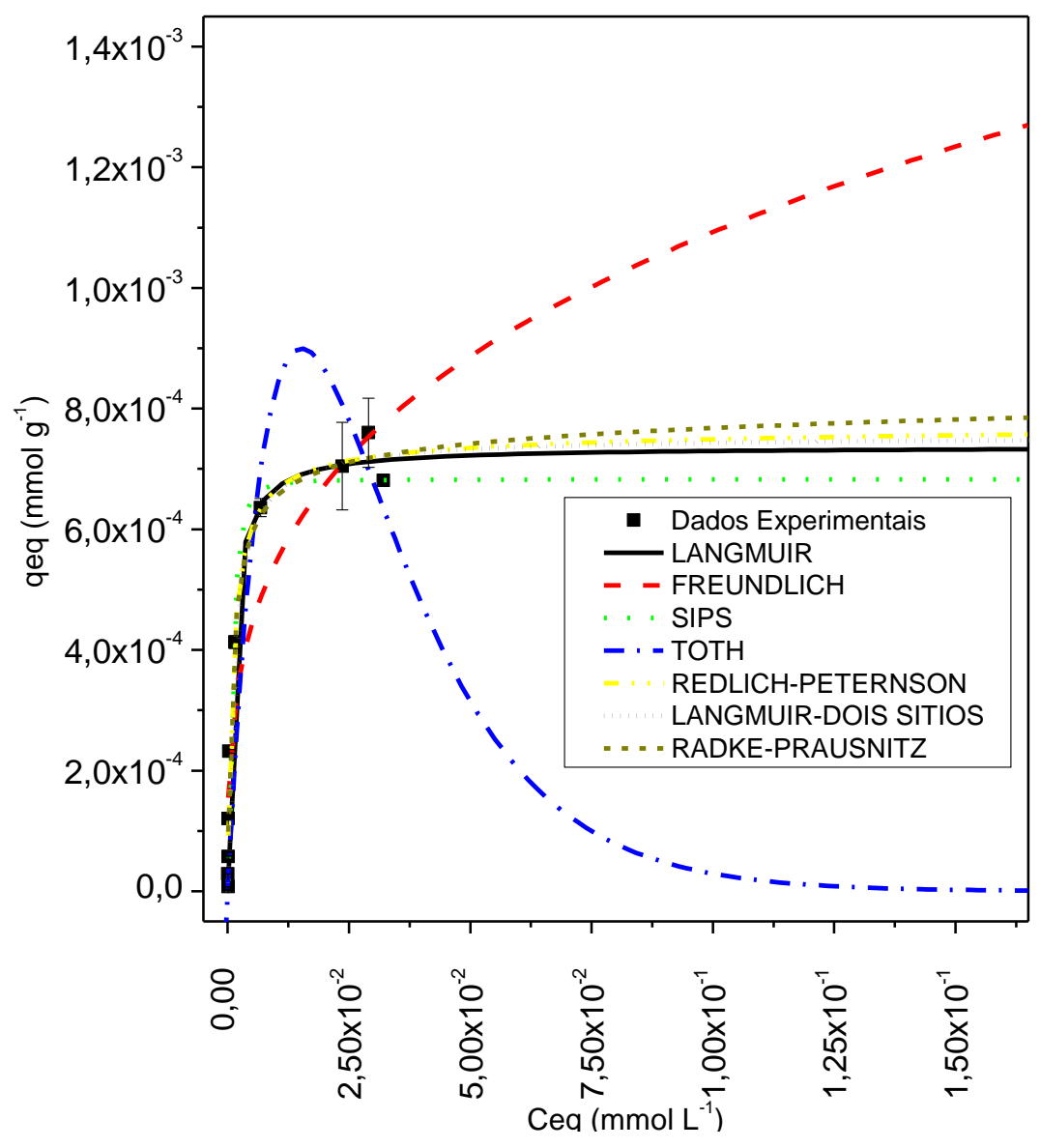

FIGURA 23 - Representação gráfica do ajuste dos modelos de isotermas aos dados experimentais para Lemna sp. 


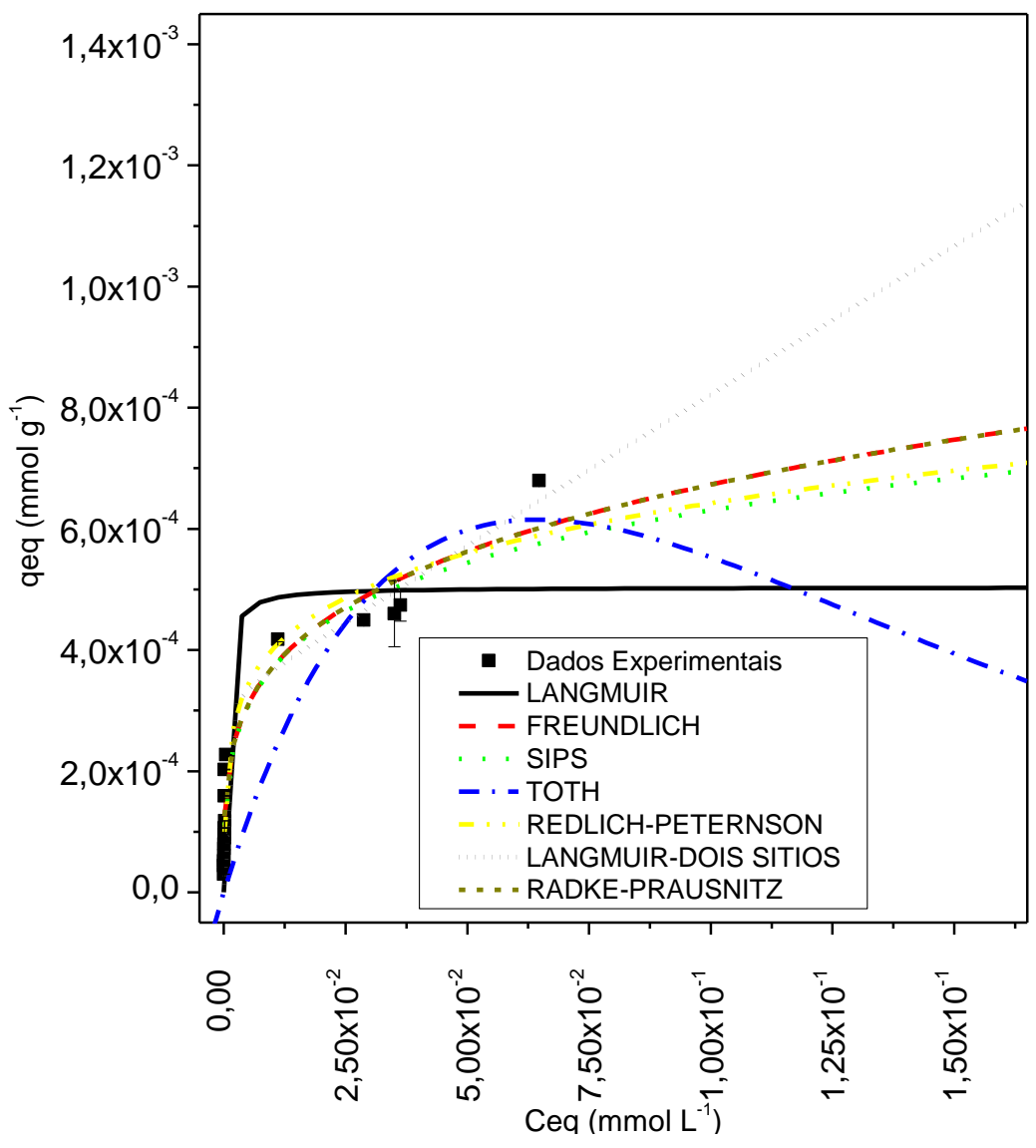

FIGURA 24 Representação gráfica do ajuste dos modelos de isotermas aos dados experimentais para Azolla sp.

De acordo com o coeficiente de correlação $R^{2}(0,95)$ para a macrófita Pistia stratiotes, o modelo de isoterma de Redlich-Peterson, foi o mais adequado para o ajuste aos dados experimentais. Esse modelo é uma isoterma híbrida que combina as características dos modelos de Langmuir e Freundlich, representando o equilíbrio de adsorção em uma ampla faixa de concentração. $O$ expoente $\beta$ se situa entre 0 e 1 e indica uma tendência maior para um desses modelos. Quanto mais próximo de 1 maior a tendência para Langmuir e mais próximo de zero para Freundlich (ZELENTSOV et al, 2012). Para a Pistia stratiotes, o valor de $\beta$ foi igual a 1, ou seja, há uma tendência maior para o modelo de Langmuir que assume 
adsorção em mono camada com números fixos de sítios de adsorção onde todos os sítios são uniformes reagindo uma única molécula com um único sitio ativo, não havendo interação entre as espécies adsorvidas.

Para a macrófita Limnobium laevigatum, os modelos de Langmuir e Freundlich podem ser considerados os melhores ajustes pois a sorção segue tanto Langmuir quanto Freundlich. Essa informação pode ser corroborada pelo modelo de isoterma de Redlich-Peterson que possui as características de ambos os modelos. O expoente $\beta(0,5)$ indica uma tendência tanto a Langmuir quanto a Freundlich e a capacidade máxima de sorção experimental está próxima a capacidade máxima teórica do modelo de Langmuir. A constante de Freundlich $1 / n$ relacionada com a intensidade indica que a adsorção ocorreu e forma favorável.

No caso da macrófita Lemna sp, todos os modelos se ajustaram aos resultados, porém o de Langmuir foi o melhor. A constante $B$ do modelo de Redlich-Peterson, cujo valor é aproximadamente 1, indica isso. Os modelos Doissítios Langmuir e Radke-Prausnitz também reforçam essa informação. A capacidade máxima experimental foi muito próxima dos teóricos obtidos nos 3 modelos (Langmuir, Langmuir dois sítios e Radke). O processo, então, assume uma biossorção com números fixos de sítios de adsorção, onde todos os sítios são uniformes e acomodam apenas uma única molécula, não havendo interação entre as espécies adsorvidas (FOO \& HAMEED, 2009).

Os modelos de Langmuir e Freundlich serviram para o ajuste dos resultados com a Azolla sp, porém pelos modelos de Redlich-Peterson, Dois sítios Langmuir e Radke-Prausnitz pode-se afirmar que há uma tendência maior ao modelo de Langmuir. Os valores de capacidade de sorção teóricos não estão de acordo com o experimental $e$ isso pode ter ocorrido pelo fato de que os experimentos não foram realizados com concentrações elevadas o suficiente para atingir a saturação do material. Assim, os modelos Dois sítios Langmuir e Radke- 
Prausnitz ajudam a compreender melhor essa situação, pois forneceram valores de capacidade máxima muito superiores ao obtido.

As FIG. 21 a 24 mostram graficamente os melhores ajustes, e segundo a classificação de GILES et al(1974) que para as macrófitas Pistia stratiotes, Limnobium laevigatum e Azolla sp. são do tipo $S$ (spherical) com inclinação positiva, caracterizada por uma inclinação que aumenta com a concentração do sorvato no meio, indicando que a afinidade entre o adsorvato e o adsorvente é a baixas concentrações é menor que a afinidade entre o adsorvente e o solvente.

Para a macrófita Lemna $S p$ as curvas que representam os melhores ajustes são do tipo L (Langmuir) convexas com formação de platô. Esse tipo de curva é apresenta uma inclinação que não aumenta com o aumento da concentração do sorvato em solução indicando a alta afinidade relativa do adsorvente pelo sorvato mesmo a baixas concentrações e diminuição da superfície livre do adsorvente. 


\subsubsection{Cinética de biossorção}

Os modelos de Pseudo-primeira ordem e Pseudo-segunda ordem foram selecionados a partir dos resultados obtidos nos ajustes dos dados experimentais para avaliar a cinética de biossorção do urânio. Os valores dos parâmetros obtidos para cada modelo de cinética e sua representação gráfica, são apresentados na TAB. 11 e nas FIG. 25 a 28. 
TABELA 11 - Parâmetros das cinéticas calculados para as biomassas utilizadas

\begin{tabular}{|c|c|c|c|c|c|}
\hline \multirow[t]{2}{*}{ Modelos } & & \multicolumn{3}{|c|}{ Biossorvente } & \multirow[b]{2}{*}{ Azolla sp } \\
\hline & & $\begin{array}{c}\text { Pistia } \\
\text { stratiotes }\end{array}$ & $\begin{array}{l}\text { Limnobium } \\
\text { laevigatum }\end{array}$ & Lemna sp & \\
\hline $\begin{array}{l}\text { Pseudo- } \\
\text { Primeira }\end{array}$ & $\begin{array}{c}\mathrm{q}_{\mathrm{eq}} \\
(\mathrm{mmol} / \mathrm{g})\end{array}$ & 2,89E-05 & 2,90E-05 & 2,90E-05 & 3,00E-05 \\
\hline \multirow[t]{2}{*}{ Ordem } & $\begin{array}{c}\mathrm{K}_{1} \\
\left(\mathrm{~min}^{-1}\right) \\
\end{array}$ & 0,17 & 0,06 & 0,45 & 0,54 \\
\hline & $\mathrm{R}^{2}$ & 1,00 & 0,99 & 1,00 & 1,00 \\
\hline $\begin{array}{l}\text { Pseudo- } \\
\text { Segunda }\end{array}$ & $\begin{array}{c}\mathrm{q}_{\mathrm{eq}} \\
(\mathrm{mmol} / \mathrm{g})\end{array}$ & $2,18 \mathrm{E}+04$ & $3,10 \mathrm{E}-05$ & 2,89E-05 & 3,00E-05 \\
\hline \multirow[t]{2}{*}{ Ordem } & $\begin{array}{c}\mathrm{K}_{2} \\
(\mathrm{~g} / \mathrm{mmol} \cdot \min ) \\
\end{array}$ & 21755,31 & 3325,92 & 51509,8 & 85914,60 \\
\hline & $\mathrm{R}^{2}$ & 1,00 & 0,98 & 1,00 & 1,00 \\
\hline
\end{tabular}




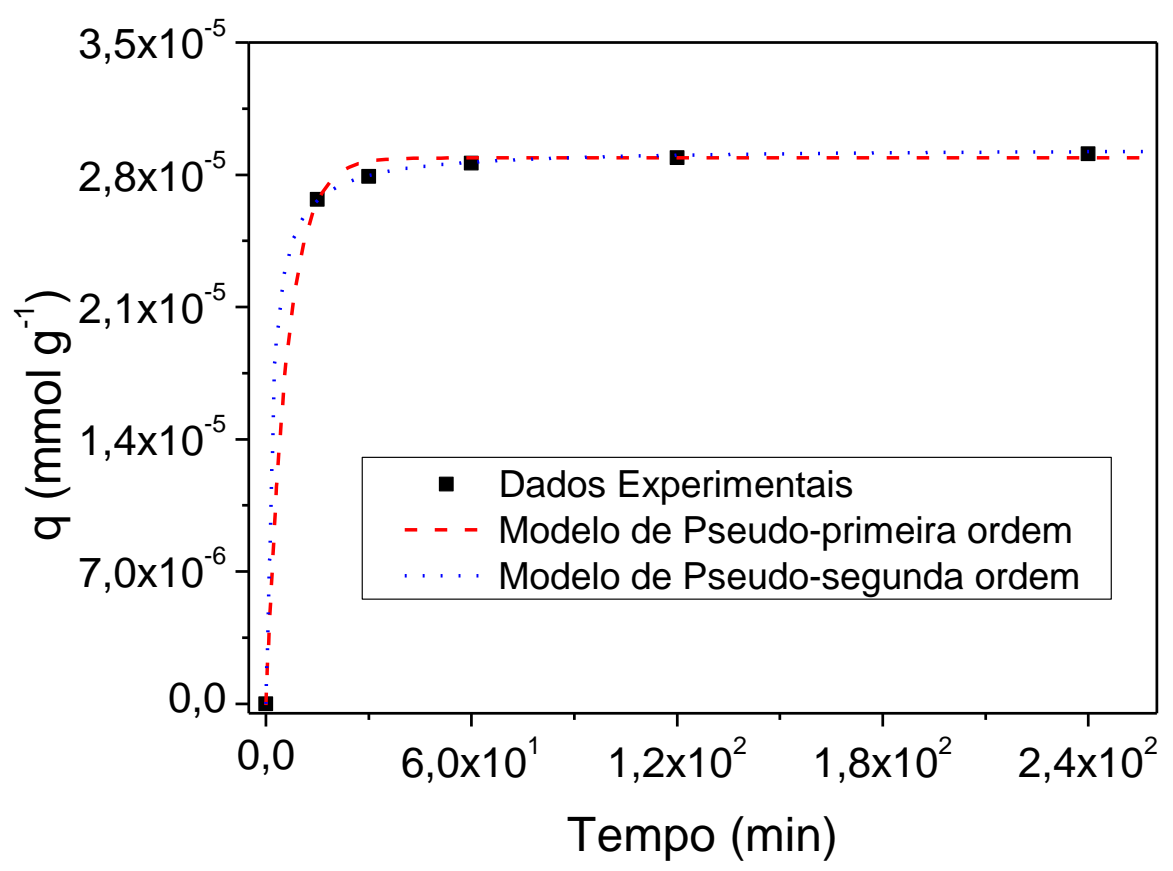

FIGURA 25 Representação gráfica dos ajustes dos modelos de cinética aos dados experimentais para a Pistia stratiotes

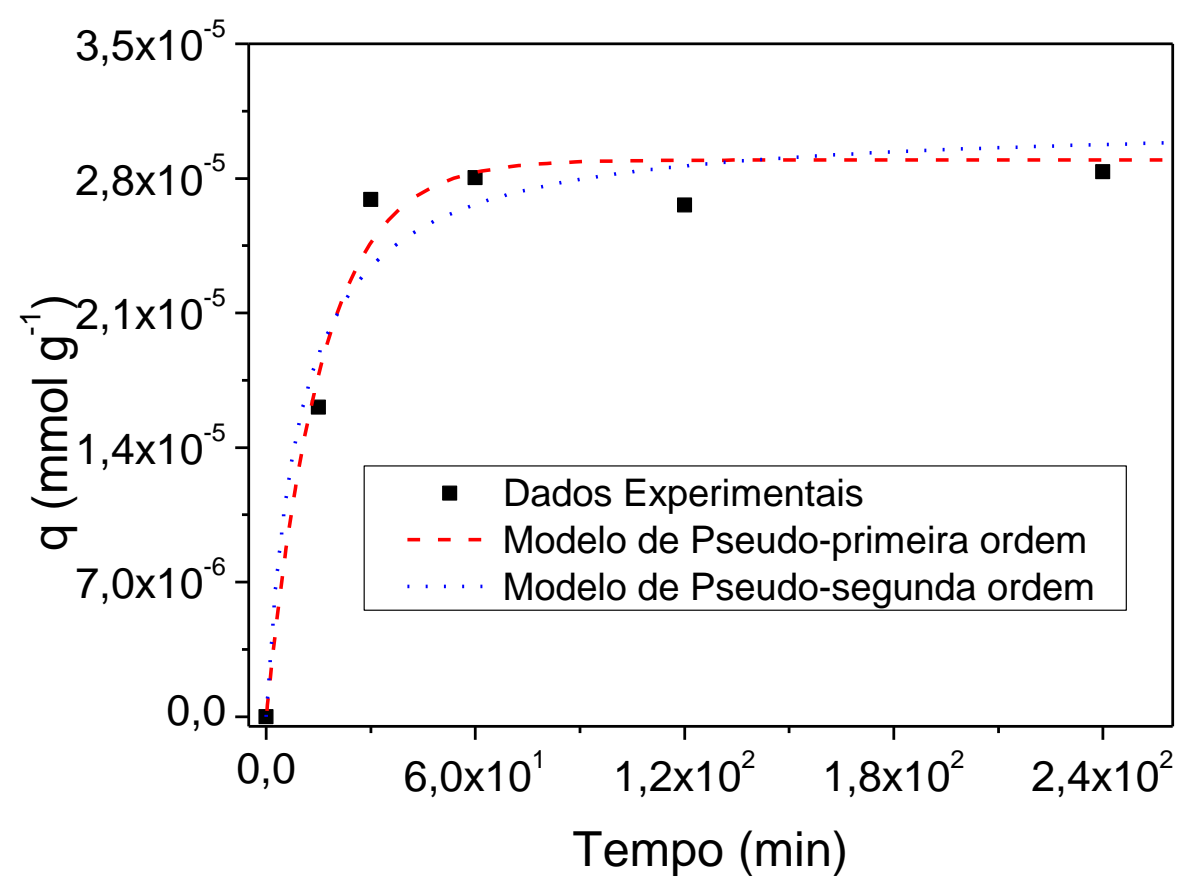

FIGURA 26 - Representação gráfica dos ajustes dos modelos de cinética aos dados experimentais para a Limnobium laevigatum 


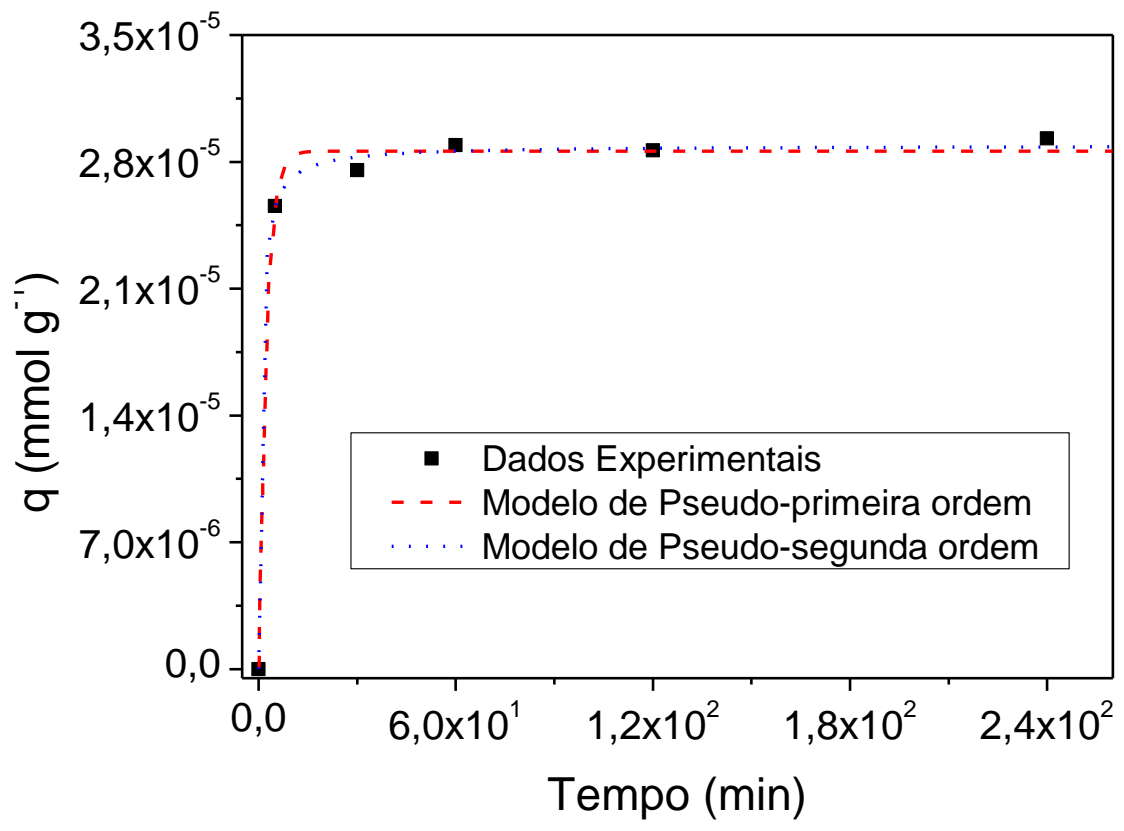

FIGURA 27 - Representação gráfica dos ajustes dos modelos de cinética aos dados experimentais para a lemna $s p$

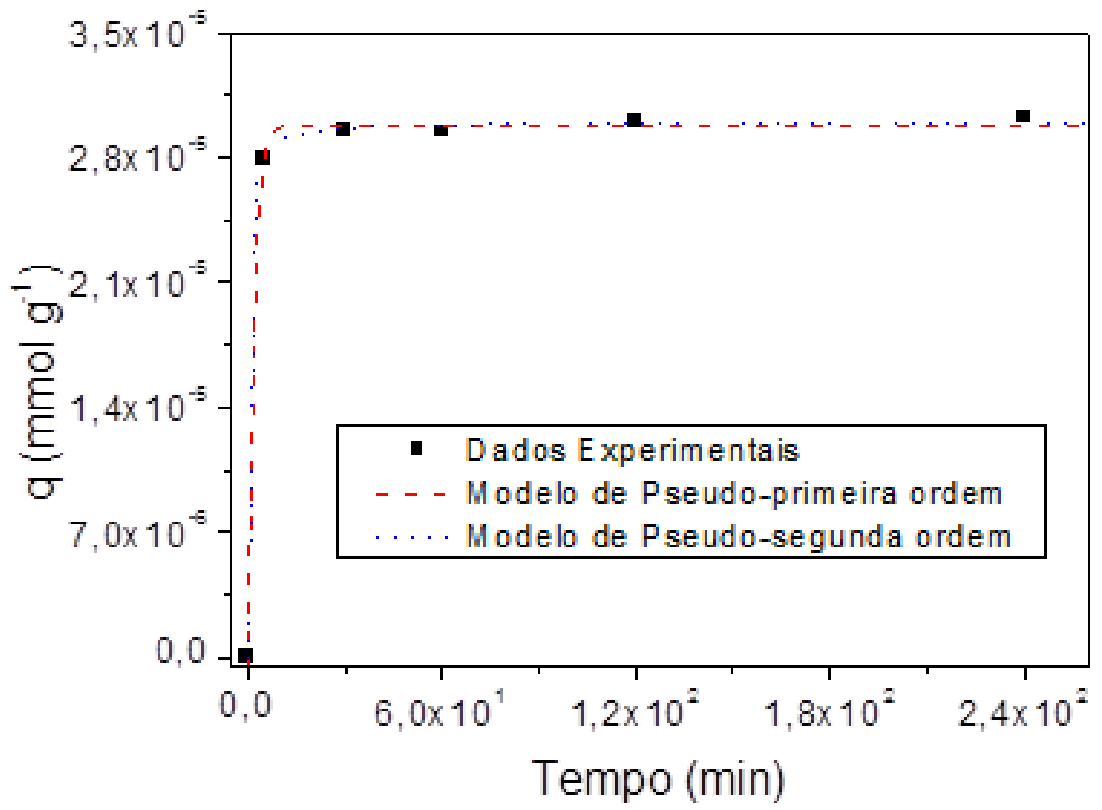

FIGURA 28 - Representação gráfica dos ajustes dos modelos de cinética aos dados experimentais para a Azolla sp 
De acordo com valores obtidos para o coeficiente de correlação $R^{2}(1,00)$ dos modelos de Pseudo-primeira Ordem e Pseudo-segunda ordem na sorção das macrófitas Pistia stratiotes, Lemna sp e Azolla sp é possível observar que ambos os modelos se ajustaram aos dados experimentais. Para a macrófita Limnobium laevigatum, a cinética de Pseudo-primeira ordem se mostrou mais eficiente no ajuste aos dados. A constante de velocidade $\mathrm{K}$ dos modelos Pseudoprimeira ordem e pseudo-segunda ordem mostram que a taxa de adsorção para a macrófita Azolla sp é maior entrando assim em equilíbrio cinético antes dos outros biossorventes testados. 


\section{CONCLUSÕES}

A capacidade de biossorção das macrófitas aquáticas das espécies Pistia stratiotes, Limnobium laevigatum, Lemna sp, Azolla sp foram avaliadas com a diferentes concentrações de urânio em solução, e rejeito real. As macrófitas que apresentaram as maiores capacidades de sorção forma avaliadas com rejeito radioativo real.

Por meio da análise dos resultados pode-se concluir que:

- As macrófitas possuem aparência e áreas superficiais distintas, mas possuem os mesmos grupos funcionais atuando diretamente no processo de biossorção;

- O tempo de remoção do urânio da solução está situado entre 30 e 60 minutos;

- As macrófitas Lemna sp e Azolla sp apresentaram as maiores capacidades de sorção;

- Os modelos das isotermas utilizados foram eficientes no entendimento do processo de biossorção do urânio pelas macrófitas estudadas. Langmuir é o modelo que se ajusta aos dados experimentais para a maior parte das biomassas;

- A macrófita Azolla sp é a mais eficaz no processo de biossorção, pois necessita de um tempo menor para remover o urânio;

- As macrófitas são biossorventes de fácil manipulação, estáveis e apresentam potencial para serem aplicadas no tratamento de rejeitos radioativos. 


\section{SUGESTÕES PARA TRABALHOS FUTUROS}

- Avaliar o comportamento da macrófita Azolla $s p$ em soluções com altas concentrações de urânio

- Empregar soluções multi-metais e avaliar a biossorção da Azolla sp frente a dois ou mais elementos químicos

- Realizar ensaios de imobilização da biomassa em cimento 


\section{REFERÊNCIAS BIBLIOGRÁFICAS}

ALLEN, S. J.; GAN, Q.; JOHNSON, P.A. Comparison of Optimized Isotherm Models for Basic Dye Adsorption by Kudzu. Bioresource Technology, v. 88, p. 143-152, 2003.

AUTA, M.; HAMEED, B.H. Acid modified local clay beads as effective low-cost adsorbent for dynamic adsorption of methylene blue. Journal of Industrial and Engineering Chemistry, v. 19, p. 1153-1161, 2013.

BAKER, A.L. 2012. Phycokey -- an image based key to Algae (PS Protista), Cyanobacteria, and other aquatic objects. University of New Hampshire Center for Freshwater Biology. Disponível em <http://cfb.unh.edu/phycokey/phycokey.htm>. Acesso em 16 fevereiro 2016.

BENVINDO DA LUZ, A.Tratamento de minérios, 3ra edição rev. e ampliada. Rio de Janeiro: CETEM/MCT, 2002.

BHATNAGAR, A.; JAIN, A.K. A. Comparative adsorption study with different industrial wastes as adsorbents for the removal of cationic dyes from water. Journal of Colloid and Interface Science, v. 281, p.49-55, 2005.

BONIOLO, M. R. Biossorção de Urânio nas Cascas de Banana. 2008. Dissertação (mestrado) - Instituto de Pesquisas Energéticas e Nucleares, São Paulo.

CHARLES, A. L.; MARKICH, S. J.; RALPH, P. Toxicity of uranium and copper individually, and in combination, to a tropical freshwater macrophyte (Lemna aequinoctialis). Chemosphere, v. 62, p. 1224-1233, 2006.

CNEN- COMISSÃO NACIONAL DE ENERGIA NUCLEAR. Licenciamento de Instalações Radiativas. CNEN-NE-6.02, Rio de Janeiro. 2014.

CNEN - COMISSÃO NACIONAL DE ENERGIA NUCLEAR. Critérios de Aceitação para Deposição de Rejeitos Radioativos de Baixo e Médio Níveis de Radiação. CNEN-NE-6.09, CNEN, Rio de Janeiro, 2002.

CNEN- COMISSÃO NACIONAL DE ENERGIA NUCLEAR. Gerência de Rejeitos Radioativos de Baixo e Médio níveis de Radiação CNEN-NN-8.01, Rio de Janeiro. 2014.

COSTA JUNIOR, I. L., Cinética de biocumulação do íon $\mathbf{P b}^{+2}$ na macrófita aquática Pistia Stratiotes. 2008. Dissertação (Mestrado) - Universidade Estadual do Oeste do Paraná. Toledo. 
DAVIS, T. A.; VOLESKY, B.; MUCCI, A.; A review of the chemistry of heavy metal biosorption by brown algae. Water Research, v. 37, p. 4311-4330, 2003.

DEMIREL, G.; CAYKARA, T.; AKAOGLU, B.; ÇAKMAK , M. Construction of a novel multilayer system and its use for oriented immobilization of immunoglobulin G. Surface Science, v. 601, p. 4563-4570, 2007.

ELANGOVAN, R.; PHILIP, L.; CHANDRARAJ, K. Biosorption of chromium species by aquatic weeds: Kinetics and mechanism studies. Journal of Hazardous Materials, v. 152, p. 100-112, 2008.

ESCUDERO, R. R.; ROBTZER, M.; DI RENZO, F.; QUIGNARDI, F. Alginate aerogels as adsorbents of polar molecules from liquid hydrocarbons: Hexanol as probe molecule. Carbohydrate Polymers v. 75, p. 52-57, 2009.

EPSTEIN, E. Nutrição mineral de plantas: princípios e perspectivas. Rio de Janeiro: Livros Técnicos e Científicos, p.341, 1975

ESTEVES, F. A. Fundamentos de Limnologia. $2^{\mathrm{a}}$ ed. Rio de Janeiro: Editora Interciência. 1998.

FERREIRA, R. V. P., Aplicação de biossorventes no tratamento de rejeitos radioativos líquidos. 2014. Tese (Doutorado) - Instituto de Pesquisas Energéticas e Nucleares, São Paulo.

FOO, K. Y.; HAMEED, B. H. Insights into the modeling of adsorption isotherm systems. Chem. Eng. J. v. 156, p. 2-10, 2010.

GADD, G.M. Biosorption: critical review of scientific rationale, environmental importance and significance for pollution treatment, Journal of Chemical Technology and Biotechnology, v.84, Issue 1, 2009.

GILES, C.H; SMITH, D; HUITSON, A. A general treatment and classification of the solute adsorption isotherm. Theoretical J. Colloid Interface Sci., v.47, p. 755765, 1974.

GRATUITO, M.K.B.; PANYATHANMAPORN, T.; CHUMNANKLANG, R.-A.; SIRINUNTAWITTAYA, N.; DUTTA, A. "Production of activated carbon from coconut shell: Optimization using response surface methodology". Bioresource Technology, v. 99, p. 4887-4895, 2008.

HENRY-SILVA, G. G.; CAMARGO, A. F. M., "Composição química de macrófitas aquáticas flutuantes utilizadas no tratamento de efluentes de Aquicultura." Planta Daninha, v. 24, n. 1, p. 21-28, 2006. 
HONORATO, A. C. Biossorção de corante azul reativo $5 \mathrm{G}$ em efluentes têxteis utilizando resíduos agroindustriais. 2015. Dissertação (Mestrado), Universidade Estadual do Oeste do Paraná, Toledo.

HUBBE, M. A.; SYED H. H.; DUCOSTE J. J. Cellulosic substrates for removal of pollutants from aqueous systems: A review. 1 Metals. BioResources, v. 6(2) p. 2161-2287, 2011.

JOURNEY, W. K.; SKILICORN, P.; SPIRA, W. 1993. Duckweed aquaculture. A new aquatic farming system for developing countries. World Banck Publication. Washington, D.C., U.S.A., 67 pp.

KHANI M.H., KESHTKAR A.R., GHANNADI M., PAHLAVANZADEH H. Equilibrium, kinetic and thermodynamic study of the biosorption of uranium onto Cystoseria Indica algae. J Hazard Mater; v 150. p. 612-618. 2008.

KHOSRAVI M., RAKHSHAEE R., GANJI M. T. Pre-treatment processes of Azolla filiculoides to remove $\mathrm{Pb}(\mathrm{II}), \mathrm{Cd}(\mathrm{II}), \mathrm{Ni}(\mathrm{II})$ and $\mathrm{Zn}(\mathrm{II})$ from aqueous solution in the batch and fixed-bed reactors. J Hazard Mater; B 127. p. 228-237, 2005.

KORESH, J.; SOFFER, A. Application of the Two-Site Langmuir Isotherm to Microspores Adsorbents Journal of Colloid and Interface Science, v. $92 \mathrm{~N} 2$ 1983.

KRESTOU A., PANIAS D. "Uranium (VI) speciation diagrams in the UO22+/CO32$/ \mathrm{H} 2 \mathrm{O}$ system at 250C" The European Journal of Mineral Processing and Environmental Protection V.4, No.2 1303-0868, p.113-129, 2004.

KUYUCAK, N. and VOLESKY, B. Biosorbents for recovery of metals from industrial solutions. Biotechnology Left. v.10, n 2, p.137-142, 1988.

LANGMUIR, I. The adsorption of gases on plane surfaces of glass, mica and platinum. Journal of the American Chemical Society. v. 40, n. 9, p. 1361-1403, 1918. B

LIMA I.; Marshal W. E utilization of turkey manure as granular active carbon: Physical, chemical and adsorptive properties. Waste Management, v.25, p. 726732, 2005.

MAINE, M. A., DUARTE, M. V. and SUÑÉ, N. L., Cadmium Uptake by Floating Macrophytes, Water Research, v. 35(11), p. 2629-2634, 2000. 
Resolução. 2008. Dissertação (Mestrado) Centro de Engenharia e Ciências Exatas UNIOESTE, Toledo.

MASHKANI S. G, GHAZVINI P. T. M, "Biotechnological potential of Azolla filiculoides for biosorption of $\mathrm{Cs}$ and Sr: Application of micro-PIXE for measurement of biosorption. Bioresource Technology, v. 100, p. 1915-1921, 2009.

MICHALAK, I.; CHOJNACKA, K.; WITEK-KROWIAK, A. State of the Art for the Biosorption Process-a Review. Appl Biochem Biotechnol, v. 170, p. 1389 14162013.

MKANDAWIRE, M.; TAUBERT, B.; DUDEL, E. G. Capacity of Lemna gibba L. (Duckweed) for Uranium and Arsenic Phytoremediation in Mine Tailing Waters. International Journal of Phytoremediation v. 6(4), p. 347-362, 2004.

PADMESH, T. V. N.; VIJAYARAGHAVAN, K.; "Application of Two- and ThreeParameter Isotherm Models: Biosorption of Acid Red 88 onto Azolla microphylla." Bioremediation Journal, v. 10(1-2), p. 37-44, 2006.

PERUZZO, L. C. Influência de agentes auxiliares na adsorção de corantes de efluentes da indústria têxtil em colunas de leito fixo. 2003. Dissertação (Mestrado) - Universidade Federal de Santa Catarina, Florianópolis.

PROBIO, PROGRAMA DE BIODIVERSIDADE. Disponível em: <http://www.ufscar.br/ probio> . Acesso em 24 de janeiro 2016.

REDLICH, O.; PETERSON, D. L. A useful adsorption isotherm, J. Phys. Chem. V. 63, p.1024-1026, 1959.

REN, G. et al. Characterization of copper oxide nanoparticles for antimicrobial applications. International journal of antimicrobial agents, Reino Unido, p. 587590. 01 jan. 2009

RODRIGUES, M. E. F. Levantamento florístico e distribuição de macrófitas aquáticas na Represa Guarapiranga, São Paulo, Brasil. 2011. Dissertação (Mestrado) - Instituto de Biociências Universidade de São Paulo, São Paulo.

RUSCHEL, A. P. Efeito sazonal sobre o desenvolvimento e fixação biológica de nitrogênio de diferentes espécies de Azolla. Pesq. agrop. Bras., v. 22, p. 559565. 1987.

SANTANA, H. S. Bioadsorção de íons de Cd2+, Cu2+, Pb2+, Ni2+ e Zn2+ pela macrófita aquática Limnobium spongia. 2012. Dissertação (Mestrado) Faculdade de Engenharia Química UNICAMP, Campinas. 
SANTOS, E. C., Macrófitas aquáticas em tratamento de águas contaminadas por arsênio. 2008. Dissertação (Mestrado) - Universidade Federal de Ouro Preto, Ouro Preto.

SEKAR, M.; SAKTHI, V.; RENGARAJ, S. Kinetics and equilibrium adsorption study of lead (II) onto activated carbon prepared from coconut shell. Journal of Colloid and Interface Science, v 279 p.307-313, 2004.

SCIVITTARO, W. B.; DA SILVA, C. A. S.; REIS, J. C. L. "Racionalização da aplicação de fertilizante nitrogenado na produção de arroz irrigado". Comunicado Técnico 200, ISSN 1806-9185 Dezembro Pelotas, RS 2008.

SIPS, R.; Combined form of Langmuir and Freundlich equations, J. Chem. Phys., v.16 p. $490-495,1948$

SOOD, A.; UNIYAL, P. L.; PRASANNA, R.; AHLUWALIA, A.S. Phytoremediation Potential of Aquatic Macrophyte, Azolla AMBIO, v. 41, p.122-137, 2012.

STAFFORD, P. J. Azollaceae. Review of Palaeobotany and Palynology, v. 123, p.9-17, 2003.

TAVARES, F. de A.. Eficiência da Lemna sp no tratamento de efluentes de suinocultura e sua utilização como fonte alternativa de alimento para tilápia. 2004. Dissertação (Mestrado) - Universidade Federal de Santa Catarina, Florianópolis.

Toth, J. State equations of the solid gas interface layer. Acta Chem.Acad. Hung, v. 69, p. 311-317, 1971.

UMALI, L. J. ; DUNCAN, J. R. ; BURGESS, J.E., Performance of dead Azolla filiculoides biomass in biosorption of Au from wastewater. Biotechnology Letters v. 28, p. 45-49, 2006.

VALITUTTO, R. S. Acumulação de poluentes inorgânicos por macrófitas aquáticas nos reservatórios de Santana e Vigário, Barra do Piraí - RJ. 2004. Dissertação (Mestrado) - Universidade Federal Fluminense, Niterói.

VIEIRA, R. H.; VOLESKY, B.; Biosorption: a solution to pollution?, International Microbiology, v. 3, p. 17-24, 2000.

VIJAYARAGHAVAN, K.; YUN. Y.S. Bacterial biosorbents and biosorption. Biotechnology Advances, v.26, p. 266-291

VOLESKY, B. Biosorbents for Metal Recovery. Tibtechnology, v.5. p.96-101. 1987.

VOLESKY, B.; Biosorption of heavy metals, CRC Press, p 396, 1990. 
VOLESKY B. Detoxication of metal-bearing efluents: biosorption for the next century. Hydrometallurgy, v. 59, p. 203-216, 2001.

VOLESKY, B. Sorption and Biosorption, Montreal, Canadian 2003.

YANG, J.; VOLESKY, B. Biosorption of uranium on Sargassum biomass. Wat. Res, v. 33, p. 3357-3363, 1999.

YI, Z.; YAO, J.; CHEN, H.; WANG, F.; YUAN, Z.; LIU, X. Uranium biosorption from aqueous solution onto Eichhornia crassipes. Journal of Environmental Radioactivity, v. 154, p. $43-51,2016$. 